\title{
Italian Association of Clinical Endocrinologists (AME) position statement: a stepwise clinical approach to the diagnosis of gastroenteropancreatic neuroendocrine neoplasms
}

\author{
Franco Grimaldi • Nicola Fazio $\cdot$ Roberto Attanasio $\cdot$ Andrea Frasoldati $\cdot$ Enrico Papini $\cdot$ Francesco Angelini $\cdot$ \\ Roberto Baldelli • Debora Berretti - Sara Bianchetti - Giancarlo Bizzarri • Marco Caputo • Roberto Castello • \\ Nadia Cremonini • Anna Crescenzi • Maria Vittoria Davì • Angela Valentina D'Elia • Antongiulio Faggiano • \\ Stefano Pizzolitto · Annibale Versari · Michele Zini · Guido Rindi $\cdot$ Kjell Öberg
}

Received: 10 February 2014/ Accepted: 29 March 2014/Published online: 20 July 2014

(C) The Author(s) 2014. This article is published with open access at Springerlink.com

Keywords Neuroendocrine tumors - Diagnostic workup · Markers · Imaging · Incidental findings · Nonfunctioning tumors · Carcinoid syndrome - Gastrinoma . Insulinoma $\cdot \mathrm{NET} \cdot \mathrm{NEC} \cdot \mathrm{NEN}$

\section{Abbreviations}

\section{5-HIAA 5-Hydroxy-indolacetic acid}

ACE Angiotensin-converting enzyme

ACTH Adrenocorticotropin

AJCC American Joint Committee on Cancer

On behalf of AME.

Other members of AME oncologic endocrinology group are listed in the conclusions.

Franco Grimaldi and Nicola Fazio contributed equally as first authors.

F. Grimaldi $(\bowtie)$

Endocrinology and Metabolic Disease Unit, Azienda

Ospedaliero-Universitaria "S. Maria della Misericordia", P.le

S.M. della Misericordia, 15-33100, Udine, Italy

e-mail: franco.grimaldi@aliceposta.it

\section{N. Fazio}

Unit of Gastrointestinal and Neuroendocrine Tumors, European Institute of Oncology, Milan, Italy

e-mail: nicola.fazio@ieo.it

\section{R. Attanasio}

Endocrinology Service, Galeazzi Institute IRCCS, Milan, Italy e-mail: roberto.serena@libero.it

A. Frasoldati · M. Zini

Endocrinology Unit, Arcispedale S. Maria Nuova IRCCS,

Reggio Emilia, Italy

e-mail: andrea.frasoldati@asmn.re.it

M. Zini

e-mail: michele.zini@asmn.re.it
AKT A protein-serine-threonine kinase that is activated by phosphorylation in response to growth factors or insulin

CD117 Antigen specific for the proto-oncogene c-kit

CD56 Antigen expressed by all lymphocytes

CD99 Cluster of differentiation

CDX-2 Transcription factor expressed specifically in gut epithelium

CEACAM1 Cell adhesion molecule

CEUS Contrast-enhanced US

CgA Chromogranin A

CK19 Cytokeratin 19

CS Carcinoid syndrome

CT Computerized tomography

DBE Double balloon enteroscopy

\section{E. Papini}

Endocrinology Unit, Regina Apostolorum Hospital, Albano

Laziale, Rome, Italy

e-mail: papinie@gmail.com

F. Angelini $\cdot$ S. Bianchetti

Oncology and Hematology Unit, Regina Apostolorum Hospital,

Albano Laziale, Rome, Italy

e-mail: angelini.f@libero.it

S. Bianchetti

e-mail: bianchetti.sara@gmail.com

R. Baldelli

Endocrinology Section, Regina Elena National Cancer Institute,

Rome, Italy

e-mail: baldelli@ifo.it

D. Berretti

Gastroenterology Unit, Azienda Ospedaliero-Universitaria "S.

Maria della Misericordia", Udine, Italy

e-mail: berretti.debora@aoud.sanita.fvg.it 


\begin{tabular}{|c|c|c|c|}
\hline DOPA & Dihydroxyphenylalanine & H2RAs & Histamine H2-receptor antagonists \\
\hline DOTA & $\begin{array}{l}\text { 1,4,7,10-Tetra-azacyclo-dodecane- } \\
\text { tetraacetic acid }\end{array}$ & Her/2 & $\begin{array}{l}\text { A cell surface protein-tyrosine kinase } \\
\text { receptor overexpressed in }\end{array}$ \\
\hline DOTANOC & DOTA-Nal3-octreotide & & adenocarcinomas \\
\hline DOTATATE & DOTA-octreotate & HPF & High-power field \\
\hline DOTATOC & DOTA-edotreotide & HPLC & High-pressure liquid chromatography \\
\hline ECLomas & Enterochromaffin-like cell carcinoids & HTP & Hydroxy-L-tryptophan \\
\hline EGDS & Esophago-gastro-duodenoscopy & IHC & Immunohistochemistry \\
\hline ELISA & Enzyme-linked immunosorbent assay & IRMA & Immunoradiometric assay \\
\hline ENETS & European Neuroendocrine Tumor Society & Ki-67 & Nuclear antigen present only in the nuclei \\
\hline ERCC-1 & Excision repair cross-complementing & & of cycling cells \\
\hline \multirow[t]{2}{*}{ ERCP } & Endoscopic-retrograde-cholangio- & LoE & Level of evidence \\
\hline & pancreatography & MANEC & Mixed adeno-neuroendocrine carcinoma \\
\hline EUS & Endoscopic ultrasonography & MAO & Monoamine oxidase \\
\hline FDG & Fluoro-deoxy-glucose & MDCT & Multidetector CT \\
\hline FGF & Fibroblast growth factor & MEN-1 & Multiple endocrine neoplasms \\
\hline FNA & Fine needle aspiration & MGMT & Methylguanine-DNA methyltransferase \\
\hline FNB & Fine needle biopsy & MIB-1 & A monoclonal antibody used to detect KI- \\
\hline FSG & Fasting serum gastrin & & 67 antigen \\
\hline GEP & Gastroenteropancreatic & MRI & Magnetic resonance imaging \\
\hline GERD & Gastroesophageal reflux disease & mTOR & Mammalian target of rapamycin \\
\hline GI & Gastrointestinal & NEC & Neuroendocrine carcinoma \\
\hline \multirow[t]{2}{*}{ GRADE } & Grading of recommendations, assessment, & NEN & Neuroendocrine neoplasm \\
\hline & development, and evaluation & NET & Neuroendocrine tumor \\
\hline hCG & Human chorionic gonadotropin & $\mathrm{NF}$ & Non-functioning \\
\hline \multirow{2}{*}{ hHAS-1 } & Human achaete-scute homolog 1 & NF1 & Neurofibromatosis type 1 \\
\hline & & $\mathrm{NIH}$ & National Institutes of Health \\
\hline
\end{tabular}

G. Bizzarri

Diagnostic Imaging Unit, Regina Apostolorum Hospital, Albano

Laziale, Rome, Italy

e-mail: bizzarrigiancarlo@libero.it

\section{Caputo}

Dipartimento Servizi di Diagnosi e Cura, AUSL 22 Regione

Veneto, Bussolengo, VR, Italy

e-mail: mcaputo@ulss22.ven.it

\section{R. Castello}

Medicina Interna ad indirizzo Endocrinologico, Azienda

Ospedaliera Universitaria Integrata, Verona, Italy

e-mail: roberto.castello@ospedaleuniverona.it

\section{N. Cremonini}

Endocrinology Unit, Maggiore and Bellaria Hospital, Bologna, Italy

e-mail: nadia.cremonini@ausl.bo.it

\section{A. Crescenzi}

Pathology Unit, Regina Apostolorum Hospital, Albano Laziale, Rome, Italy

e-mail: crescenzianna@libero.it

M. V. Davì

Medicina Interna D, Azienda Ospedaliera Universitaria Integrata, Verona, Italy

e-mail: mariavittoria.davi@ospedaleuniverona.it
A. V. D'Elia

Genetic Service, Azienda Ospedaliero-Universitaria "S. Maria della Misericordia", Udine, Italy

e-mail: delia.angela@aoud.sanita.fvg.it

A. Faggiano

Department of Clinical Medicine and Surgery, Federico II

University, Naples, Italy

e-mail: afaggian@unina.it

S. Pizzolitto

Pathology Unit, Azienda Ospedaliero-Universitaria "S. Maria

della Misericordia", Udine, Italy

e-mail: pizzolitto.stefano@aoud.sanita.fvg.it

A. Versari

Nuclear Medicine Service, Arcispedale S. Maria Nuova IRCCS,

Reggio Emilia, Italy

e-mail: versari.annibale@asmn.re.it

G. Rindi

Institute of Pathology, Policlinico A. Gemelli, Università

Cattolica del Sacro Cuore, Rome, Italy

e-mail: guido.rindi@rm.unicatt.it

\section{K. Öberg}

Department of Endocrine Oncology, University Hospital,

Uppsala, Sweden

e-mail: kjell.oberg@medsci.uu.se 


$\begin{array}{ll}\text { NPV } & \text { Negative predictive value } \\ \text { NSE } & \text { Neuron-specific enolase } \\ \text { NSP-55 } & \text { Neuroendocrine-specific protein } \\ \text { OS } & \text { Overall survival } \\ \text { PAX-8 } & \text { Paired box gene } 8 \\ \text { PET } & \text { Positron emission tomography } \\ \text { PGP.9.5 } & \text { Pan neuronal marker protein in the Islets of } \\ & \text { Langerhans } \\ \text { PIK3 } & \text { Phosphoinositide-3-kinase } \\ \text { PLGF } & \text { Placental growth factor } \\ \text { pNEN } & \text { Pancreatic NEN } \\ \text { PPIs } & \text { Proton pump inhibitors } \\ \text { PPV } & \text { Positive predictive value } \\ \text { PTEN } & \text { Phosphatase and tensin homolog (mutated } \\ & \text { in multiple advanced cancers) } \\ \text { RIA } & \text { Radioimmunoassay } \\ \text { SA } & \text { Somatostatin analog } \\ \text { SEER } & \text { Surveillance, epidemiology and end results } \\ \text { SPECT } & \text { Single photon emission computed } \\ & \text { tomography } \\ \text { SRS } & \text { Somatostatin receptor scintigraphy } \\ \text { SSTR } & \text { Somatostatin subtype receptor } \\ \text { TNM } & \text { Tumor-node-metastases } \\ \text { TSC } & \text { Tuberous sclerosis complex } \\ \text { TTF-1 } & \text { Thyroid transcription factor 1 } \\ \text { UICC } & \text { Union for International Cancer Control } \\ \text { UPN } & \text { Unknown primary NEN } \\ \text { US } & \text { Ultrasonography } \\ \text { VCE } & \text { Video-capsule endoscopy } \\ \text { VHL } & \text { von Hippel-Lindau disease } \\ \text { VIP } & \text { Vasoactive intestinal peptide } \\ \text { ZES } & \text { Zollinger-Ellison syndrome } \\ & \end{array}$

\section{Table of contents}

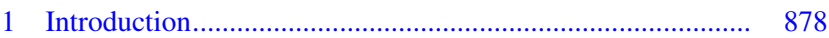

1.1 Why this document................................................... 878

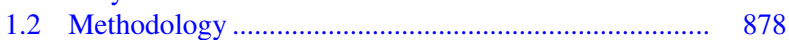

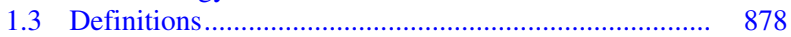

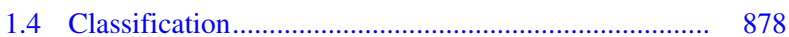

1.4.1 Grading assessment ................................. 879

1.4.2 Pathologic staging ...................................... 879

2 Diagnostic tools ............................................................. 879

2.1 Histology, cytology, immunohistochemistry, and molecular

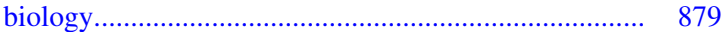

2.1.1 Morphologic criteria.................................. 879

2.1.2 Immunohistochemistry and molecular biology techniques .................................................... 880

2.1.3 Working with the pathologist and his pathologic report
2.1.4 Genetic assessment.................................... 881

2.2 Laboratory assessment ........................................... 882

2.2.1 "Unspecific markers" ................................ 882

2.2.1.1 Chromogranin A...................... 882

2.2.1.2 Other unspecific markers ........... 883

2.2.2 "Specific markers" ................................... 883

2.2.2.1 5-HIAA ..................................... 883

2.2.2.2 Gastrin...................................... 883

2.2.2.3 Insulin ................................. 884

2.2.2.4 Other specific markers ............... 884

2.3 Imaging procedures .............................................. 885

2.3.1 Radiologic procedures................................ 885

2.3.1.1 Ultrasonography ......................... 885

2.3.1.2 Multislice triple phase CT ......... 885

2.3.1.3 MRI.......................................... 885

2.3.2 Nuclear medicine procedures........................ 886

2.3.2.1 SSTR functional imaging........... 886

2.3.2.2 PET with other tracers ................ 886

2.3.3 Endoscopic procedures............................... 887

2.3.3.1 Upper and lower gastrointestinal

NENs........................................ 887

2.3.3.2 Small-bowel NENs.................... 887

2.3.3.3 Pancreatic NENs ........................ 887

3 A step-by-step multidisciplinary approach to clinical diagno-

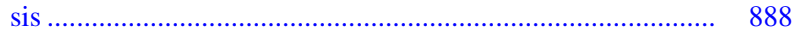

3.1 Incidental finding .................................................. 888

3.1.1 GEP-NENs suspected at endoscopy ........... 888

3.1.2 GEP-NEN suspected at morphological (US/CT/ MR) imaging .......................................... 888

3.1.3 GEP-NEN suspected after elevated serum CgA levels ............................................. 889

3.2 Symptomatic patient with symptoms due to GEP-NENrelated local effects..................................................... 890

3.2.1 When to suspect a GEP-NEN …………....... 890

3.2.2 Work-up in the patient with local compressive symptoms .......................................... 890

3.2.2.1 Isolated abdominal pain .............. 890

3.2.2.2 Subocclusive picture ….............. 890

3.2.2.3 Jaundice .................................... 891

3.2.2.4 Gastrointestinal bleeding........... 891

3.3 Symptomatic patient with syndromes ........................ 892

3.3.1 Diarrhea and flushing................................. 892

3.3.1.1 Clinical approach: when to suspect a GEP-NEN …............................. 892

3.3.1.2 Work-up in the patient with suspected carcinoid syndrome .................... 893

3.3.2 Resistant/relapsing ulcer disease ................. 894

3.3.2.1 Clinical approach: when to suspect a GEP-NEN …..................... 894

3.3.2.2 Work-up in the patient with suspected gastrinoma ….............................. 895

3.3.3 Spontaneous hypoglycemia.......................... 896

3.3.3.1 Clinical approach: when to suspect a GEP-NEN ............................... 896

3.3.3.2 Work-up in the patient with suspected insulinoma .................................... 897

3.4 Work-up in the patient with metastatic disease and unknown primary tumor .............................................................. 899

3.5 When and how to stage a previously diagnosed GEP-

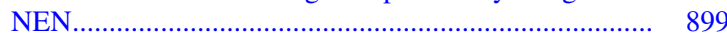

4 Conclusions ................................................................. 900

5 References ............................................................ 901 


\section{Introduction}

\subsection{Why this document}

Neuroendocrine neoplasms (NENs) can arise almost throughout the entire body and share common morphological, ultrastructural, and immunohistochemical characteristics.

Neuroendocrine neoplasms are an emerging entity that can occur at any age, with the median age at diagnosis in the late fifth decade and an age-related incidence increase. About two-thirds involve the gastro-entero-pancreatic (GEP) tract and epidemiological studies show their increasing incidence [1]. In the last decades, the overall reported incidence of GEP-NENs increased from 1.0 to 5.25/100.000 persons/year, with a present estimated prevalence of 35/100.000 [1-10]. Physicians' awareness, endoscopic screening and increased sensitivity of diagnostic tools may at least in part explain this growing trend.

Most guidelines are focused on staging, treatment and follow-up of NENs. However, an appropriate clinical suspicion and a correct diagnostic work-up are critical starting points. A multidisciplinary approach, moreover, is crucial to provide a timely and integrated care. Hence, this document is neither a review, nor a guideline; rather, it is a clinical guide for a stepwise and integrated diagnostic work-up of GEP-NENs. Hopefully, this will result in a correct utilization of resources and optimization of the cost/ benefit ratio.

\subsection{Methodology}

The grading of recommendations, assessment, development, and evaluation (GRADE) system was adopted for the present position statement [11-14]. Briefly, the GRADE system classifies evidence into four quality levels (high, moderate, low, or very low), and recommendations into two grades (strong or weak).

Whenever possible, the level of evidence (LoE) has been ranked as follows: very low $(\otimes \bigcirc \bigcirc)$ ), low $(\otimes \otimes \bigcirc \bigcirc)$, moderate $(\otimes \otimes \otimes \bigcirc)$, and high $(\otimes \otimes \otimes \otimes)$. "Very low quality" evidence corresponds to unsystematic clinical observations (case report, case series) or indirect evidence (e.g., surrogate end points); "low quality" evidence corresponds to observational studies or randomized controlled trials (RCT) with major limits; "moderate quality evidence" corresponds to RCTs with limitations or rigorous observational studies; and "high quality evidence" corresponds to well performed RCTs and strong evidence from unbiased observational studies [13].

We labeled as "recommendations" and "suggestions" the strong and weak recommendations, respectively. Each recommendation/suggestion is based on the quality of supporting evidence, downgraded or upgraded according to adjunctive factors (e.g., inconsistency of results, indirectness of evidence, lack of precision and limited number of relevant publications downgrade the recommendation/ suggestion; large effect size, narrow confidence intervals, clinically very significant end points upgrade the recommendation/suggestion), and the level of panel agreement [13].

\subsection{Definitions}

Neuroendocrine neoplasms neoplastic cells possess features of both neural and epithelial cells. Therefore, in line with the WHO classification, the term neuroendocrine will be adopted throughout this document [15].

WHO recommends the use of the term "neuroendocrine neoplasm" (NEN) to indicate low- to high-grade lesions. The term "neuroendocrine tumor" (NET) will be used throughout this document, due to its widespread diffusion, to indicate low- to intermediate-grade lesions and the term "neuroendocrine carcinoma" (NEC) to indicate high-grade lesions. Terms like "carcinoids" and the embryological classification of GEP-NENs in tumors of foregut (thymus, esophagus, lung, stomach, duodenum, pancreas), midgut (appendix, ileum, cecum, ascending colon) and hindgut (distal colon and rectum) will be avoided.

\subsection{Classification}

In the last 10 years WHO has repeatedly revised the pathologic classification of GEP-NENs (Table 1) [16].

According to the 2010 classification, NET G1 includes the "carcinoids" or "well-differentiated tumors" of the

Table 1 WHO classifications of GEP-NENs

\begin{tabular}{lcc}
\hline WHO 1980 & WHO 2000 & WHO 2010 \\
\hline I. Carcinoid & $\begin{array}{c}\text { Well-differentiated } \\
\text { endocrine tumor } \\
\text { Well-differentiated } \\
\text { endocrine carcinoma }\end{array}$ & $\begin{array}{c}\text { Neuroendocrine } \\
\text { tumors }\end{array}$ \\
& NET G1 (Grade 1) & NET G2 (Grade 2) \\
& endocrine carcinoma/ & Neuroendocrine \\
& small-cell carcinoma & NEC G3 (Grade 3): \\
& & Large-cell NEC \\
& & small-cell NEC \\
& & Mixed adeno- \\
& & neuroendocrine \\
II. Mucocarcinoid & Mixed exocrine- & carcinoma \\
III. Mixed & endocrine carcinoma & (MANEC) \\
carcinoid- & & \\
adenocarcinoma & & \\
forms & & Hyperplastic and \\
IV. Pseudotumor & Tumor-like lesions & preneoplastic \\
lesions & & \\
& &
\end{tabular}


Table 2 Grading system for GEP-NENs (adapted from 19)

\begin{tabular}{lll}
\hline & Ki-67 index $(\%)^{\mathrm{a}}$ & Mitotic count/10 HPF \\
\hline NET G1 & $\leq 2$ & $<2$ \\
NET G2 & $3-20$ & $2-20$ \\
NEC G3 & $>20$ & $>20$ \\
\hline
\end{tabular}

a Assessed by MIB-1 labeling in at least 2,000 tumor cells in high nuclear density ("hot spot") areas

b $10 \mathrm{HPF}=2 \mathrm{~mm}^{2}$, at least 50 optical fields in high-density mitotic areas

1980 and 2000 WHO classifications. These tumors are usually indolent, but can occasionally behave as malignant.

NET G2 may be considered a "grey zone", with heterogeneous behavior, and requires a tailored management.

NEC (G3) is a malignant neoplasm with an aggressive clinical course.

MANEC has a malignant phenotype with features of both adenocarcinoma and NET. This definition requires the presence of at least $25 \%$ of each component. Neuroendocrine cells are usually interspersed and the two populations may be identified only by immunohistochemistry (IHC). Less frequently, neuroendocrine cells may be grouped in distinct regions that are recognized by light microscopy.

The WHO 2010 classification strongly relies on tumor grading. Grading relates to the biological aggressiveness of the neoplasm, whereas differentiation indicates its similarity to the tissue of origin [15]. The clinical behavior of NENs may be basically predicted by their grading, staging, and evidence of hormonal syndromes. All these data should be collected and weighted to establish the prognosis and management of the patient.

\subsubsection{Grading assessment}

The grade of a tumor is the primary predictor of its clinical outcome. Grading is based on the proliferation rate of the tumor, as assessed by the Ki-67 cell labeling and by the mitotic count (number of mitosis $\times 10$ high power fieldsHPF) (Table 2) [15-23].

Visual estimates are currently used as the standard technique for evaluating both $\mathrm{Ki}-67$ and the mitotic count $[24,25]$. Several areas should be assessed within the tumor to reduce the risk of evaluation bias due to intratumoral heterogeneity. Densely stained regions ("hot spots") should be preferentially evaluated. Results from these areas should be reported as a single percentage reflecting the highest identified count [16, 21, 22].

Potential pitfalls and limitations are:

a. technical problems (e.g., tissue processing, differences in Ki-67 antibodies, etc.); b. intratumoral heterogeneity and sampling limitations (e.g., a single biopsy sample may not be representative of the tumor grade within the whole neoplastic mass) $[24,26]$;

c. discordances:

I. between the proliferative rate and the degree of differentiation (e.g., a morphologically well-differentiated NEN may exhibit a high proliferative rate);

II. between the predictive value for prognosis and that for treatment response (e.g., Ki-67 is a reliable predictor of disease progression and overall survival (OS), but seems a less efficient predictor of response to medical treatment) [27].

\subsubsection{Pathologic staging}

GEP-NENs are staged according to tumor size, site of origin, and locoregional or distant spreading [21-23]. The staging information is integrated with the 2010 WHO classification to stratify the prognostic risk and optimize the therapeutic and follow-up strategies (Fig. 1).

We recommend the use of the 2010 WHO classification.

We recommend for staging the use of the AJCCTNM 2009, and just for pancreas and appendix AJCC-TNM 2009 and ENETS-TNM 2006/07. The selected system should be specified in the pathologic report.

We recommend NEN classification and clinical actions be based on the less favorable data in case of conflicting findings.

\section{Diagnostic tools}

2.1 Histology, cytology, immunohistochemistry, and molecular biology

\subsubsection{Morphologic criteria}

Pathologic assessment is required for the diagnosis, classification and staging of NENs.

GEP-NENs present a broad architectural spectrum [28]. Well-differentiated tumors show an organoid pattern that ranges from solid nests to micro-macrotrabecular/gyriform pattern. A rich sinusoidal vascularity is usually observed. Stromal fibrosis, amyloid deposition, and calcification may be present. Necrosis can be present either as large infarct- 
Fig. 1 Integrated pathologic and biologic classification (modified from 15)
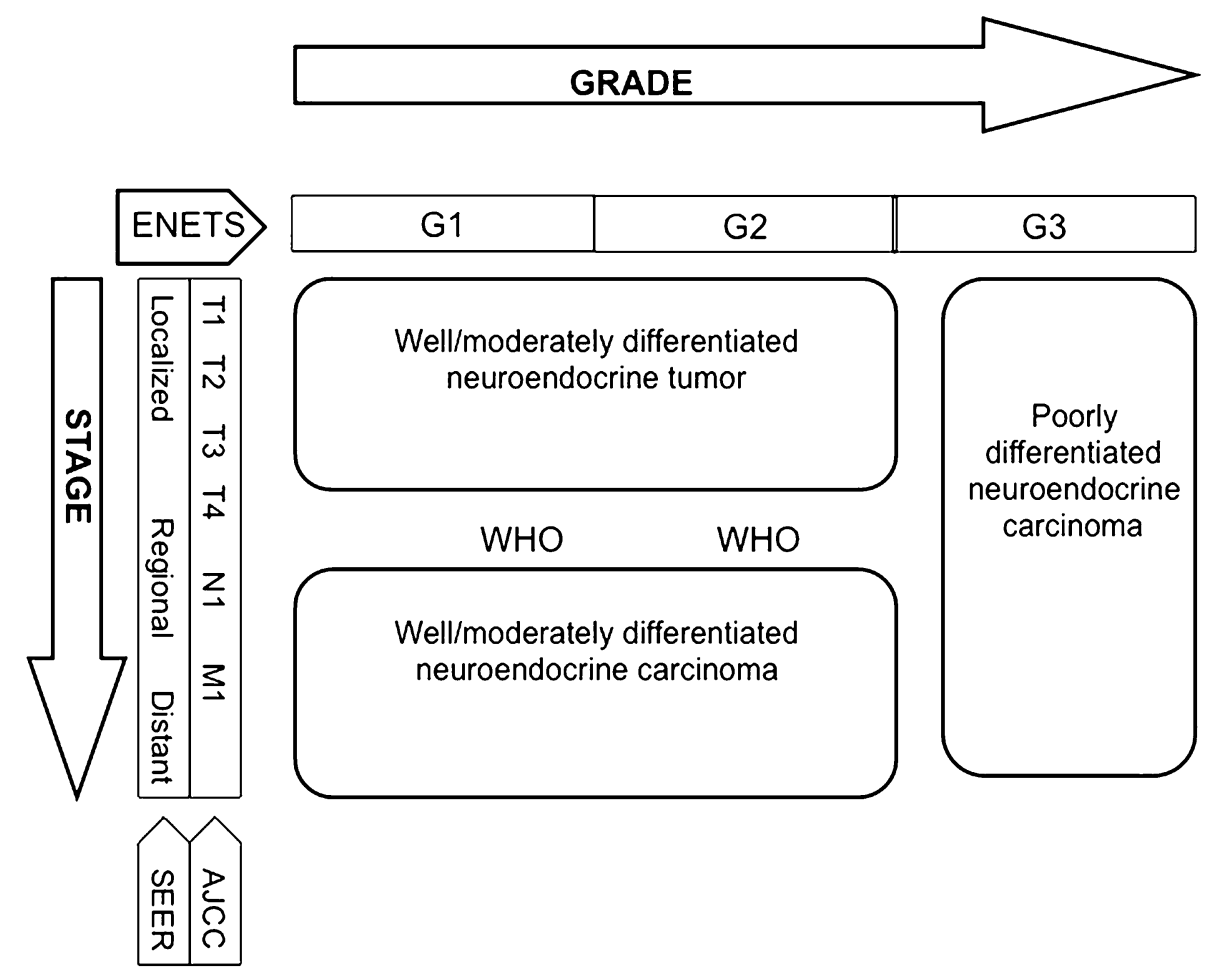

like areas or as punctate foci in the center of neoplastic nests. Regardless of their growth pattern, NEN cells have a similar cytological appearance: small- to medium-size cells with round to oval shape and eosinophilic, lightly granular, cytoplasm. The nuclei are usually centrally placed, fairly uniform, with a finely dispersed ("salt and pepper") chromatin pattern. Rarely, the neoplastic cells have a "plasmocytoid appearance" due to peripherally located nuclei. Nucleoli are usually inconspicuous or absent. Intracytoplasmatic hyaline globules or nuclear pseudoinclusions may be seen.

High-grade NENs are composed of small or large-tointermediate cells with high-grade features (marked nuclear atypia, multifocal necrosis, high mitotic index) and diffuse growth, sometimes with organoid feature resembling NEN.

The subgroup of GEP-NENs with $\mathrm{Ki67}>20 \%$ (and therefore G3 according to WHO 2010), but with a morphology of well-/moderately differentiated tumor should be considered low/intermediate rather than high-grade NENs [29].

Cytological specimens, which may be the only source of diagnostic material, pose some problems for clinical management. Cytology effectively separates high-grade NENs from low-grade NENs, but the distinction between low- and intermediate-grade NENs may be impossible. The diagnostic accuracy of aspiration techniques may be limited by the small sample size, the suboptimal reproducibility and the risk of contamination from contiguous tissues.

Cytology is gaining a major role for the diagnosis in duodeno-pancreatic tumors. The endoscopic ultrasonography (EUS) fine needle aspiration (FNA) technique appears reliable, with a reported specificity of about $75 \%$, sensitivity of $87.5 \%$, accuracy of $89 \%$, positive predictive value (PPV) of $93 \%$, and negative predictive value (NPV) of $60 \%$ [30-32].

\subsubsection{Immunohistochemistry and molecular biology techniques}

Neuroendocrine differentiation Synaptophysin (a small vesicle-associated marker) and Chromogranin A ( $\mathrm{CgA}$, a large secretory granule-associated marker) are useful IHC markers for the diagnosis of NENs. In NEC, the staining for both these markers is required to confirm the diagnosis, because CgA may be negative [15]. Routine IHC staining for peptide hormones and bioamines is not recommended. Other neuroendocrine markers, such as PGP.9.5, NSE, CD56, NSP-55, are of questionable specificity and clinical usefulness.

Prognostic markers proposed in addition to Ki-67 are CK19, CD117, CD99, p53, Her/2, CEACAM1, E-cadherin, $\beta$-catenin, hHAS-1, FGF13, PLGF, PAX-8, PTEN. None is presently recommended for clinical practice. The research of circulating tumor cells or the use of microRNAs is not indicated for routine use [33, 34]. 
Markers of primary site These markers may be a key for determining the unknown primary tumor in metastatic lesions. The most useful are [35]:

- TTF-1, indicative of pulmonary or thyroid origin;

- serotonin and CDX-2, indicative of intestinal origin;

- PAX-8 and histidine-decarboxylase, indicative of pancreatic origin;

- xenin, indicative of duodenal origin.

Markers predictive of response to specific treatments These biomarkers are not indicated for routine diagnostic practice. They include [19]:

- somatostatin receptors (SSTR)-2A (IHC determination at the cell membrane level), for planning the treatment with somatostatin analogs (SA);

- Akt/mTOR pathway molecules (PIK3, PTEN, TSC2), for treatment with everolimus;

- thymidylate synthase, for treatment with antifolates;

- ERCC-1, for treatment with platinum;

- topoisomerase Ii $\alpha$, for treatment with etoposide;

- epigenetic events, as methylation of MGMT promoter, for treatment with alkylating agents.

We recommend routine $\mathrm{IHC}$ assessment of synaptophysin and $\mathrm{CgA}$.

We suggest IHC assessment of peptide hormones or bioamines as optional in selected cases.

We recommend against routine use of other IHC markers in clinical practice.

\subsubsection{Working with the pathologist and his pathologic report}

The modality and timing of sampling techniques should be planned by a multidisciplinary team.

The pathologist should be provided with accurate clinical information including signs and symptoms, laboratory findings and imaging studies [36].

The ideal pathologic report should include:

- description of the macroscopic specimen;

- tumor size (three dimensions);

- description of cell features and histologic architecture;

- differentiation (well or poorly differentiated);

- IHC findings (CgA and synaptophysin routinely, SSTR2A when appropriate (e.g., when functional imaging for SSTR2 is negative);

- Ki-67 and mitotic count;
- completeness of resection, distance of the surgical margins from the tumoral edge, depth of invasion;

- signs of malignancy (angiolymphatic and/or perineural invasion, necrosis, infiltration of the capsule and/or of gastrointestinal (GI) wall and/or surrounding tissues);

- number of examined lymph nodes, and number of lymph node metastases; presence of micrometastases; diameter of largest metastasis;

- presence of distant metastases, if demonstrated;

- functional activity (if appropriate).

The report should be concluded with the WHO diagnosis and classification of the lesion (NET G1-G2 or NEC G3) based on proliferative index (Ki-67 and/or mitotic count), and with the tumor stage (the staging system should be specified).

The minimum pathology data set for resected specimens (both primary and metastatic) should include [37]:

- site;

- diagnosis (e.g., pure neuroendocrine neoplasm);

- differentiation (i.e., well or poor);

- proliferation (i.e., G1 or G2 or G3).

We recommend histology as the diagnostic standard, cytology if histology is not available.

We recommend classification according to WHO 2010.

We recommend grading according to $\mathrm{Ki}-67$ index and/or mitotic count.

We recommend staging according to AJCC/UICC TNM and ENETS.

\subsubsection{Genetic assessment}

Approximately 5-10\% of GEP-NENs have a hereditary background as part of tumor susceptibility syndromes: multiple endocrine neoplasia type 1 (MEN-1), von HippelLindau disease (VHL), neurofibromatosis type 1 (von Recklinghausen disease, NF1) and the tuberous sclerosis complex (TSC). All are inherited autosomal dominant disorders [38].

$M E N-1$ GEP-NENs are the second most common manifestation of MEN-1, reported in 30-70\% of cases in different series [mostly non-functioning (NF)] [39, 40]. A germ-line $M E N-1$ mutation is identifiable in about 80-90\% of familial cases [41] and in about $42 \%$ of sporadic cases [42]. Germline mutations arise de novo without any family history in approximately $10 \%$ of patients [43]. MEN-1 
mutation testing should be offered to index cases and to their first-degree relatives, even if asymptomatic [40]. Genetic counseling is recommended [40]. The family members who carry the $M E N-1$ mutation require routine surveillance for early detection of endocrine tumors, whereas those who do not carry the mutation can be reassured. When molecular genetic testing is not available locally, patients highly suspected for MEN-1 should be addressed to a referral centers. No genotype/phenotype correlations have been demonstrated in MEN-1 syndrome [44, 45].

VHL Endocrine pancreatic NF tumors occur in 11-17\% of patients with VHL disease [46]. The penetrance of $V H L$ mutations is almost complete by age 65 years [47]. Genetic testing detects mutations in virtually all affected individuals [48] and should be offered to all individuals with clinical evidence of VHL and to first-degree relatives. As ophthalmologic screening for those at risk for VHL disease begins before age five, molecular genetic testing is suggested also in young asymptomatic children [49, 50].

NF1 GEP-NENs occur in $1 \%$ of the NF1 patients [51]. Half of affected individuals have NF1 as the result of a de novo mutation. The offspring of an affected individual is at a $50 \%$ risk of inheriting the altered $N F 1$ gene, and the disease manifestations are extremely variable, even within the same family [52]. Molecular testing for NF1 is not usually recommended in the clinical practice: screening for NF1 mutations is useful only in individuals who do not completely fulfill the NIH diagnostic criteria.

TSC A few cases of pancreatic (p)NENs have been described in patients with TSC [53-55]. The diagnosis of TSC is usually based on clinical findings and mutations can be identified in approximately $85 \%$ of individuals who meet the diagnostic criteria [56]. Two-thirds of affected individuals have TSC as the result of a de novo mutation.

We recommend germ-line DNA testing only in presence of a family history or clinical findings suggestive of MEN-1 or VHL. Genetic testing should include mutational screening and sequencing. A preliminary genetic counseling is needed.

We suggest the routine determination of serum calcium and PTH levels in patients with duodeno-pancreatic NEN as a first-line screening for MEN-1.

We recommend against routine somatic (tumor tissue) DNA testing.

\subsection{Laboratory assessment}

The determination of GEP-NENs serum markers should not be used as a first-line diagnostic tool whereas it is appropriate for monitoring the response to treatment and for long-term follow-up [57, 58].

Serum markers should be determined after:

1. an established diagnosis or strong clinical suspicion of GEP-NEN;

2. exclusion of physiologic and pathologic confounding conditions.

NEN markers may be regarded as "unspecific" or "disease-specific".

\subsection{1 "Unspecific markers"}

2.2.1.1 Chromogranin A Chromogranin A is a widely employed serum marker for GEP-NENs, but its use presents limitations [59]. CgA circulates under different antigenic forms and no universal calibration standard is available [60]. IRMA and RIA results may be considered roughly equivalent [61], but the reference intervals are variable and results obtained with different assays cannot be compared.

Chromogranin A level may be increased in a number of pathologic conditions (Table 3), and in healthy subjects after eating or physical exercise. Accordingly, CgA levels are highly variable in the general population [62], and may partially overlap between GEP-NEN patients and controls. Hence, $\mathrm{CgA}$ has a poor first-line diagnostic value $[5,60$, 62-66].

Proton pump inhibitors (PPIs) increase (up to sevenfold) CgA levels. The effects of PPIs persist for several days after drug discontinuation. Therefore, $\mathrm{CgA}$ testing should be performed after an at least 2-week PPIs withdrawal [62, 67]. The effects of H2-receptor antagonists (H2RAs) on CgA are still controversial [68].

Table 3 Potential confounders causing CgA increase [64]

Neoplastic (other than GEP-NENs)
Breast cancer
Prostate cancer
Ovarian cancer
Hepatocarcinoma
Pancreas adenocarcinoma
Colon cancer
Non-neoplastic
Kidney or heart failure
Endocrine diseases (hyperthyroidism, hyperparathyroidism)
Local or systemic inflammatory disease
Chronic obstructive broncho-pulmonary disease
Gastro-enteric pathologies: chronic atrophic gastritis,
pancreatitis, inflammatory bowel disease, cirrhosis, chronic
hepatitis


Diagnostic accuracy of $\mathrm{CgA}$ depends on different variables:

- tumor burden (sensitivity $60-100$ vs. $29-50 \%$ in metastatic and localized disease, respectively) [62, 64, 69];

- type and site of tumor (sensitivity 96 vs. $75 \%$ in functioning and NF tumors, respectively) $[63,70]$.

2.2.1.2 Other unspecific markers Neuron-specific enolase (NSE) is an enzyme found in neuroectoderm-derived cells. The presence of NSE has been reported in thyroid and prostate carcinomas, neuroblastomas, small-cell lung carcinomas, and pheochromocytomas. The clinical usefulness of this marker is hampered by its poor specificity [71]. NSE level is elevated in $30-50 \%$ of patients with NEN, particularly those with poor differentiation. The combined determination of NSE and CgA may improve sensitivity in GEP-NEN diagnosis [72].

Pancreatic polypeptide (PP) is secreted by specialized pancreatic islet cells and inhibits gut motility and pancreatic exocrine secretion. PP has been proposed for the diagnosis and monitoring of NF pNENs, as its combination with $\mathrm{CgA}$ increases sensitivity up to $93 \%$ [69]. Its routine use is not recommended due to the low diagnostic performance (sensitivity $63 \%$ and specificity $81 \%$ ). PP levels may increase in old age, diarrhea, laxative abuse, gut inflammatory processes and chronic renal disease.

Beta subunit of human chorionic gonadotropin (hCG), a glycoprotein synthesized by the syncytiotrophoblastic cells of the placenta during pregnancy, may be increased in patients with pNENs [73], but has no use in every day practice.

As a whole, the clinical usefulness of the above reported markers is limited.

\subsection{2 "Specific markers"}

2.2.2.1 5-HIAA 5-HIAA, the main urinary metabolite of human serotonin, is determined by HPLC on $24 \mathrm{~h}$ urine samples. Results may be expressed as absolute values or as a ratio to creatinine excretion.

Some pre-analytical variables, mostly tryptophan/serotonin-rich foods and drugs, may interfere with serotonin metabolism (Table 4) [74]. These products should be avoided prior to urine collection, respectively, for at least 72 and $24 \mathrm{~h}$ [64].

The normal 5-HIAA urinary excretion ranges from 2 to $8 \mathrm{mg} /$ day, but unspecific elevations (up to $30 \mathrm{mg} /$ day) may be found in malabsorption syndromes, such as celiac and Whipple's disease [75-77].

The determination of 24-h urinary excretion of 5HIAA has a sensitivity of over $90 \%$ and a specificity of $90 \%$ for
Table 4 Drugs and foods interfering with 5-HIAA assay

False negative results
Acetylsalicylic acid
Phenothiazines: chlorpromazine, promethazine
Imipramine and MAO-inhibitors
ACTH
Ethanol
MethylDOPA and hydrazine derivatives
Ketoacids
LevoDOPA
Isoniazid, methenamine, gentisic and homogentisic acid
Streptozotocin
Heparin
False positive results
Acetaminophen, naproxen, phenacetin
Caffeine, nicotine
Coumaric acid
Diazepam
Ephedrine
Fluorouracil, melphalan
Phenobarbital
Phentolamine, reserpine, guaifenesin, mephenesin
Methamphetamine, Phenmetrazine
Methocarbamol
Mesalamine
Foods: bananas, avocados, kiwi, pineapples, peanuts, tomatoes,
chocolate, vanilla, sweets, and cookies (sugar and marmalade
are allowed)
Plums, eggplant, walnuts, pecans, coffee, tea, coa/

full-blown carcinoid syndrome (CS, see "Box 2, Carcinoid syndrome"). Urinary 5-HIAA excretion in these patients is reportedly higher than $90 \mathrm{mg} /$ day (up to $2,000 \mathrm{mg} /$ day). The test sensitivity, however, is definitely lower in absence of clinical symptoms [77, 78].

There is a possibility to analyze plasma 5-HIAA which might replace urinary-5-HIAA in a future [79].

Various blood serotonin assays have been proposed, but their actual accuracy has not been established. False positives may occur due to several interfering factors, as the release of platelet serotonin or the previous ingestion of tryptophan/serotonin-rich foods [80]. Accordingly, serotonin determination is not recommended in clinical practice.

2.2.2.2 Gastrin Gastrin determination has a key role in the evaluation of patients with signs and symptoms suggestive of Zollinger-Ellison syndrome (ZES, see "Box 3, Gastrinoma").

Various antigenic isoforms of gastrin circulate in the blood. Care must be taken because some commercial 
Table 5 Main drugs and foods that may interfere in gastrin assay

\begin{tabular}{l}
\hline False negative results \\
Acetylsalicylic acid \\
LevoDOPA \\
False positive results \\
Hypochlorhydria/achlorhydria due to chronic use of PPIs and \\
H2RAs or chronic atrophic gastritis (often associated with \\
pernicious anemia) \\
Helicobacter pylori infection \\
Gastric outlet obstruction \\
Renal failure \\
Antral G-cell syndromes \\
Short-bowel syndrome \\
Retained antrum
\end{tabular}

immunoassay kits detect only the gastrin-17 molecule [81] and may cause false positive results.

Hypergastrinemia is commonly defined as a fasting serum gastrin above $100 \mathrm{pg} / \mathrm{mL}$. Simultaneous measurement of gastric $\mathrm{pH}$ on a single sample is needed to rule out secondary hypergastrinemia due to other causes. In achlorhydria, pernicious anemia or atrophic gastritis high gastrin levels are usually associated to high (i.e., >4) $\mathrm{pH}$ values. On the contrary, serum gastrin levels $>1,000 \mathrm{pg} /$ $\mathrm{mL}$ combined with a $<2$ gastric $\mathrm{pH}$ are virtually diagnostic of ZES. Falsely elevated gastrin levels may be due to a few drugs (Table 5) that should be discontinued at least 2 weeks before the test $[77,82-86]$.

In general, gastrin levels are higher in pancreatic than in duodenal NENs, and are proportional to tumor burden and in patients with metastatic disease, exceedingly high gastrin levels may be observed. However, the majority of patients with ZES show mildly elevated (e.g., $150-1,000 \mathrm{pg} / \mathrm{mL}$ ) gastrin levels, partially overlapping those of patients with renal insufficiency, small-bowel resection, retained gastric antrum, or on potent antisecretory drugs [87]. When the diagnosis is equivocal, a secretin stimulation test is needed. A gastrin increase $>120 \mathrm{pg} / \mathrm{mL}$ over basal level is considered diagnostic [88].

2.2.2.3 Insulin The occurrence of repeated symptomatic hypoglycemia $(<60 \mathrm{mg} / \mathrm{dL})$ is suspicious for insulinoma (see "Box 4") in subjects without diabetes. The diagnosis is confirmed by the presence of non-suppressed insulin levels in presence of low glucose levels (see "Spontaneous hypoglycemia"). To rule out a spurious hypoglycemia, laboratory processing should not be delayed. In subjects with leucocytosis glucose determination should be repeated with a collection tube that contains an inhibitor of glycolysis.
In presence of an episode of spontaneous severe hypoglycemia with hyperinsulinism, the simultaneous measurement of serum C-peptide and beta-hydroxybutyrate is appropriate. If factitious hypoglycemia is suspected, urinary sulfonylureas should be tested as well. The work-up may be completed with the measurement of serum proinsulin [89]. This test, even if not widely available, is diagnostic of insulinomas secreting immature forms of insulin.

In selected patients with endogenous hyperinsulinism, autoimmune hypoglycemia, suspected on the basis of negative imaging tests and coexistence of autoimmune disorders, should be ruled out with the determination of insulin autoantibodies [90].

If the patient is not hypoglycemic when observed, the association of severe hypoglycemia with non-suppressed insulin levels should be seeked under the conditions in which hypoglycemia would be expected (see provocative testing, "Spontaneous hypoglycemia") [89].

\subsubsection{Other specific markers Glucagon: Glucagonoma} is associated with serum glucagon concentrations higher than $500 \mathrm{pg} / \mathrm{mL}$ and a characteristic clinical syndrome (diabetes mellitus and cutaneous manifestations, such as migratory necrolytic erythema, nail dystrophies, stomatitis, etc.) [91]. Glucagon concentrations higher than 1,000 pg/ $\mathrm{mL}$ are virtually diagnostic for the disease, but some patients may exhibit levels within the physiologically elevated range. Moderate elevations in serum glucagon may be caused by protracted fasting in normal subjects or by renal and hepatic failure, trauma, sepsis, pancreatitis, abdominal surgery, and Cushing's syndrome.

Due to the fast degradation of glucagon in vitro, blood must be collected in test tubes containing aprotinin and should be rapidly delivered to the laboratory. Results obtained with different glucagon assays may profoundly differ, due to the different calibration standards and the variable cross-reactivity with glucagon isoforms.

Vasointestinal peptide (VIP): Vasointestinal peptidesecreting tumors cause the Verner-Morrison syndrome, characterized by variable combination of watery diarrhea (>700 mL/day even during fasting, with tea-colored, odorless stools), hypokalemia, achlorhydria, weight loss, metabolic acidosis, hypercalcemia, glucose intolerance, and flushing. The diagnosis is established by high-volume secretory diarrhea associated with VIP levels higher than $75 \mathrm{pg} / \mathrm{mL}$ (to be confirmed by a second RIA determination) $[92,93]$. VIP blood concentration is, in fact, extremely low in healthy subjects. Commercial kits are available, but their use is usually limited to tertiary referral centers. 
We recommend against the use of biochemical markers as the initial diagnostic step for potential GEP-NEN patients.

We recommend the determination of the appropriate biochemical marker only after the diagnosis or strong clinical suspicion of GEP-NEN. The panel of markers should take into account the clinical picture and local availability/expertise.

We recommend considering all possible clinical and analytical interfering factors in presence of elevated serum or urinary levels of GEP-NEN markers. The determination should be repeated, if possible, after their timely withdrawal.

We suggest PPIs discontinuation at least 2 weeks before $\mathrm{CgA}$ and gastrin measurements.

We recommend, after the finding of an elevated gastrin level, its repeated determination together with the assessment of gastric $\mathrm{pH}$.

We recommend for the follow-up of the markers expressed by GEP-NENs a serial measurement with the same laboratory assay.

\subsection{Imaging procedures}

\subsubsection{Radiologic procedures}

2.3.1.1 Ultrasonography Transabdominal US is an inexpensive, safe, rapid and non-invasive tool. US accuracy is, however, operator dependent and its sensitivity is generally low (13-27\%), when compared with MultiDetector CT (MDCT) and magnetic resonance imaging (MRI) [94]. In case of pNEN, a mean $39 \%$ US detection rate has been reported $[95,96]$.

Contrast-enhanced US (CEUS) enables identification of hypervascular lesions, even in case of fast-flow tumor circulation, as in NF pNENs. Therefore, CEUS is significantly superior to B-mode US both in the detection of NF pNENs and in the diagnosis of liver metastases, visualized as hyperenhancing non-homogeneous lesions [96-98], with a reported sensitivity of $82 \%$ [99, 100]. US may help in defining complications of advanced disease (i.e., biliary stricture) and/or guide diagnostic or therapeutic procedures [101].

Endoscopic ultrasonography and EUS-guided FNA, a fundamental procedure for the diagnosis of pNENs [96, 102, 103], will be treated in "Pancreatic NENs".

2.3.1.2 Multislice triple phase CT Multidetector CT is considered the first choice imaging modality for detection, staging and follow-up of GEP-NENs. When compared to conventional CT, MDCT allows a markedly higher spatial and temporal resolution. MDCT sensitivity and specificity are increased due to multiphase scanning. Images should be acquired in precontrast, arterial, portal and equilibrium phases.

Non-functioning pNENs and NEN liver metastases typically appear as hypervascular lesions. In the evaluation of NF pNENs, the combination of arterial dominant-phase and portal venous-phase CT improves the detection of primary tumors and hepatic metastases [96].

Reported mean sensitivity and specificity of MDCT are $73 \%(63-82 \%)$ and $96 \%(83-100 \%)$ for pNENs, and $82 \%(78-100 \%)$ and $92 \%(83-100 \%)$ for liver metastases, respectively [104-106].

When a small ileum lesion is suspected, MDCT enterography can be performed by distending the small bowel with a large volume of neutral or low-attenuating oral contrast medium [107-109]. The reported sensitivity and specificity of MDCT enterography are variable, ranging from 50 to $85 \%$ and from 25 to $97 \%$, respectively.

Due to radiation exposure, MDCT examination should be tailored, particularly in young people, to reduce the scanned volume and the number of phases.

2.3.1.3 MRI Like MDCT, MRI offers a high spatial and time resolution with the possibility of multiplanar acquisition and reconstruction and multiphase examination after contrast injection. Along with the absence of ionizing radiations, an advantage of MRI over MDCT is the intrinsic signal difference (contrast) between the neoplasm and the healthy parenchyma. This characteristic is increased with imaging sequences based on proton diffusion. If compared with MDCT, the major drawbacks of MRI are the higher cost, lower accessibility and longer scanning time. Furthermore, MRI is more dependent on patient cooperation. At MRI, GEP-NENs show the same enhancement characteristic described for MDCT. As for contrast medium, Gadolinium-based (Gd-EOB DTPA) agents (Primovist for MRI) should not be used in patients with advanced renal function impairment.

Magnetic resonance imaging demonstrates a particular sensitivity for liver, bone, soft-tissue, and central nervous system metastases [87, 95]. Multiphase CT scan and MRI have similar effectiveness in the detection of islet cell tumors if fat-saturated T1-weighted and delayed enhanced T1-weighted sequences are included.

In clinical practice, MRI should be used when MDCT does not offer clear-cut results or when contrast medium is contraindicated [95]. Due to the absence of radiation exposure, MRI is used, in association with US, either as a screening image modality in young patients or in long-term surveillance [110]. 
We recommend chest-abdomen MDCT as the routine morphologic imaging modality for the detection and staging of GEP-NENs.

We recommend MRI when the evaluation of bone and CNS is required. In all the other cases MRI should be used as a second-line imaging study, when MDCT is not conclusive or contraindicated.

We suggest CEUS or MRI for a better characterization of liver involvement.

\subsubsection{Nuclear medicine procedures}

2.3.2.1 SSTR functional imaging Up to $80 \%$ of GEPNENs express primarily SSTR2 and SSTR5: this feature enables imaging with SA compounds, labeled with radioactive tracers.

The most common radiopharmaceutical SA is ${ }^{111} \mathrm{In}$ pentetreotide (commercially available as Octreoscan ${ }^{\circledR}$ ) used for scintigraphy, SPECT and SPECT/CT [111, 112]. Modern hybrid acquisition systems as SPECT/CT allow a coregistration of functional and morphologic imaging, which improves the localization of lesions [113].

Due to its high affinity to SSTR2, Octreoscan ${ }^{\circledR}$ shows a higher detection rate of NEN lesions as compared to conventional imaging, with a sensitivity ranging from 67 to near $100 \%$ [114-119].

Among other radiolabeled SA, ${ }^{68}$ Ga-DOTA-D-Phe1Tyr3-octreotide (DOTATOC) binds SSTR2 and SSTR5 with higher affinity than Octreoscan ${ }^{\circledR}$ [120]. In light of higher spatial resolution $(3-5 \mathrm{~mm})$ and better quantification of tracer uptake offered by PET in comparison with scintigraphy, PET and PET/CT scan with ${ }^{68}$ Ga-DOTATOC have significant advantages over SRS imaging, particularly in organs with high physiologic uptake (e.g., liver) and in case of small lesions $(<1.5 \mathrm{~cm})$ [121-123]. Furthermore, ${ }^{68} \mathrm{Ga}$-DOTATOC has proven to be superior to CT and bone scintigraphy in the detection of bone metastases from GEPNENs [124].

Similar results have been obtained with PET imaging using other ${ }^{68} \mathrm{Ga}$-labeled peptides (e.g., ${ }^{68} \mathrm{Ga}$-DOTATATE and $\left.{ }^{68} \mathrm{Ga}-\mathrm{DOTANOC}\right)$ [125-130]. PET/CT with ${ }^{68} \mathrm{Ga}-$ labeled SA is quite effective, both in terms of diagnostic accuracy and impact on clinical management [131-134].
Accordingly, this imaging procedure is recommended for routine use [73]. PET/CT with ${ }^{68} \mathrm{Ga}$-labeled SA is presently available at a limited number of institutions, but will hopefully become diffusely adopted worldwide in the next future (Table 6).

Clinical indications for nuclear imaging based on radiolabeled SA are [135]:

- primary tumor localization and staging;

- restaging (detection of residual, recurrent or progressive disease);

- SSTR status evaluation (patients with high positivity are more likely to respond to octreotide therapy);

- response to therapy monitoring;

- selection of patients eligible for peptide receptor radionuclide therapy.

As octreotide therapy can theoretically interfere with ${ }^{111}$ In-pentetreotide uptake, a brief (1-2 months) withdrawal of long-acting SA or a transient switch to shortacting SA should be considered [135].

2.3.2.2 PET with other tracers ${ }^{18}$ F-FDG-PET/CT has been traditionally thought to play a minor role in GEPNENs imaging due to the expected low FDG uptake of low-grade GEP-NENs [136]. As FDG uptake is greater in high-grade tumors, ${ }^{18} \mathrm{~F}$-FDG-PET/CT has been proposed in patients with advanced, metastatic GEP-NENs with promising results $[137,138]$. In addition, combined functional imaging with both ${ }^{68} \mathrm{Ga}$-DOTATATE and ${ }^{18} \mathrm{~F}$-FDG may be useful for a more comprehensive tumor assessment in intermediate and high-grade tumors [125]. Two recent studies confirm that FDG-PET is a sensitive technique for staging GEP-NENs with high ( $\geq 10-15 \%)$ Ki-67 [139, 140]. As for other tumors, it has been suggested that FDG positivity points to a worse prognosis [141-143].

${ }^{18} \mathrm{~F}$ - and ${ }^{11} \mathrm{C}$-labeled amine precursors L-dihydroxyphenylalanine (DOPA) [144-148] and 5-hydroxy-L-tryptophan [146, 149, 150] have been utilized for PET imaging of GEP-NENs in a limited number of studies with promising results. A still investigational tool is ${ }^{18} \mathrm{~F}$-fluorothymidine PET that seems to provide non-invasive assessment of cell proliferation. Finally, there is the possibility of utilizing glucagon-like peptide-1 receptor imaging for the localization of insulinomas [151]. Clinical application of these radiopharmaceuticals is not for routine use and needs confirmation.
Table 6 Comparison between Octreoscan and Ga-DOTApeptides

\begin{tabular}{|c|c|c|c|c|c|}
\hline & Availability & Duration & Accuracy & NPV & PPV \\
\hline${ }^{111}$ In-pentetreotide $\left(\right.$ Octreoscan $\left.{ }^{\circledR}\right)$ & Widespread & 2 days & ++ & ++ & +++ \\
\hline${ }^{68}$ Ga-DOTA-conjugate peptides & Low & $2 \mathrm{~h}$ & +++ & +++ & +++ \\
\hline
\end{tabular}


We recommend the use of SSTR functional imaging for localization and staging of G1-G2 GEP-NENs. We recommend PET/CT with ${ }^{68} \mathrm{Ga}$-labeled SA as the procedure of choice. When not available, ${ }^{111} \mathrm{In}$ pentetreotide (Octreoscan $\AA$ ) scintigraphy may be used.

We recommend against the routine use of ${ }^{18} \mathrm{~F}-\mathrm{FDG}$ PET/CT.

We suggest ${ }^{18}$ F-FDG PET/CT for staging high grade (G3) and selected G2 GEP-NENs.

\subsubsection{Endoscopic procedures}

2.3.3.1 Upper and lower gastrointestinal NENs Upper gastrointestinal endoscopy (EGDS) with gastric biopsy is required for the detection of gastric NENs.

Esophago-gastro-duodenoscopy is the only recommended imaging procedure in small $(<1 \mathrm{~cm})$ enterochromaffin-like cell tumors (ECLomas). Type 1 and 2 gastric NENs generally present (in $65-77 \%$ of cases) as small $(<2 \mathrm{~cm})$ multifocal polypoid mucosal protrusions in the body and/or fundus of the stomach. Type 3 tumors are usually solitary, ulcerated and larger than $2 \mathrm{~cm}$. In addition to biopsies of the largest polyps, samples should be taken from the antrum (two biopsies) and body/fundus (four biopsies) [152, 153]. Regardless of the type of gastric NEN, EUS may help to determine the presence of tumor invasion of the gastric wall and it is recommended before the resection of polyps $>1-2 \mathrm{~cm}$ in diameter. EUS is useful for the assessment of the regional lymph node involvement and for cyto-histologic confirmation by FNA [154].

Duodenal NENs are approached in the same manner, namely EGDS with biopsies and EUS [155, 156].

The majority of rectal NENs are diagnosed endoscopically. Most lesions present as polyps, which are completely removed by snare polypectomy, but their diagnosis may be established only after histologic evaluation. Full colonoscopic assessment is required to exclude concomitant colonic disease as part of staging, and the possibility of synchronous carcinoma must be excluded. EUS is very useful in assessing rectal NENs extension preoperatively and it accurately assesses tumor size, depth of invasion and perirectal lymph node metastases. Hence, EUS provides information critical for the choice of final treatment (endoscopic vs. surgical) [157, 158].
2.3.3.2 Small-bowel NENs Direct visualization of smallbowel NENs may be obtained by standard colonoscopy if the tumor is prolapsed through the ileocecal valve into the colon, or if intubation of the ileum via the ileocecal valve is performed. Newer modalities to investigate the proximal parts of the ileum or the jejunum include video-capsule endoscopy (VCE) and enteroscopy. Small-scale studies have reported successful detection of occult small-bowel NENs by VCE where other techniques have failed. It is advisable to use a dissolvable "patency" capsule to avoid capsule "retention" within strictures. Major VCE limitations are as follows: (a) precise localization of the tumor is not usually possible; (b) in case of predominantly extraluminal GEP-NEN, the evaluation of the tumor cannot be accurate; and (c) cost and operating time. VCE revealed a sensitivity of $60 \%$ and a specificity of $100 \%$ as compared to CT enteroclysis [107, 159].

In selected cases, double balloon enteroscopy (DBE) seems to be a valuable method. It allows histologic confirmation by luminal biopsy and accurate preoperative localization by tumor marking with ink injection. A $33 \%$ diagnostic yield of DBE for primary tumor detection in patients with metastatic or suspected GEP-NEN has been reported [160].

2.3.3.3 Pancreatic NENs Endoscopic ultrasonography is an effective tool to identify pNENs, which typically appear as well-defined hypoechoic, hypervascular masses. Cystic change, calcifications, and necrosis are common in large tumors. EUS-guided FNA (or biopsy, FNAB) is useful to confirm the diagnosis of pNEN. EUS sensitivity is quite high (79-100 \%) with a PPV close to $100 \%$ [161-164]. The accuracy decreases in case of lesions located in the pancreatic tail [165]. While EUS shows a higher sensitivity than cross sectional imaging in the diagnosis of small, multiple pNENs in MEN-1 or VHL syndromes, its accuracy in the detection of small duodenal tumor is controversial. The combination of dual-phase thin-section multidetector CT and EUS has been reported as the most accurate procedure to detect insulinomas [166]. EUS plus FNA is highly cost-effective when used early in the preoperative work-up, reducing the need for additional invasive tests $[167,168]$; complication rate is quite low $(<1 \%)$ [168]. A close correlation between aspiration cytology and the final histology after resection has been demonstrated [169]. EUS is thus useful in the preoperative setting as it provides information that significantly influences the therapeutic planning [170]. 
We recommend endoscopy with biopsy in gastroduodenal and colorectal NENs. If an ileal involvement is suspected, colonoscopy should possibly be extended to terminal ileum.

We recommend EUS to locally stage the disease before resection of gastric, duodenal and rectal polypoid lesions.

We suggest VCE and/or DBE as second-line tools for the diagnosis of small bowel NENs.

We recommend EUS plus FNA for the diagnosis of suspected pNENs.

\section{A step-by-step multidisciplinary approach to clinical diagnosis}

The suspicion of GEP-NEN can be raised in four different scenarios: (1) incidental finding either in a totally asymptomatic patient or in a patient with symptoms unrelated to GEP-NEN; (2) symptomatic patient with GEP-NEN-related local effects, (3) syndromes, and (4) metastases from unknown primary GEP-NEN. The first two scenarios are typical of NF GEP-NENs.

\subsection{Incidental finding}

GEP-NENs are often suspected following incidental imaging (e.g., US, CT, MRI) or endoscopic findings, in patients without signs or symptoms related to GEP-NEN $[1,3,6]$.

The patient should be checked for minor GI complains (diarrhea, constipation, peptic disease, gastroesophageal reflux), any palpable mass, skin and metabolic signs/ symptoms, possibly suggesting a functioning syndrome. An accurate clinical history of the patient's family should also be collected to confirm or rule out a hereditary syndrome [6].

\subsubsection{GEP-NENs suspected at endoscopy}

Incidental diagnosis of GEP-NENs often follows the histologic examination of polypoid lesions found during endoscopic procedures in an asymptomatic patient. Otherwise, gastroduodenal and colorectal NENs may be suspected in case of single or multifocal polypoid mucosal protrusions [152, 155, 158], even though no endoscopic finding is highly specific of NEN.

An endoscopic biopsy of the suspected lesion is mandatory. In case, the endoscopic biopsy is either not feasible or non-diagnostic, morphologic imaging studies should be programmed as the second step. Image-guided or laparoscopic biopsy should be discussed by the multidisciplinary team. Functional imaging could subsequently be performed as a complementary staging-prognostic tool.

No lab tests are indicated in the diagnostic work-up. The finding of hypergastrinemia, achlorhydria, macrocytic anemia, $B_{12}$ deficiency and/or intrinsic factor antibodies may be useful to categorize a gastric NEN (Fig. 2).

\subsubsection{GEP-NEN suspected at morphological (US/CT/MR) imaging}

This incidental finding is usually related to primary pancreatic tumor or liver metastases from a GEP-NEN.

A pNEN might be suspected in case of hypoechoic, hypervascular, and/or well-defined lesions at US/CEUS and of enhancing hypervascular lesions at CT scan or MRI. Cystic changes, calcifications, and necrosis are frequently observed in large lesions [171].
Fig. 2 Diagnostic flow-chart for GEP-NEN suspected at endoscopy

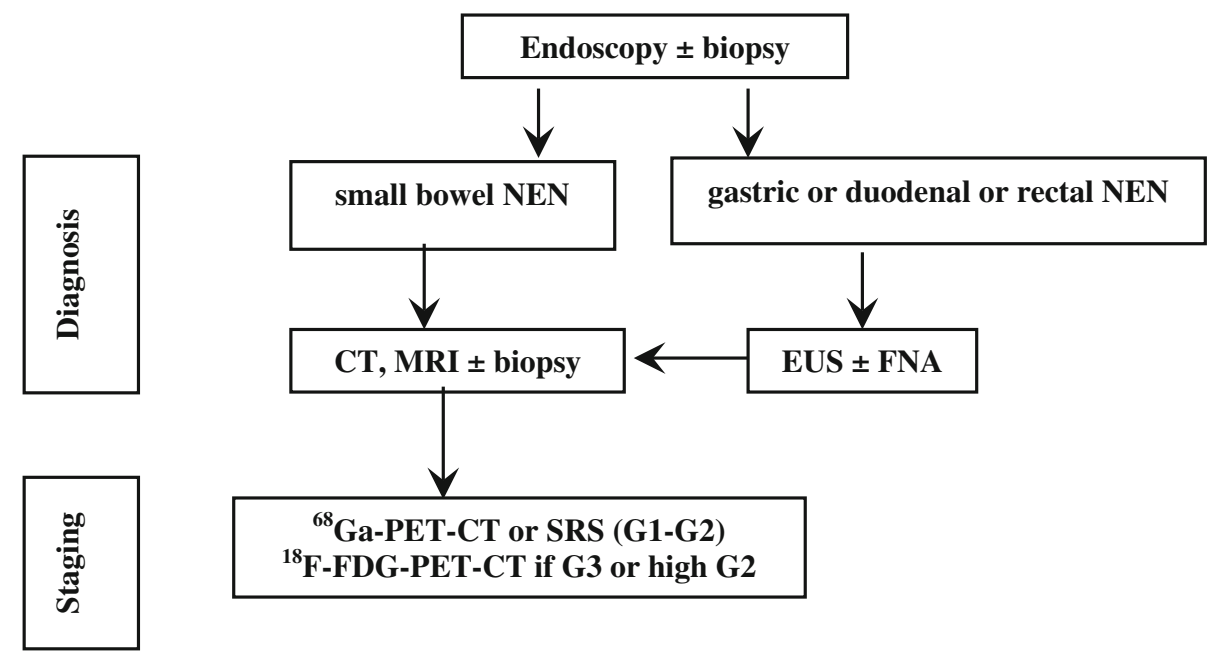


Fig. 3 Diagnostic flow-chart for GEP-NEN suspected at morphological imaging

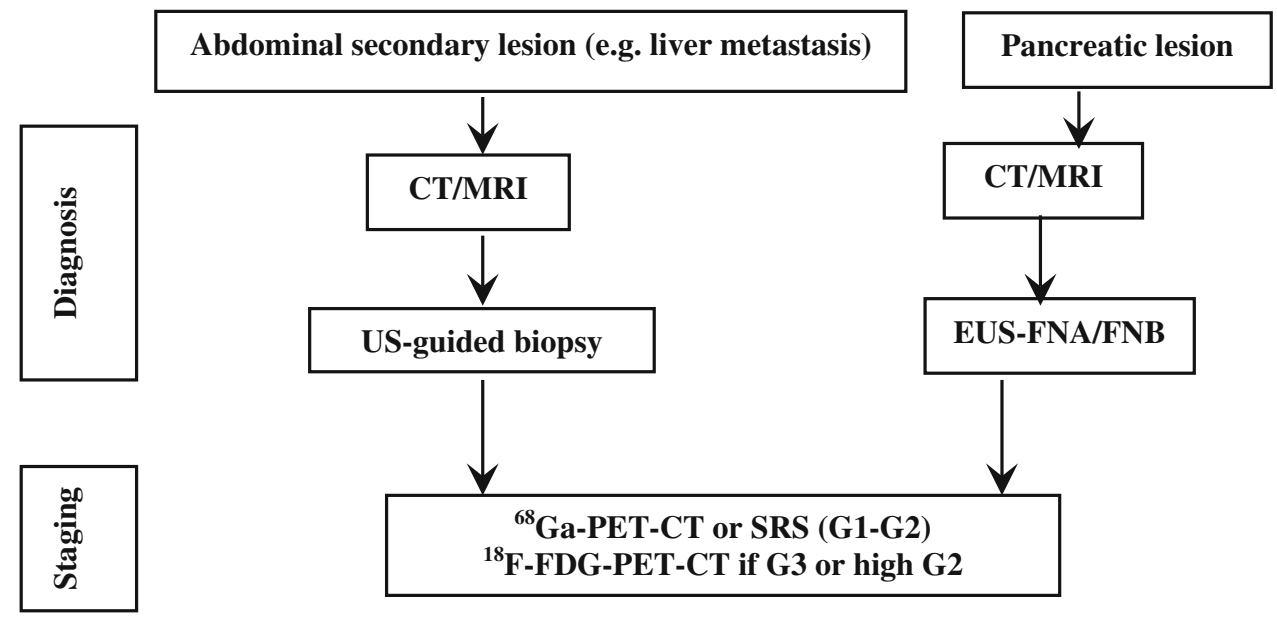

False positives, especially in case of US imaging, like hemangiomas, hepatocellular and pancreatic carcinomas, intraductal pancreatic mucinous tumors, adenomas and metastasis from other tumors [94, 95, 97-101] should be ruled out by the multidisciplinary team.

A histologic/cytological specimen should possibly be obtained [96, 172].

Once the diagnosis of GEP-NEN is pathologically confirmed, proceed to morphologic and functional staging (see below, "When and how to stage a previously diagnosed GEP-NEN"). If biopsy is unfeasible or inconclusive, a second imaging technique (e.g., EUS, CEUS, liver-specific contrast-enhanced MRI, etc.) should be performed according to local expertise and availability [6].

Metastatic lesion(s) from occult primary may require a specific work-up (see below, "Work-up in the patient with metastatic disease and unknown primary tumor").

No lab tests are recommended in the diagnostic workup. Nevertheless, elevated 5-HIAA urinary excretion is highly specific of GEP-NEN liver metastases and may, therefore, be a strong diagnostic clue in case of a nondiagnostic biopsy. In patients with pNENs, the occurrence of subclinical, vague functional signs/symptoms possibly indicating a functional syndrome should always be carefully checked. Accordingly, specific hormonal assays may be required in selected cases (Fig. 3).

We recommend biopsy as the first diagnostic step in all lesions suspected for GEP-NEN.

We recommend diagnostic work-up to be routinely discussed within a NEN multidisciplinary team.

We recommend against the use of laboratory assays or functional imaging as a first-line diagnostic procedure.

\subsubsection{GEP-NEN suspected after elevated serum CgA levels}

Chromogranin A must never be considered a first-line diagnostic test. Nevertheless, NEN suspicion may occasionally be driven by the finding of elevated serum $\mathrm{CgA}$ levels, measured on the basis of unspecific symptoms or signs.

Before proceeding to imaging/endoscopic studies, all factors affecting $\mathrm{CgA}$ levels must thoroughly be ruled out (see "Table 3"). A second CgA determination is always required for confirmation. In patients on PPI treatment, serum $\mathrm{CgA}$ should be repeated after a two-week PPI withdrawal.

If $\mathrm{CgA}$ levels are confirmed elevated in absence of confounding factors, transabdominal US should be performed. A further diagnostic work-up should be discussed by a multidisciplinary team or a referral center should be involved (Fig. 4).

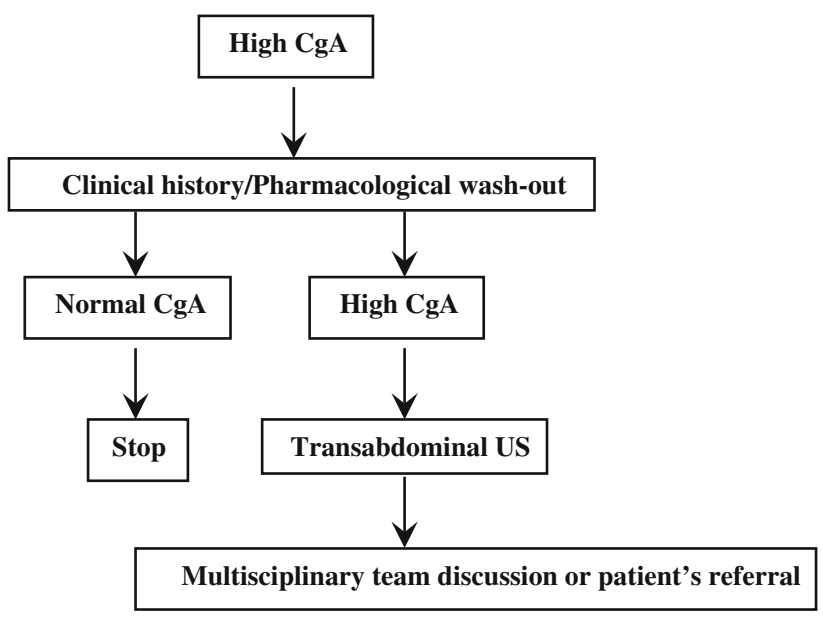

Fig. 4 Diagnostic flow-chart for NEN suspected after high CgA 
We recommend careful exclusion of all potentially interfering factors in patients with elevated serum $\mathrm{CgA}$ levels and no previous NEN diagnosis.

We suggest transabdominal US as first step in case of confirmed $\mathrm{CgA}$ increase.

We recommend discussion of further work-up in a multidisciplinary team, involving a referral center when required.

3.2 Symptomatic patient with symptoms due to GEPNEN-related local effects

\subsubsection{When to suspect a GEP-NEN}

Non-functioning GEP-NENs (Box 1) may become symptomatic when they compress or invade adjacent structures or when they metastasize. The suspicion of GEP-NEN might be raised by suggestive imaging findings (see above) and/or by the apparently slow progression of the disease [73]. Lab findings (e.g., frankly elevated $\mathrm{CgA}$ levels in absence of confounding factors) may reinforce the suspicion. As previously stated, only pathology (cytological or histologic characterization), however, will establish the diagnosis [6].

\section{Box 1}

Non-functioning GEP-NENs

Definition: NF GEP-NENs are tumors that do not show symptoms related to hormonal hypersecretion. Intracellular hormones or peptides may be demonstrated by IHC, but they are either not secreted, or secreted in quantities unable to elicit a clinical syndrome and/or in an inactive form [3]. Clinical presentation of NF GEP-NENs depends upon the site of origin and metastases. They can be incidentally discovered when asymptomatic due to the widespread use of diagnostic imaging [1, 3]. Clinical presentations according to the site of origin are listed below.

Pancreas: Up to 60\% of pNENs is NF. Most NF pNENs are well differentiated. Annual incidence is 1.8 and 2.6 per million in females and males, respectively [3]. NF pNEN were traditionally diagnosed late in the course of the disease, with metastases in 46 to $73 \%$ of cases, but presently the number of incidentally found small lesions is steeply increasing. Presenting symptoms and signs are abdominal pain (35-78\%), weight loss (20-35\%), anorexia and nausea (45\%), intra-abdominal hemorrhage (4-20\%), jaundice (17-50\%), and a palpable mass $(7-40 \%)$ [96, 172]. NF pNEN may occur in familiar syndromes such as MEN-1,VHL, and TSC.

Gastrointestinal: NENs are frequently detected during a screening program or an imaging exam performed to search the primary tumor in an asymptomatic but metastatic patient [1, 3]. Alternatively, a common clinical presentation is abdominal pain that may be caused by gastro-intestinal dysmotility or obstruction (associated or not to nausea, vomiting or constipation), or by bacterial overgrowth. Less common symptoms and signs are jaundice, weight loss, fatigue, fever and bleeding (massive or dripping). Clinical presentation of appendiceal NEN may mimic acute appendicitis [1, 3]. Obstructive symptoms are typical of small bowel, whereas minor bleeding is frequent in rectal disease [6, 73, 173].

\subsubsection{Work-up in the patient with local compressive symptoms}

A detailed history and complete physical examination are required.

Abdominal pain is the most common presenting symptom of NF GEP-NENs and may be related to the primary tumor or metastatic lesions [1,3]. Pain localization and characteristics should be carefully examined. Four different scenarios can be distinguished.

3.2.2.1 Isolated abdominal pain A persistent and oppressive upper-abdominal pain may signal a pancreatic or retroperitoneal mass (pattern 1a) [96, 172], while a discontinuous cramping pain usually refers to an intestinal origin (pattern 1b) $[73,173]$. In the former case, a radiological imaging should be performed first, followed by endoscopy/EUS as second step for pancreatic and duodenal lesions. In the latter case, endoscopy is recommended [73, 173]. A cytologic/histologic sampling should be obtained whenever possible (Fig. 5) [96, 172].

An ill-defined and diffuse abdominal pain (pattern 1c) can also be related to liver or nodal metastases. Abdominal US followed by a whole-body CT scan and a US-guided biopsy should be performed (Fig. 5).

3.2.2.2 Subocclusive picture It may be due to a large, often metastatic, ileal NEN and/or peritoneal carcinomatosis. Depending on the severity of the clinical picture, a direct abdomen-X-ray and/or an endoscopy could be performed [73, 173]. If an extrinsic obstruction is suspected, then an abdomen CT scan should be performed. If a peritoneal carcinomatosis is suspected, a transit evaluation water-soluble contrast medium X-ray could be useful (Fig. 6). If possible, histological specimens should be obtained through endoscopy. If not, a US/CT-guided biopsy 
Fig. 5 Diagnostic flow-chart for GEP-NEN suspected after pattern $1 \mathrm{a}$ and $1 \mathrm{~b}$
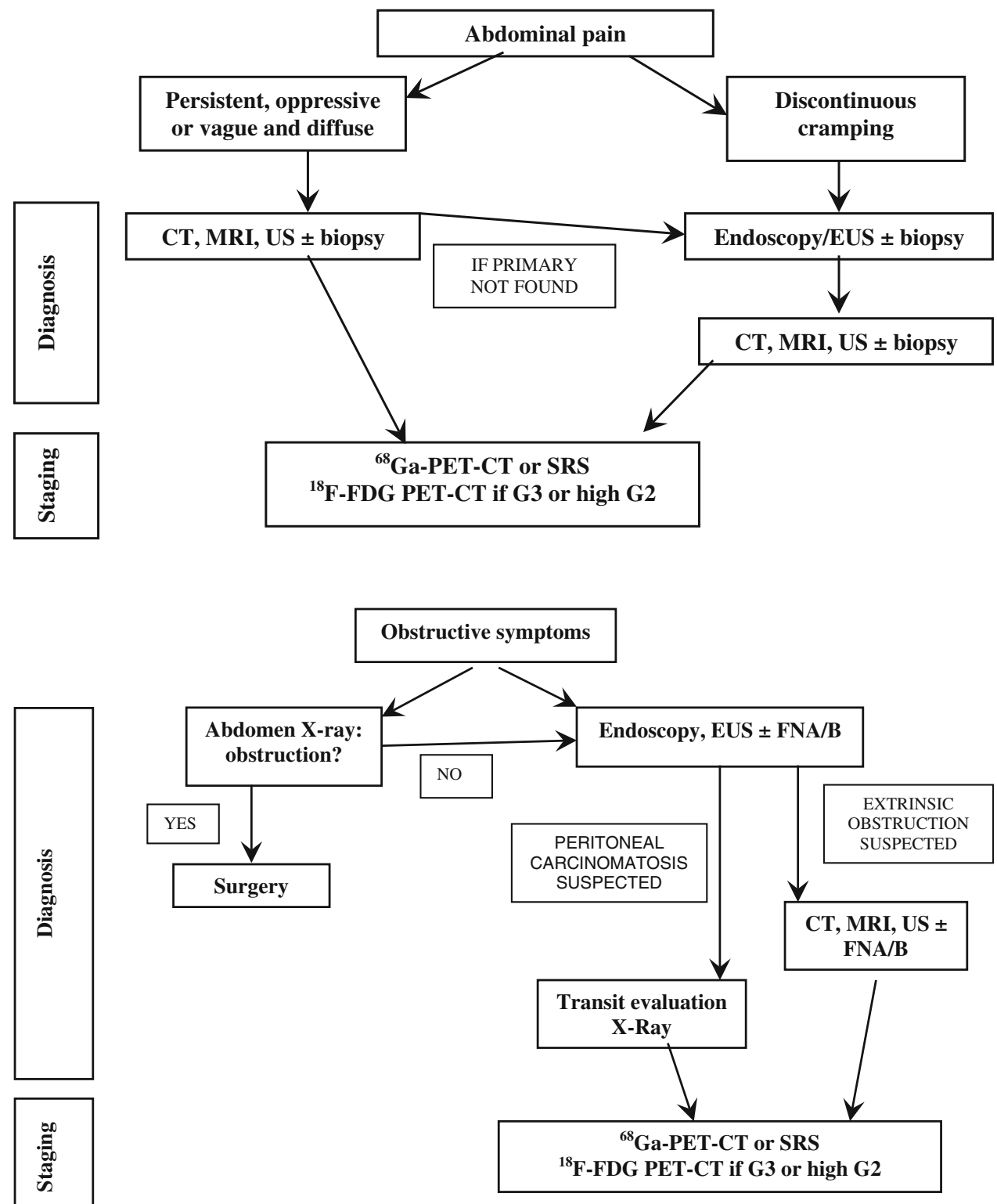

Fig. 6 Diagnostic flow-chart for GEP-NEN suspected after subocclusive picture of the liver or other site lesions or laparoscopy-guided biopsy should be discussed in a multidisciplinary team.

3.2.2.3 Jaundice This clinical presentation points to the involvement of the liver, biliary tract or pancreas. Liver function and structure should be assessed by blood tests and US, to rule out the obstruction of the biliary tract. Compressive effects of lymphadenopathies or a pancreatic mass may cause an extra-hepatic tract dilatation, whereas liver metastases are more likely related to an intra-hepatic tract dilatation [96, 172]. In case of obstructive jaundice, a cholangio-MRI and endoscopic-retrograde-cholangio-pancreatography (ERCP) can be considered. Cytology by means of brushing or histology can be obtained through ERCP. Whole-body CT scan and endoscopy should be used to define the primary site of the tumor and for staging purpose (Fig. 7).

3.2.2.4 Gastrointestinal bleeding It can be related to the compressive and infiltrating effects of a tumor mass. Bleeding can be massive (hematemesis, melena and rectal bleeding) or dripping and occult. Blood tests, iron assessment and endoscopy must be performed. Massive bleeding always requires hospitalization and may require angiography $[73,173]$. In case of lesions located in the stomachduodenum or in terminal ileum-colon tract, a histologic diagnosis may be obtained through biopsy during EGDS or ileo-colonoscopy. If upper and lower endoscopy is negative, enteroscopy, enteroCT/MRI, VCE should be discussed in the multidisciplinary team according to the local 


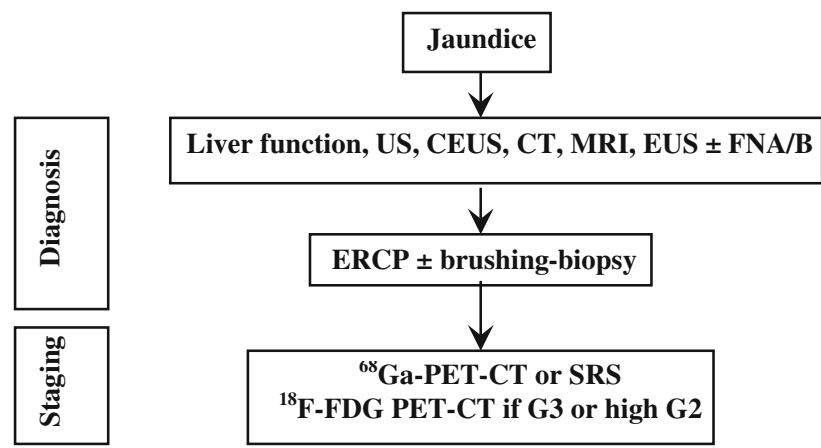

Fig. 7 Diagnostic flow-chart for GEP-NEN suspected after jaundice

availability and expertise (Fig. 8). For lesions located in the small bowel, a surgical diagnostic/therapeutic approach should be considered

We recommend to consider GEP-NEN as possible causes of isolated abdominal pain, subocclusive symptoms, jaundice or gastrointestinal bleeding.

We recommend to obtain a histologic or cytological diagnosis.

We recommend a specific diagnostic work-up, according to clinical presentation.

\subsection{Symptomatic patient with syndromes}

\subsubsection{Diarrhea and flushing}

3.3.1.1 Clinical approach: when to suspect a GEP-NEN The patient with diarrhea and flushing should raise the suspicion of CS (Box 2).
Carcinoid syndrome diagnosis may be difficult. A detailed history and complete physical examination are must. Symptoms may be under-reported by patients or be attributed to other, more common GI disorders. Differential diagnoses include irritable/inflammatory bowel diseases, microscopic colitis, food intolerance/allergy, bacterial overgrowth, celiac disease, hypersecretory states (i.e., gastrinoma, see "Resistant/relapsing ulcer disease"), chronic pancreatitis, other neoplastic (i.e., colon carcinoma, lymphoma) and non-neoplastic conditions (asthma, anxiety, alcoholism) [6].

Diarrhea in patients with CS is chronic, predominantly secretory, does not change with fasting, and is associated with fluid and electrolyte imbalance. A detailed history of the diarrhea and specific questioning about other possible manifestations of CS (i.e., facial flushing) are required. The stools are usually watery and result from intestinal hypermotility and hypersecretion. Nocturnal diarrhea is generally considered as characteristic of CS. The incomplete response to antidiarrhoic treatment should raise the suspicion of possible CS [174].

Flushing is the most common symptom in CS. Eating, emotion, alcohol, and exercise may worsen flushing. The face, neck and upper trunk usually turn pink to red in color and the skin is characteristically dry. Flushing may also be associated with transient hypotension and bronchoconstriction. Other causes of flushing/sweating disorders to be considered are [175]:

- pheochromocytoma, menopause, ZES, and medullary thyroid carcinoma (intermittent flushing);

- alcoholism, polycythemia, mitral stenosis, and Cushing's syndrome (constant flushing).

Fig. 8 Diagnostic flow-chart for GEP-NEN suspected after GI bleeding

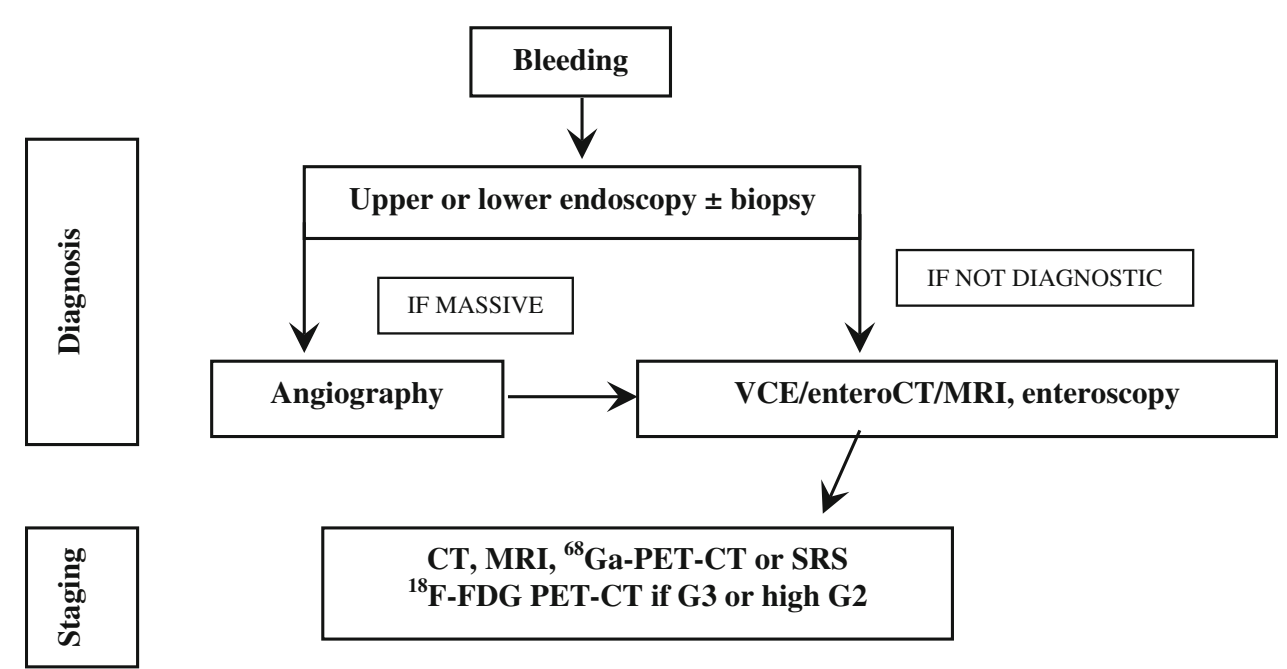


We recommend considering $\mathrm{CS}$ in patients with chronic diarrhea and/or flushing. The additional presence of abdominal pain and wheezing strengthens the suspicion.

\section{Box 2}

\section{Carcinoid syndrome}

CS is classified as typical or atypical, accounting for 95\% and 5\% of total cases, respectively [176,177,178]. Typical CS occurs in about 15-20\% of patients with jejunoileal NENs, with liver metastases. In less than $5 \%$, it can be caused by retroperitoneal or ovarian metastases that release serotonin or tachykinin, bypass the liver and enter the systemic circulation [179, 180,181, 182]. These socalled "functioning carcinoids" exhibit a variable clinical presentation, due to the type of secreted bioactive substances (serotonin, tachykinins, kallikreins, and prostaglandins). Typical CS may present with cutaneous flushing (face, neck, upper chest), GI hypermotility with pain (intermittent and crampy, described as dull, achy and colicky, and not relieved by defecation), telangiectasia, peripheral edema, wheezing, cyanosis, pellagra, and rightsided heart failure caused by cardiac valve abnormalities. Symptoms may occur spontaneously or be triggered by alcohol intake, serotonin-rich foods, and exercise [182].

Atypical CS is associated to overproduction of histamine and is characterized by prolonged flushing, bronchoconstriction and hypotension [178]. Wheezing might suggest asthma that can be identified by lung function tests.

Carcinoid crisis is an extreme and life-threatening expression of the CS, induced by the massive release of amines into the circulation following anesthesia, interventional procedures or medication [183]. Main features of carcinoid crisis are: hypotension, rarely hypertension, tachycardia, bronchial wheezing, and central nervous system dysfunction [184].

Carcinoid heart disease affects 10-20\% of the patients at presentation. CS causes a thickening of the heart valves, impairing their proper function, resulting in insufficiency. Heart failure typically involves the rightside valves. Signs and symptoms include fatigue and shortness of breath during physical activity and peripheral edema in 1 out of 5 patients. Up to $50 \%$ of deaths in CS are due to heart failure [185, 186].

3.3.1.2 Work-up in the patient with suspected carcinoid syndrome Before proceeding to the work-up, other causes of flushing with or without diarrhea must be excluded (Table 7) [187]. To this aim it could be useful a 2 to 4 -week detailed self-recording of the flushing and diarrhea episodes.
Since symptoms associated with CS can be triggered by alcohol intake and serotonin-rich foods [188-190], the patient should follow an exclusion diet for at least 3 days before starting urinary collection for 5-HIAA and should avoid for at least $24 \mathrm{~h}$ (or according to half-life) drugs that affect this test (see Table 4).

Biochemical testing: Urinary excretion of 5-HIAA is the most useful test in patients with typical CS due to jejunoileal NENs. Atypical CS is induced by gastroduodenal and bronchial NENs that only rarely secrete serotonin because they lack DOPA-decarboxylase, the enzyme that converts 5-hydroxytryptophan into serotonin [191]. These tumors may thus produce 5-hydroxytryptophan and histamine instead of serotonin, but no assay for urinary 5-hydroxytryptophan is commercially available, whereas histamine assays are limited to very few centers.

5-HIAA testing is highly sensitive (up to $90 \%$ ) and specific (85-90\%) for the diagnosis of CS. In patients with CS 5-HIAA levels are usually at least twice as high as the upper normal limit. They may reflect the tumor burden and are rarely normal in patients with CS $[57,73,76,77,192$ 194]. Attention must always be paid to factors causing falsely high or low levels (see Table 4).

Serum serotonin determination is not recommended because it may vary considerably according to activity and stress levels [73]. CgA is poorly specific whereas NSE has no diagnostic role [77, 193, 195].

Imaging procedures: Carcinoid syndrome is most frequently due to a NEN in the small bowel associated with liver metastases [196]. Therefore liver assessment examinations should be firstly performed, including US/CEUS (useful to drive biopsy), CT and MRI (superior to CT for small lesions) [95, 197-200].

The type of work-up aimed to the detection of the primary tumor (see "Work-up in the patient with metastatic disease and unknown primary tumor") and to rule out atypical situations should be discussed in a multidisciplinary panel, also taking into account the possible surgical resection.

Functional imaging studies (SRS, or when available ${ }^{68}$ Ga-DOTA-peptide-PET) may help in localizing the

Table 7 Differential diagnosis of flushing

\begin{tabular}{ll}
\hline Drugs & $\begin{array}{c}\text { All vasodilators, calcium channel blockers, } \\
\text { morphine and other opiates, etc. } \\
\text { Menopause }\end{array}$ \\
Mastocytosis & $\begin{array}{l}\text { Flushing lasting longer than CS, may be } \\
\text { accompanied by headache, dyspnea, } \\
\text { palpitations, abdominal pain and diarrhea }\end{array}$ \\
$\begin{array}{c}\text { Medullary thyroid } \\
\text { carcinoma }\end{array}$ & $\begin{array}{c}\text { Associated with diarrhea in patients with } \\
\text { advanced disease }\end{array}$ \\
Pheochromocytoma & $\begin{array}{c}\text { Rare, but it may occur after a paroxysm of } \\
\text { hypertension, tachycardia and palpitations } \\
\text { and is preceded by pallor }\end{array}$ \\
&
\end{tabular}


primary tumor and small metastases, and as a predictive factor for somatostatin receptor driven therapies. Combination of SRS or PET with CT increases the sensitivity [117].

In case of persistently negative results of morphological and functional studies, the primary tumor may be located by intraoperative palpation [73].

Transthoracic echocardiography should be performed at diagnosis of CS and then annually to detect any right-sided fibrosis involving tricuspid and pulmonary valves [201] (Fig. 9).

We recommend to rule out other causes of flushing and diarrhea (history and physical examination) before proceeding with work-up of CS.

We recommend to perform urinary 5-HIAA and serum $\mathrm{CgA}$ plus abdomen US as first step if $\mathrm{CS}$ is clinically suspected.

We recommend against routine use of other circulating biomarkers.

We recommend contrast-enhanced abdominal CT scan or MRI plus SSTR-related imaging when first step studies are positive.

If first step studies are negative, we suggest considering other diagnoses, atypical CS or very rare non-metastatic NENs in a multidisciplinary team, involving a referral center when required.

We recommend echocardiography for each patient with CS.

\subsubsection{Resistant/relapsing ulcer disease}

3.3.2.1 Clinical approach: when to suspect a GEP-NEN ZES (Box 3) is characterized by gastric acid hypersecretion resulting in severe peptic disease and gastroesophageal reflux disease (GERD) [202-205].

The majority of ZES patients presents with a single duodenal ulcer, peptic symptoms, GERD symptoms or ulcer complications and diarrhea. Multiple ulcers or ulcers in unusual locations are a less frequent presenting feature than in the past $[8,84,85,87,202,204-208]$. With the widespread use of gastric antisecretory drugs, particularly PPIs and H2RAs, symptoms may be masked. The diagnosis is most often suggested by a long history of peptic ulcer disease or GERD symptoms or their recurrence after treatment $[83-85,206,208]$. This delay may postpone the diagnosis of gastrinoma to a higher stage of the disease.
Fig. 9 Diagnostic flow-chart for suspected carcinoid syndrome 


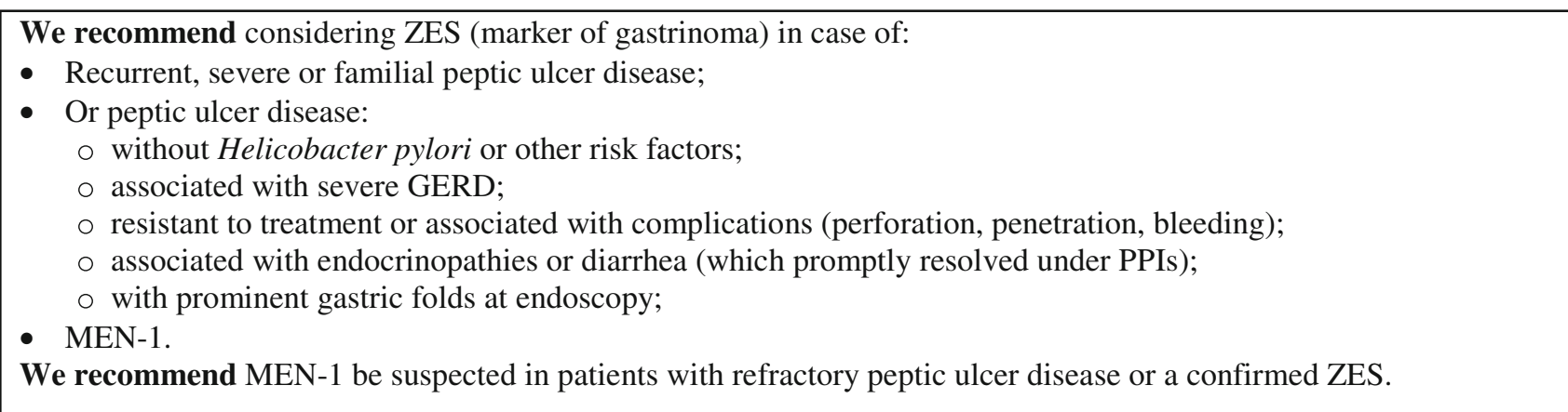

\section{Box 3}

\section{Gastrinoma}

Gastrinoma is a functioning GEP-NEN, usually located in the duodenum or pancreas that secretes gastrin and causes a clinical syndrome known as ZES.

The incidence of gastrinomas is 0.5-2/million population/ year. Gastrinoma is one of the most common functioning GEP-NEN in the general population [8] and occurs in 25-40\% of subjects with MEN-1 [207, 209]. ZES occurs at an earlier age (mean 32-35 years] in patients with MEN-1 than in those with sporadic disease [204, 207, 209].

Pancreatic gastrinomas may occur in any portion of the pancreas, while duodenal gastrinomas are predominantly found in the first part of the duodenum including the bulb [210, 211]. At surgery, 70-85\% of gastrinomas are found in the right upper quadrant (duodenal and pancreatic head area), the so-called "gastrinoma triangle" [210, 211, 212].

The main symptoms classically associated to ZES are due to gastric acid hypersecretion and are represented by abdominal pain (75-98\% of the cases), diarrhea (30-73\%), heartburn (44-56\%), bleeding (44-75\%), nausea/vomiting (12-30\%), and weight loss (7-53\%) [85, 204, 205).

At presentation, $>97 \%$ of patients have an elevated fasting serum gastrin (FSG) level, 87-90\% have marked gastric acid hypersecretion (basal acid output $>15 \mathrm{mEq} / \mathrm{h}$ ) and $100 \%$ have a gastric acid $\mathrm{pH}<2$ [202, 213).

The rate of malignancy is high with liver metastases in 30-40\% of cases [214].

3.3.2.2 Work-up in the patient with suspected gastrinoma History and clinical examination are the first steps in the diagnosis of ZES. The use of acetylsalicylic acid and other non-steroidal anti-inflammatory drugs, which can mimic a ZES picture, should be ruled out [215].

Multiple endocrine neoplasms should be considered in all patients with ZES, especially in case of familial or personal history of endocrine disease, kidney stones, other NENs [88, 207]. Due to high penetrance of primary hyperparathyroidism in MEN-1 [40], serum calcium and PTH are the first step to rule out the diagnosis.

Biochemical testing: Fasting serum gastrin is an excellent screening test ( $>98 \%$ sensitivity). False positive conditions should always be excluded (Table 5). The diagnosis of ZES requires inappropriately elevated FSG levels in association with a $>15 \mathrm{mEq} / \mathrm{h}(>5 \mathrm{mEq} / \mathrm{h}$ in gastrectomized patients) basal acid output or in association with a gastric $\mathrm{pH}<2.0$. Under these conditions, FSG $>1,000 \mathrm{pg} / \mathrm{mL}$ means a certain diagnosis of ZES. On the contrary, a gastric $\mathrm{pH}>2.0$ virtually excludes $\mathrm{ZES}$ [84]. In subjects under chronic therapy with PPIs these drugs have to be withdrawn for at least 1 week [84, 216], although the optimal wash-out time for PPIs should be longer (4 weeks). H2RAs exert a less pronounced suppression of gastric acid output than PPIs [217, 218]. In case of subjects on PPIs who are at risk of bleeding ulcer, diarrhea with dehydration or hypokalemia, these drugs may be replaced with $\mathrm{H} 2 \mathrm{RAs}$ for at least 1 week under medical supervision [219, 220].

Secretin test (2 U/kg rapid infusion), a gastrin provocative test, may be performed in controversial cases [77, 221]. Withdrawal of antacid and anticholinergic drugs (12 h), and of PPIs (1 week) is recommended [222]. The secretin test is positive when a $>120 \mathrm{pg} / \mathrm{mL}$ increase of FSG over the basal value is found (sensitivity $94 \%$, specificity $100 \%$ ) [88, 223]. Calcium stimulation test ( $5 \mathrm{mg} / \mathrm{kg}$ body weight per hour, infused over $3 \mathrm{~h}$, increase $>395 \mathrm{pg} / \mathrm{mL}$ over the basal FSG as cut-off) may alternatively be used. However, it is hampered by lower sensitivity, specificity and higher side effects [88]. Gastric acid secretion stimuli are no longer performed [203].

Imaging: After biochemical diagnosis, EGDS is required. In ZES, peptic ulcer disease is found distally to the duodenal bulb within the descending part of the duodenum or even further distally within the jejunum. Peptic ulcers frequently occur in groups indicating some substantial acid hypersecretion [84].

The following imaging procedures may be used to localize the primary tumor, determine the extent of the disease, evaluate indication to surgery, and assess response 
Fig. 10 Diagnostic flow-chart for suspected gastrinoma

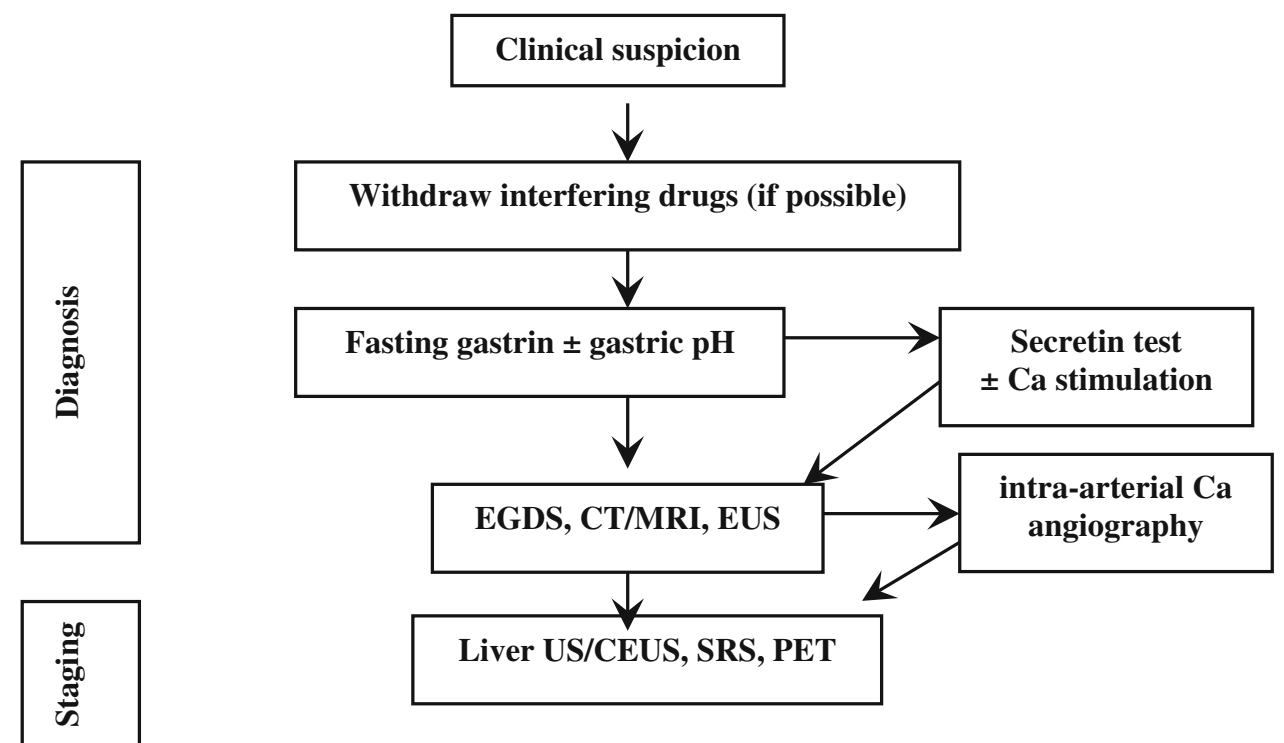

to treatments [88]: (1) contrast-enhanced CT and/or MRI, EUS; (2) functional imaging (SRS, PET); and (3) selective intra-arterial calcium injection angiography [84, 88].

Accurate localization of the tumor can result in complete surgical resection, decreased rate of developing lymph node metastases, and increasing survival [88, 222, 224-226] (Fig. 10).

We recommend fasting serum gastrin as the first step in patients with clinical suspicion of ZES.

We recommend exclusion of all other causes of hypergastrinemia before proceeding with the diagnostic work-up.

We suggest secretin test when the diagnosis of ZES is unclear/controversial.

We recommend morphological and functional imaging in all patients with biochemically established ZES.

\subsubsection{Spontaneous hypoglycemia}

3.3.3.1 Clinical approach: when to suspect a GEPNEN Hypoglycemia (plasma glucose $<60 \mathrm{mg} / \mathrm{dL}$ on a venous blood sample) is an uncommon clinical problem in non-diabetic adults. The presence of symptoms reinforces the clinical relevance of this finding because some normal subjects may have an asymptomatic low glucose level after prolonged fasting. Symptoms may be due to sympathoadrenal activation ("adrenergic symptoms", i.e., sweating, shakiness, tachycardia, anxiety, hunger) and/or neurogly- copenia (weakness, dizziness, inappropriate behavior, altered concentration, confusion, blurred vision and, in extreme cases, coma and death) [227-229]. Symptoms may present at a variable glucose level (generally as low as <55-60 mg/dL) [227, 228, 230, 231].

Hypoglycemia may be due to several conditions beyond insulin-secreting tumors [232] (Table 8).

Insulinoma (Box 4) should be strongly suspected in presence of the Whipple triad, which occurs in about $75 \%$ of patients and combines (1) symptoms of hypoglycemia, (2) low blood sugar concurrent with symptoms, and (3) reversal of symptoms after glucose administration [233]. Neuroglycopenic symptoms usually dominate the clinical picture so that insulinoma may be misdiagnosed with cognitive impairment, psychiatric illnesses or seizure disorders. Frequently, the occurrence of bizarre behavior or confusion states is more precisely described by concerned relatives or friends than by the patient himself. Adrenergic and neuroglycopenic symptoms may coexist, especially in the early phase of the disease. A detailed description of pure adrenergic symptoms, however, is more specific of a "functional hypoglycemia".

Hypoglycemic symptoms occur most frequently at night and/or early morning and, anyway, in a protracted fasting state. Yet, the occurrence of post-prandial hypoglycemia does not exclude an insulinoma [234, 235]. Symptoms can be worsened by exercise, alcohol, hypocaloric diet, and by concomitant clinical conditions or use of drugs (see above) [236, 237]. Weight gain occurs in $20-40 \%$ of patients that may develop overweight because of hyperinsulinism. 
Fig. 11 Diagnostic flow-chart for suspected insulinoma

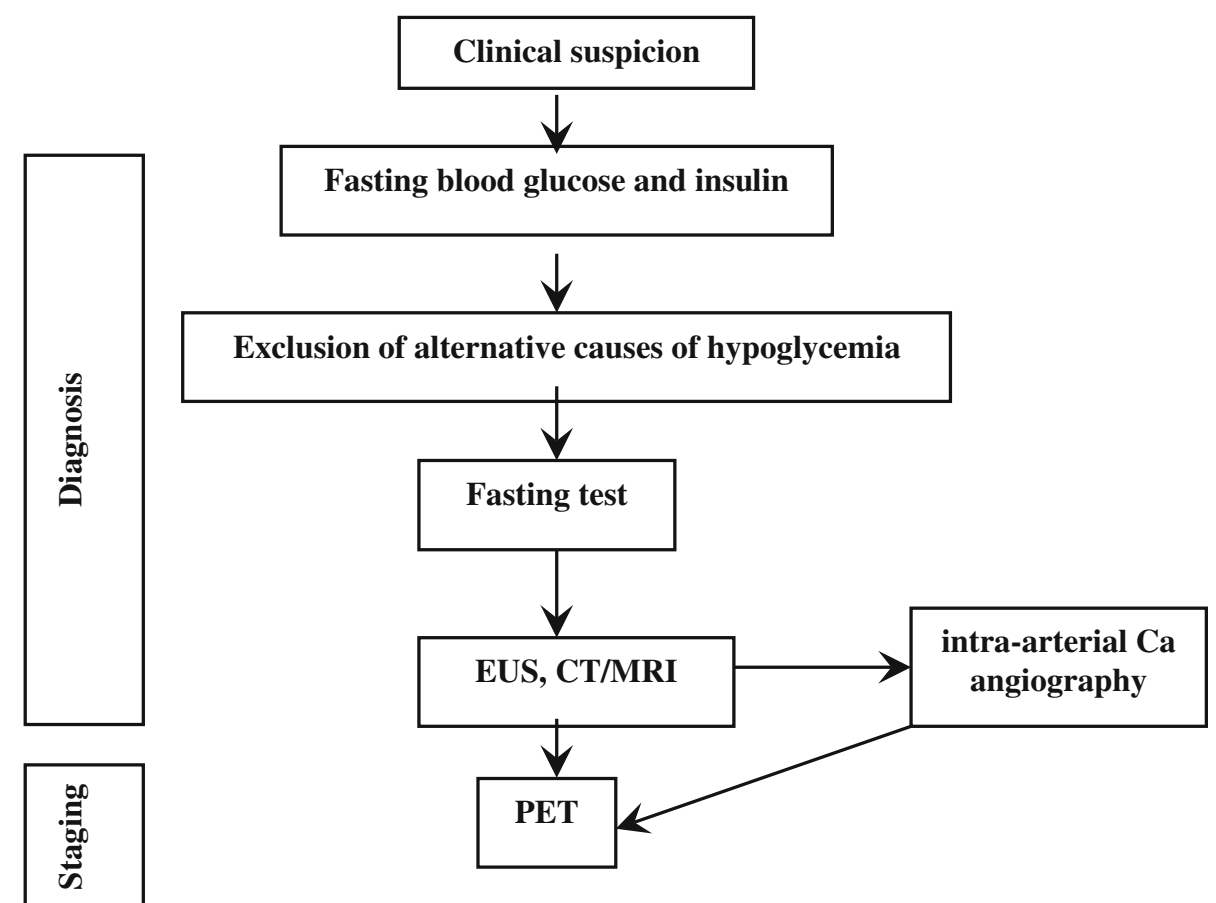

We recommend the immediate determination of blood glucose and insulin in any subject with acute change in mental status, especially if recurrent.

We recommend the exclusion of all alternative causes of hypoglycemia before starting a work-up for insulinoma.

We suggest considering insulinoma as a probable cause in patients with predominant neuroglycopenic symptoms, recurrent fasting hypoglycemia, and weight gain.

\section{Box 4 \\ Insulinoma [236, 237] \\ Insulinoma is a NEN arising from insulin-secreting cells in pancreatic islets. Other hormones and metabolites (gastrin, ACTH, glucagon, hCG, somatostatin, and 5-HIAA) may be also secreted from this neoplasm. \\ About $90 \%$ of insulinomas are benign. In rare cases neither a single nor multiple tumors can be identified and the syndrome depends on diffuse beta-cell hyperplasia. In malignant forms with liver metastases, a 16-26 months survival is to be expected. Only $5 \%$ of all insulinomas are associated with MEN-1; in case of multiple insulinomas (near 10\%), MEN-1 prevalence raises to $50 \%$.}

3.3.3.2 Work-up in the patient with suspected insulinoma Biochemical assessment: Symptoms and/or signs suggesting hypoglycemia combined with a $\leq 55 \mathrm{mg} / \mathrm{dL}$
Table 8 Differential diagnosis of hypoglycemia

\begin{tabular}{lc}
\hline Drugs & Insulin, oral hypoglycemic drugs \\
& Quinine, pentamidine, indomethacin, \\
& lithium \\
& More rarely: ACE-inhibitors, \\
& levofloxacin, trimethoprim- \\
& sulfamethoxazole, and heparin \\
& Block of stored glucose release \\
Excessive alcohol & \\
consumption & Depletion of substrates required for \\
Liver, kidney or heart & gluconeogenesis \\
failure & Depletion of substrates required for \\
Long-term starvation & gluconeogenesis \\
(anorexia nervosa) & Excessive production of IGF-II that \\
Non-islet cell tumors & causes the use of too much glucose \\
& Accelerated transit and malabsorption \\
Gastric surgery (post- & \\
gastric bypass) & Deficiency of hormones that regulate \\
Hypoadrenalism and & glucose production \\
hypopituitarism & \\
Insulin autoimmune & \\
hypoglycemia & \\
\hline
\end{tabular}

( $3.0 \mathrm{mmol} / \mathrm{L})$ plasma glucose, a $\geq 3.0 \mu \mathrm{U} / \mathrm{mL}(18 \mathrm{pmol} / \mathrm{L})$ plasma insulin, a $\geq 0.6 \mathrm{ng} / \mathrm{mL}(0.2 \mathrm{nmol} / \mathrm{L}) \mathrm{C}$-peptide, and $\mathrm{a} \geq 5.0 \mathrm{pmol} / \mathrm{L}$ proinsulin indicate endogenous hyperinsulinism [227, 228, 231]. Exogenous insulin-induced hypoglycemia is always associated with low levels of C-peptide. In patients with insulinoma, proinsulin corresponds to about $70 \%$ of insulin immunoreactivity, whereas it is normally limited to $20 \%$. 
Fig. 12 Diagnostic flow-chart in the patient with metastatic disease and unknown primary tumor

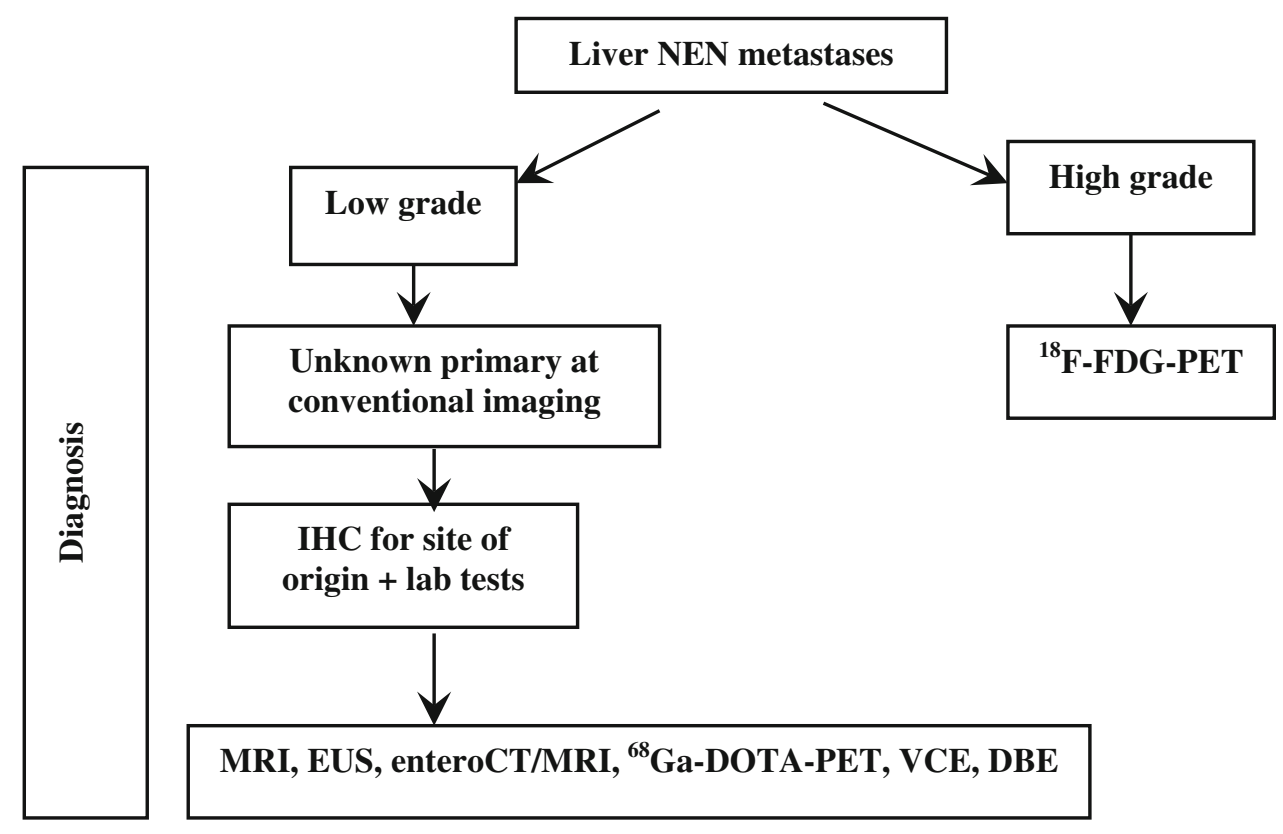

Blood and urine assays for sulfonylureas will detect factitious hypoglycemia caused by these drugs. Pituitary and adrenal function tests are useful to rule out hypoadrenalism and hypopituitarism [227, 228, 230, 238].

Provocative tests: Biochemical diagnosis is based on lack of suppression of endogenous insulin secretion by hypoglycemia [239] and inappropriately elevated insulin level during hypoglycemia is the diagnostic key point. In $95 \%$ of cases, the diagnosis is achieved only during prolonged fasting (up to $72 \mathrm{~h}$ ) inducing symptomatic hypoglycemia [240]. The test should be performed on inpatients under close supervision and with regular control of glycaemia and mental status. $\mathrm{A} \geq 3 \mu \mathrm{U} / \mathrm{mL}(\geq 18 \mathrm{pmol} / \mathrm{L})$ insulin value, in the presence of glucose level $<55 \mathrm{mg} / \mathrm{dL}$ has recently been proposed as diagnostic cut-off [223]. Plasma $\beta$-hydroxybutyrate levels $\leq 2.7 \mathrm{mmol} / \mathrm{L}$ may confirm the diagnosis, demonstrating the suppressive effect of insulin on ketogenesis even during a protracted fasting [231].

At the end of the 72-h fasting test, in the absence of hypoglycemia, the use of stimulation tests was proposed [231]. Stimulation tests, e.g., tolbutamide, glucagon or calcium, are not recommended because they may induce a prolonged and refractory hypoglycemic condition, but longterm fasting can be finished after $72 \mathrm{~h}$ with bicycle test.

Imaging: In all patients with a confirmed biochemical diagnosis, imaging is indicated to localize the tumor [241].

Since $80 \%$ of insulinomas are $<2 \mathrm{~cm}$ in size, they are frequently missed by high-resolution transabdominal US (50\% sensitivity), while EUS is more sensitive (77\%) and should be preferred [242]. Helical or multislice CT and
MRI offer a comparable (82-94\%), but incomplete, sensitivity [243, 244]. Selective arteriography has an $82 \%$ sensitivity and a $95 \%$ specificity.

Due to small size and/or lack of SSTR2 expression in $50 \%$ of insulinoma [151], SSTR-related imaging plays a minor role than morphological imaging. DOPA-PET has been proposed as an alternative tool [245]. Radiolabelling with ${ }^{111}$ In-labeled glucagon-like peptide-1 receptors agonist $\left({ }^{111}\right.$ In-DOTA-exendin-4) is a promising technique, still not routinely used [246].

Arteriography combined with selective calcium stimulation: Calcium is able to stimulate insulin release from neoplastic tissue, but not from normal islets. Hence, the catheterization of the arterial branches of the celiac system and the measurement of insulin in the blood sampled from hepatic veins during selective intra-arterial calcium injection localize the pancreatic area nesting the tumors in 88-100 \% of cases [34, 247, 248]. This test is cumbersome, expensive and poorly available. Accordingly, it should be reserved only to selected, biochemically proved cases with negative imaging studies.

In spite of all the above reported diagnostic techniques, only $60-70 \%$ of patients have a successful preoperative localization. In patients with less threatening symptoms that are fairly controlled by medical treatment a close surveillance may be advisable. In severely symptomatic cases, the use of intraoperative US and the pancreatic exploration conducted by an experienced surgeon identifies more than $90 \%$ of the insulin-secreting tumors [242, 249] (Fig. 11). 
We recommend the simultaneous evaluation of blood glucose, insulin and C-peptide to detect endogenous hyperinsulinemia in all patients with spontaneous hypoglycemia.

We recommend a prolonged fasting test (up to $72 \mathrm{~h}$ ) in patients referred for a previous hypoglycemic episode who are free of symptoms at the moment of medical examination.

We recommend against the use of stimulation tests for the diagnosis of insulinoma.

We recommend the use of localization tests (CT/ CEUS and EUS) only after the biochemical diagnosis of insulinoma is established.

\subsection{Work-up in the patient with metastatic disease and unknown primary tumor}

Unknown primary NEN (UPN) is a condition of metastatic histologic or cytological confirmed NEN without evidence of a primary site after a first diagnostic work-up, including chestabdomen CT scan, SRS, and upper and lower endoscopy.

The frequency of well-differentiated UPNs ranges from 9 to $19 \%$ [250, 251]. The presence of liver metastases largely influences prognosis in all types of NENs and is dependent on primary tumor site, tumor extent (T-stage), and histologic differentiation (NET vs. NEC). Reported survival rate at 5 years of G1-G2 small intestinal and pancreatic NENs in the SEER database is 54 and $27 \%$, respectively [252]. Furthermore, survival is reportedly worse in UPN patients as compared to patients with liver metastases whose primary NEN is known [253]. In liver metastatic patients survival rate is influenced by the presence of obstructive symptoms or symptoms related to peptide secretion.

The evaluation of a patient with UPN should encompass a detailed clinical history, including family history to identify affected relatives and a patient's increased risk for endocrine tumors (i.e., MEN type 1 or 2), laboratory and radiographic studies [254].

Histologic preparations should be reevaluated by IHC to guide the search for the primary tumor: TTF-1 (pulmonary or medullary thyroid carcinoma), CDX-2 (intestinal), PAX8, histidine-decarboxylase (pancreatic), xenin (duodenal), gastrin (occult gastrinoma), and PP/glucagon (pancreatic) $[38,255]$. Biochemical work-up may include 5-HIAA, gastrin, and other locally available tumor markers [256].

It has been recently reported that most UPNs are derived from pancreas and small bowel [257]. Accordingly, further investigations for localizing the primary site in well-differentiated NENs might include abdomen MRI, EUS, enteroCT/MR, ${ }^{68} \mathrm{Ga}$-PET, VCE, DBE to be shared within a multidisciplinary team according to clinics, local availability and expertise [124, 258, 259]. In NECs ${ }^{18}$ F-FDGPET may be useful (Fig. 12)

We recommend biopsy at the metastatic site with histologic and IHC examination as a first step to confirm NEN diagnosis.

We recommend a detailed clinical history to elicit signs or symptoms that could point to the primary site (carcinoid syndrome, asthma, diarrhea, etc.), as well as a complete family history.

In all cases of unknown primary of low grade metastatic liver NEN after a conventional imaging, including chest-abdomen CT scan, upper and lower endoscopy and SRS, we recommend an IHC for site of origin, and imaging according to results.

\subsection{When and how to stage a previously diagnosed GEP-NEN}

Evaluation of disease extension has a pivotal role in treatment planning.

Pre-treatment staging should include morphologic and functional imaging. Morphological imaging is required for all GEP-NENs, irrespectively of their grade. SSTR-based functional imaging (SRS or ${ }^{68} \mathrm{Ga}$-DOTA-peptide-PET) should be used for low-/intermediate-grade GEP-NENs (WHO 2010 G1-G2), whereas ${ }^{18}$ F-FDG-PET should be preferentially used in G3 GEP-NENs and in some G2 cases.

For morphologic staging, a chest-abdomen-pelvis multidetector CT or a chest basal CT plus abdomen-pelvis MRI should be used [87]. For functional staging, SRS using ${ }^{111}$ In-pentetreotide (Octreoscan ${ }^{\circledR}$ ) is presently regarded as the gold standard. However, if available, ${ }^{68} \mathrm{Ga}$-DOTApeptide-PET with simultaneous CT should be preferred to SRS. In facts, PET lacks the anatomic details required for therapeutic stratification (surgical planning or dose calculation for radioembolization with radiolabeled microspheres). Recently, MRI with liver-specific contrast combined with ${ }^{68}$ Ga-DOTA-peptides-PET has been reported to be more accurate than PET-CT to detect GEPNEN hepatic metastases [260].

${ }^{18} \mathrm{~F}$-DOPA-PET-CT and ${ }^{11} \mathrm{C}-5 \mathrm{HTP}-\mathrm{PET}-\mathrm{CT}$ are promising tools. Their use might be considered if results of SRS or ${ }^{68}$ Ga-DOTA-peptides-PET are negative [261].

Gastric NENs In small $(<1 \mathrm{~cm})$ type 1 and type 2 tumors, EGDS is usually the only recommended imaging 
procedure [153]. Tumor invasiveness through the gastric wall must be evaluated with EUS study: it is recommended before resection for polyps $>1 \mathrm{~cm}$ in diameter. EUS is also useful in assessing regional lymph nodes involvement, and allows histological confirmation by FNA. Type 1 tumors do not require either abdomen multislice CT or MRI, or SRS $/{ }^{68} \mathrm{Ga}$-DOTA-peptides-PET; these imaging studies should be performed for type 2 and type 3 neoplasm staging.

Duodenal NENs EUS is useful before resection of polypoid lesions; multislice abdomen CT or MRI should be performed to assess local and distant disease extension. In patients with local advanced neoplasm and/or liver metastases, bone scan and MRI of spine and pelvis should be performed [153].

Jejuno-ileum NENs Chest-abdomen-pelvis CT scan or chest basal CT scan and abdomen-pelvis MRI, SRS or ${ }^{68} \mathrm{Ga}$-DOTA-peptides-PET should be performed looking for distant metastases [73]. Liver CT scan should be performed by multislice and multiphase technique. Colonoscopy should be performed to rule out synchronous colorectal carcinoma.

Colorectal NENs Chest-abdomen-pelvis multislice CT should be carried out. Endoanal/rectal US is very useful for assessing preoperatively the depth of tumor invasion in the rectal wall and regional lymph node involvement [173].

NF pNENs For morphologic staging a multislice/multiphase CT or fat-saturated T1-weighted and delayed enhanced T1-weighted MRI can be performed and EUS with biopsy [262]. Afterwards, SRS or ${ }^{68}$ Ga-DOTA-peptides-PET should be performed.

We recommend contrast enhanced chest-abdomenpelvis multidetector $\mathrm{CT}$ scan or basal chest $\mathrm{CT}$ scan plus abdomen-pelvis MRI in pre-treatment staging of GEP-NENs.

We recommend ${ }^{68} \mathrm{Ga}$-DOTA-peptides-PET-CT for functional staging of well-differentiated GEP-NENs, or, if not available, ${ }^{111}$ In-pentetreotide (Octreoscan $\AA$ ) scintigraphy.

If SSTR-related imaging is negative, we suggest further functional staging with alternative radiotracers.

We suggest ${ }^{18} \mathrm{~F}$-FDG-PET-CT for staging of selected G3 and high G2 GEP-NENs.

We recommend EUS study for local staging of $>1$ $\mathrm{cm}$ gastric, duodenal, and rectal polypoid NEN lesions.

\section{Conclusions}

The management of patients with GEP-NENs poses a significant challenge to clinicians from the very start of the diagnostic work-up. The wide heterogeneity of disease presentation, with a majority of asymptomatic patients and poorly specific clinical pictures may account for a delay in definite diagnosis and appropriate treatment. The present document has, therefore, been drawn with the purpose of offering a practical guide to physicians facing the suspicion of GEP-NENs, in light of the available clinical evidence and experience. Of course, many questions are still to be fully answered and many others still to be addressed in the near future, as we move forward to new promising techniques and diagnostic tools. For these reasons, in spite of its goal as a state-of-the-art update, our document has not been conceived as the repository of the "ultimate truth" in the field of GEP-NENs diagnosis. Instead, much attention has been devoted to the logical framework, which should back up the clinical reasoning. Furthermore, the diagnosis of GEP-NENs is heavily based on the contribution of a wide range of know-how and skills provided by different specialists. The core team may include a varying combination of different specialists, according to the local expertise and facilities; nevertheless, the pathologist plays a key role in the diagnosis and classification of GEP-NENs, because his/her information is critical to guide the prognosis and treatment planning. Hence, a multidisciplinary team model is recommended as the best opportunity to reach an accurate, safe and cost-effective diagnosis, likely to improve the outcome of patients with GEP-NENs.

In conclusion, the Italian Association of Clinical Endocrinologists (AME) hopes the present Position Statement will constitute an effective tool in helping the clinical management of patients with GEP-NENs. Further implementations and updates of this document will follow as new evidence and progress in the field emerge.

Other members of AME oncologic endocrinology group Giorgio Borretta, Cuneo; Renato Cozzi, Milan; Giuseppe Francia, Verona; Rinaldo Guglielmi, Albano Laziale; Gabriele Luppi, Modena; Salvatore Monti, Rome; Silvia Nasoni, Albano Laziale; Micaela Pellegrino, Cuneo; Anna Pia, Turin; Sara Pusceddu, Milan; Valeria Ramundo, Naples; Francesco Scavuzzo, Naples; Alessandro Scoppola, Rome; Ettore Seregni, Milan; Francesca Spada, Milan; Laura Tonutti, Udine; Vincenzo Toscano, Rome; Maria Chiara Zatelli, Ferrara.

Conflict of interest The authors declare they have no conflict of interest. 
Open Access This article is distributed under the terms of the Creative Commons Attribution License which permits any use, distribution, and reproduction in any medium, provided the original author(s) and the source are credited.

\section{References}

1. Modlin IR, Lye KD, Kidd M (2003) A 5-decade analysis of 13.715 carcinoid tumors. Cancer 97:934-959 (LoE $\otimes \otimes \otimes O)$

2. Hauso O, Gustafsson BI, Kidd M, Waldum HL, Drozdov I, Chan AKC, Modlin IM (2008) Neuroendocrine tumor epidemiology. Contrasting Norway and north America. Cancer 113:2655-2664 $(\mathrm{LoE} \otimes \otimes O \bigcirc)$

3. Yao JC, Hassan M, Phan A, Dagohoy C, Leary C, Mares JE, Abdalla EK, Fleming JB, Vauthey JN, Rashid A, Evans DB (2008) One hundred years after 'carcinoid': epidemiology of and prognostic factors for neuroendocrine tumors in 35,825 cases in the United States. J Clin Oncol 26:3063-3072 (LoE $\otimes \otimes \bigcirc \bigcirc)$

4. Garcia-Carbonero R, Capdevila J, Crespo-Herrero G, DíazPérez JA, Martínez Del Prado MP, Alonso Orduña V, SevillaGarcía I, Villabona-Artero C, Beguiristain-Gómez A, LlanosMuñoz M, Marazuela M, Alvarez-Escola C, Castellano D, Vilar E, Jiménez-Fonseca P, Teulé A, Sastre-Valera J, Benavent-Viñuelas M, Monleon A, Salazar R (2010) Incidence, patterns of care and prognostic factors for outcome of gastroenteropancreatic neuroendocrine tumors (GEP-NETs): results from National Cancer Registry of Spain (RGETNE). Ann Oncol 21:1794-1803 $(\mathrm{LoE} \otimes \otimes \otimes \bigcirc)$

5. Lawrence B, Gustafsson BJ, Kidd M, Pavel M, Svejda B, Modlin IM (2011) The clinical relevance of chromogranin A as a biomarker for gastroenteropancreatic neuroendocrine tumors. Endocrinol Metab Clin North Am 40:111-134

6. Öberg K, Knigge U, Kwekkeboom D, Perren A, ESMO Guidelines Working Group (2012) Neuroendocrine gastro-entero-pancreatic tumors: ESMO clinical practice guidelines for diagnosis, treatment and follow-up. Ann Oncol 23(Suppl 7): $124-130$

7. Cho M-Y, Kim JM, Sohn JH, Kim MJ, Kim KM, Kim WH, Kim H, Kook MC, Park Y, Lee JH, Chang H, Jung ES, Kim HK, Jin SY, Choi JH, Gu MJ, Kim S, Kang MS, Cho CH, Park do MI, Kang YK, Kim YW, Yoon SO, Bae HI, Joo M, Moon WS, Kang DY, Chang SJ (2012) Current trends of the incidence and pathological diagnosis of gastroenteropancreatic neuroendocrine tumors (GEP-NETs) in Korea 2000-2009: multicentre study. Cancer Res Treat 44:157-165

8. Faggiano A, Ferolla P, Grimaldi F, Campana D, Manzoni M, Davì MV, Bianchi A, Valcavi R, Papini E, Giuffrida D, Ferone D, Fanciulli G, Arnaldi G, Franchi GM, Francia G, Fasola G, Crinò L, Pontecorvi A, Tomassetti P, Colao A, Natural history of gastro-entero-pancreatic and thoracic neuroendocrine tumors (2012) Data from a large prospective and retrospective Italian epidemiological study: the NET management study. J Endocrinol Invest 35:817-823 ( $\mathrm{LoE} \otimes \otimes \otimes O)$

9. Lepage C, Bouvier AM, Faivre J (2013) Epidemiology of malignant digestive neuroendocrine tumours. Eur J Endocrinol 168:R77-R83

10. Niederle MB, Hackl M, Kaserer K, Niederle B (2010) Gastroenteropancreatic neuroendocrine tumours: the current incidence and staging based on the WHO and European Neuroendocrine Tumour Society classification: an analysis based on prospectively collected parameters. Endocr Relat Cancer 17:909-918 (LoE $\otimes \otimes O \bigcirc)$

11. GRADE Working Group website. http://www.grade workinggroup.org (accessed 21 January 2014)
12. Atkins D, Best D, Briss PA, Eccles M, Falck-Ytter Y, Flottorp S, Guyatt GH, Harbour RT, Haugh MC, Henry D, Hill S, Jaeschke R, Leng G, Liberati A, Magrini N, Mason J, Middleton P, Mrukowicz J, O'Connell D, Oxman AD, Phillips B, Schünemann HJ, Edejer T, Varonen H, Vist GE, GRADE Working Group (2004) Grading quality of evidence and strength of recommendations. Br Med J 328:1490-1497

13. Swiglo BA, Murad MH, Schünemann HJ, Kunz R, Vigersky RA, Guyatt GH, Montori VM (2008) A case for clarity, consistency, and helpfulness: state-of-the-art clinical practice guidelines in endocrinology using the Grading of Recommendations, Assessment, Development, and Evaluation System. J Clin Endocrinol Metab 93:666-673

14. Guyatt GH, Oxman AD, Vist GE, Kunz R, Falck-Ytter Y, AlonsoCoello P, Schünemann HJ, GRADE Working Group (2008) GRADE: an emerging consensus on rating quality of evidence and strength of recommendations. Br Med J 336:924-926

15. Klimstra DS, Modlin IR, Coppola D, Lloyd RV, Suster S (2010) The pathologic classification of neuroendocrine tumors. A review of nomenclature, grading, and staging systems. Pancreas 39:707-712

16. Bosman F, Carneiro F, Hruban R, Theise ND (2010) WHO classification of tumours of the digestive system, 4th edn. IARC Press, Lyon

17. Singh S, Rowsell C, Ingbe N, et al (2010) The role of Ki-67 in the prognosis and management of neuroendocrine (NET) patients in a multidisciplinary cancer center. ASCO Gastrointestinal Cancers Symposium. Abstract no. 266

18. Singh S, Feinberg Y, Rowsell C, et al (2011) Significance and reliability of pathologic marker $\mathrm{Ki}-67$ in patients with neuroendocrine cancers. J Clin Oncol 29(suppl 4):abstr 264

19. Klimstra DS (2013) Pathology reporting of neuroendocrine tumors: essential elements for accurate diagnosis, classification, and staging. Semin Oncol 40:23-36

20. Jann H, Roll S, Couvelard A, Hentic O, Pavel M, Müller-Nordhorn J, Koch M, Röcken C, Rindi G, Ruszniewski P, Wiedenmann B, Pape UF (2011) Neuroendocrine tumors of midgut and hindgut origin: tumor-node-metastasis classification determines clinical outcome. Cancer 117:3332-3341 ( $\mathrm{LoE} \otimes \otimes \otimes \bigcirc)$

21. Rindi G, Kloppel G, Alhman H, Caplin M, Couvelard A, de Herder WW, Eriksson B, Falchetti A, Falconi M, Komminoth P, Körner M, Lopes JM, McNicol AM, Nilsson O, Perren A, Scarpa A, Scoazec JY, Wiedenmann B, all other Frascati Consensus Conference participants, European Neuroendocrine Tumor Society (ENETS) (2006) TNM staging of foregut (neuro)endocrine tumors: a consensus proposal including a grading system. Virchows Arch 449:395-401

22. Rindi G, Kloppel G, Couvelard A, Komminoth P, Körner M, Lopes JM, McNicol AM, Nilsson O, Perren A, Scarpa A, Scoazec JY, Wiedenmann B (2007) TNM staging of hindgut (neuro)endocrine tumors: a consensus proposal including a grading system. Virchows Arch 451:757-762

23. Sobin LH, Gospodarowicz M, Wittekind C (2009) TNM classification of malignant tumours. 7th edn. Wiley Blackwell, Oxford

24. Yang Z, Tang LH, Klimstra DS (2011) Effect of tumor heterogeneity on the assessment of Ki-67 labeling index in welldifferentiated neuroendocrine tumors metastatic to the liver: implications for prognostic stratification. Am J Surg Pathol 35:853-860 ( $\mathrm{LoE} \otimes \otimes \bigcirc \bigcirc)$

25. Tang LH, Gonen M, Hedvat C, Modlin I, Klimstra DS (2012) Objective quantification of the Ki-67 proliferation index in neuroendocrine tumors of the gastroenteropancreatic system. Am J Surg Pathol 36:1761-1770 (LoE $\otimes \otimes \bigcirc \bigcirc)$

26. Kahn MS, Luong TV, Watkins J, Toumpanakis C, Caplin ME, Meyer T (2013) A comparison of Ki-67 and mitotic count as 
prognostic markers for metastatic pancreatic and midgut neuroendocrine neoplasms. Br J Cancer 108:1838-1845 (LoE $\otimes \otimes \bigcirc 0)$

27. Sorbye H, Welin S, Langer SW, Westermark LW, Holt N, Osterlund P, Duelend S, Hofsli E, Guren MG, Ohrling K, Birkemayer E, Thiis-Evensen E, Biagini M, Gronbaek H, Soveri ML, Olsen IH, Federspiel B, Assmus J, Janson ET, Knigge U (2012) Predictive and prognostic factors for treatment and survival in 305 patients with advanced gastrointestinal neuroendocrine carcinoma (WHO G3): the NORDIC NEC study. Ann Oncol 11:1-9 (LoE $\otimes \otimes \bigcirc \bigcirc)$

28. Chetty R (2008) An overwiew of practical issues in the diagnosis of gastroenteropancreatic neuroendocrine pathology. Arch Pathol Lab Med 132:1285-1289

29. Vélayoudom-Céphise FL, Duvillard P, Foucan L, Hadoux J, Chougnet CN, Leboulleux S, Malka D, Guigay J, Goere D, Debaere T, Caramella C, Schlumberger M, Planchard D, Elias D, Ducreux M, Scoazec JY, Baudin E (2013) Are G3 ENETS neuroendocrine neoplasms heterogeneous? Endocr Relat Cancer 20:649-657 (LoE $\otimes \otimes \bigcirc \bigcirc)$

30. Petrone M, Testoni SGG, Carrara S, Balzano G, Manzoni M, Doglioni C, Testoni PA, Arcidiacono PA (2012) EUS-Guided FNA for proliferative rate in pancreatic neuroendocrine tumors: a single center experience over a 11-year period. JOP $13(5$ Suppl):569

31. Larghi A, Capurso G, Carnuccio A, Ricci R, Alfieri S, Galasso D, Lugli F, Bianchi A, Panzuto F, De Marinis L, Falconi M, Delle Fave G, Doglietto GB, Costamagna G, Rindi G (2011) KI67 grading of nonfunctioning pancreatic neuroendocrine tumors on histologic samples obtaining by EUS-guide fine-needle tissue acquisition: a prospective study. Gastrointest Endosc 76:570-577 (LoE $\otimes \otimes \bigcirc \bigcirc)$

32. Iqbal S, Friedel D, Gupta M, Ogden L, Stavroulos SN (2012) Endoscopic-ultrasound-guided fine needle aspiration and the role of the cytopathologist in solid pancreatic lesion diagnosis. Pathol Res Intern 2012:1-17

33. Ramage J, Ahmed A, Ardill J, Bax N, Breen DJ, Caplin ME, Corrie P, Davar J, Davies AH, Lewington V, Meyer T, NewellPrice J, Poston G, Reed N, Rockall A, Steward W, Thakker RV, Toubanakis C, Valle J, Verbeke C, Grossman AB, UK and Ireland Neuroendocrine Tumour Society (2012) Guidelines for the management of gastroenteropancreatic neuroendocrine (including carcinoid) tumours (NETs). Gut 61:6-32

34. Salazar R, Wiedenmann B, Rindi G, Ruszniewskj P (2012) ENETS 2011 consensus guidelines for the management of patients with digestive neuroendocrine tumours: an update. Neuroendocrinology 95:71-73

35. Bellizzi A (2013) Assigning site of origin in metastatic neuroendocrine neoplasms: a clinically significant application of diagnostic immunohistochemistry. Adv Anat Pathol 20:285-314

36. Metz DC, Choi J, Strasberg J, Heaney AP, Howden CW, Klimstra D, Yao JC (2012) A rationale for multidisciplinary care in treating neuroendocrine tumors. Curr Opin Endocrinol Diabetes Obes 19:306-313

37. Klimstra DS, Modlin I, Adsay NV, Chetty R, Deshpande V, Gönen M, Jensen RT, Kidd M, Kulke MH, Lloyd RV, Moran C, Moss SF, Oberg K, O'Toole D, Rindi G, Robert ME, Suster S, Tang LH, Tzen CY, Washington MK, Wiedenmann B, Yao J (2010) Pathology reporting of neuroendocrine tumors: application of the Delphic consensus process to the development of a minimum pathology data set. Am J Surg Pathol 34:300-313

38. Anlauf M, Garbrecht N, Bauersfeld J, Schmitt A, Henopp T, Komminoth P, Heitz PU, Perren A, Klöppel G (2007) Hereditary neuroendocrine tumors of the gastroenteropancreatic system. Virchows Arch 451(Suppl 1):S29-S38
39. Starker LF, Carling T (2008) Molecular genetics of gastroenteropancreatic neuroendocrine tumors. Curr Opin Oncol 21:29-33

40. Thakker RV, Newey PJ, Walls GV, Bilezikian J, Dralle H, Ebeling PR, Melmed S, Sakurai A, Tonelli F, Brandi ML, Endocrine Society (2012) Clinical practice guidelines for multiple endocrine neoplasia type 1 (MEN1). J Clin Endocrinol Metab 97:2990-3011

41. Brandi ML, Gagel RF, Angeli A, Bilezikian JP, Beck-Peccoz P, Bordi C, Conte-Devolx B, Falchetti A, Gheri RG, Libroia A, Lips CJ, Lombardi G, Mannelli M, Pacini F, Ponder BA, Raue F, Skogseid B, Tamburrano G, Thakker RV, Thompson NW, Tomassetti P, Tonelli F, Wells SA, Marx SJ (2001) Guidelines for diagnosis and therapy of MEN type 1 and type 2. J Clin Endocrinol Metab 86:5658-5671

42. Ellard S, Hattersley AT, Brewer CM, Vaidya B (2005) Detection of an MEN1 gene mutation depends on clinical features and supports current referral criteria for diagnostic molecular genetic testing. Clin Endocrinol 62:169-175 (LoE $\otimes \otimes \bigcirc \bigcirc)$

43. Bassett JHD, Forbes SA, Pannett AAJ, Lloyd SE, Christie PT, Wooding C, Harding B, Besser GM, Edwards CR, Monson JP, Sampson J, Wass JAH, Wheeler MH, Thakker RV (1998) Characterization of mutations in patients with multiple endocrine neoplasia type I. Am J Hum Genet 62:232-244

44. Lemos MC, Thakker RV (2008) Multiple endocrine neoplasia type 1 (MEN1): analysis of 1336 mutations reported in the first decade following identification of the gene. Hum Mutat 29:22-32

45. Wautot V, Vercherat C, Lespinasse J, Chambe B, Lenoir GM, Zhang CX, Porchet N, Cordier M, Beroud C, Calender A (2002) Germline mutation profile of MEN1 in multiple endocrine neoplasia type 1: search for correlation between phenotype and the functional domains of the MEN1 protein. Hum Mutat 20:35-47

46. Corcos O, Couvelard A, Giraud S, Vullierme MP, O'Toole Dermot, Rebours V, Stievenart JL, Penfornis A, Niccoli-Sire P, Baudin E, Sauvanet A, Levy P, Ruszniewski P, Richard S, Hammel P (2008) Endocrine pancreatic tumors in von HippelLindau disease: clinical, histological, and genetic features. Pancreas 37:85-93

47. Maher ER, Iselius L, Yates JR, Littler M, Benjamin C, Harris R, Sampson J, Williams A, Ferguson-Smith MA, Morton N (1991) Von Hippel-Lindau disease: a genetic study. J Med Genet 28:443-447

48. Lonser RR, Glenn GM, Walther M, Chew EY, Libutti SK, Linehan WM, Oldfield EH (2003) von Hippel-Lindau disease. Lancet 361:2059-2067

49. Rasmussen A, Nava-Salazar S, Yescas P, Alonso E, Revuelta R, Ortiz I, Canizales-Quinteros S, Tusie-Luna MT, Lopez-Lopez M (2006) von Hippel-Lindau disease germline mutations in Mexican patients with cerebellar hemangioblastoma. J Neurosurg 104:389-394 (LoE $\otimes \otimes \bigcirc O)$

50. American Society of Clinical Oncology (2003) Policy statement update: genetic testing for cancer susceptibility. J Clin Oncol 21:2397-2406

51. Dayal Y, Tallberg KA, Nunnemacher G, DeLellis RA, Wolfe HJ (1986) Duodenal carcinoids in patients with and without neurofibromatosis. A comparative study. Am J Surg Pathol 10:348-357 (LoE $\otimes \bigcirc \bigcirc O)$

52. Williams VC, Lucas J, Babcock MA, Gutmann DH, Korf B, Maria BL (2009) Neurofibromatosis type 1 revisited. Pediatrics 123:124-133

53. Davoren PM, Epstein MT (1992) Insulinoma complicating tuberous sclerosis. J Neurol Neurosurg Psychiatry 55:1209

54. Francalanci P, Diomedi-Camassei F, Purificato C, Santorelli FM, Giannotti A, Dominici C, Inserra A, Boldrini R (2003) Malignant pancreatic endocrine tumor in a child with tuberous sclerosis. Am J Surg Pathol 27:1386-1389 
55. van Slegtenhorst M, de Hoogt R, Hermans C, Nellist M, Janssen B, Verhoef S, Lindhout D, van den Ouweland A, Halley D, Young J, Burley M, Jeremiah S, Woodward K, Nahmias J, Fox M, Ekong R, Osborne J, Wolfe J, Povey S, Snell RG, Cheadle JP, Jones AC, Tachataki M, Ravine D, Sampson JR, Reeve MP, Richardson P, Wilmer F, Munro C, Hawkins TL, Sepp T, Ali JB, Ward S, Green AJ, Yates JR, Kwiatkowska J, Henske EP, Short MP, Haines JH, Jozwiak S, Kwiatkowski DJ (1997) Identification of the tuberous sclerosis gene TSC1 on chromosome $9 \mathrm{q} 34$. Science 277:805-808

56. Sancak O, Nellist M, Goedbloed M, Elfferich P, Wouters C, Maat-Kievit A, Zonnenberg B, Verhoef S, Halley D, van den Ouweland A (2005) Mutational analysis of the TSC1 and TSC2 genes in a diagnostic setting: genotype-phenotype correlations and comparison of diagnostic DNA techniques in tuberous sclerosis complex. Eur J Hum Genet 13:731-741

57. Ardill JE, Eriksson B (2003) The importance of the measurement of circulating markers in patients with neuroendocrine tumours of the pancreas and gut. Endocr Relat Cancer 10:459-462

58. Ardill JES, O'Dorisio TM (2010) Circulating biomarkers in neuroendocrine tumors of the enteropancreatic tract: application to diagnosis, monitoring disease, and as prognostic indicators. Endocrinol Metab Clin North Am 40:777-790

59. Stridsberg M, Öberg K, Li Q, Engström U, Lundqvist G (1995) Measurements of chromogranin A, chromogranin B (secretogranin I), chromogranin $\mathrm{C}$ (secretogranin II) and pancreastatin in plasma and urine from patients with carcinoid tumours and endocrine pancreatic tumours. J Endocrinol 144:49-59 (LoE $\otimes 0 \bigcirc \bigcirc)$

60. Stridsberg M, Eriksson B, Öberg K, Janson ET (2003) A comparison between three commercial kits for chromogranin A measurements. J Endocrinol 177:337-341 (LoE $\otimes 0 \bigcirc 0)$

61. Zatelli MC, Torta M, Leon A, Ambrosio MR, Gion M, Tomassetti P, De Braud F, Delle Fave G, Dogliotti L, Degli Uberti EC, Italian CromaNet Working Group (2007) Chromogranin A as a marker of neuroendocrine neoplasia: an Italian Multicenter Study. Endocr Relat Cancer 14:473-482 (LoE $\otimes \otimes \bigcirc \bigcirc)$

62. Granberg D, Stridsberg M, Seensalu R, Eriksson B, Lundqvist G, Öberg K, Skogseid B (1999) Plasma chromogranin A in patients with multiple endocrine neoplasia type 1. J Clin Endocrinol Metan 84:2712-2717 ( $\mathrm{LoE} \otimes 0 \bigcirc 0)$

63. Campana D, Nori F, Piscitelli L, Morselli-Labate AM, Pezzilli R, Corinaldesi R, Tomassetti P (2007) Chromogranin A: is it a useful marker of neuroendocrine tumors? J Clin Oncol 25:1967-1973 (LoE $\otimes O \bigcirc O)$

64. Modlin IM, Gustafsson BI, Moss SF, Pavel M, Tsolakis AV, Kidd M (2010) Chromogranin A-biological function and clinical utility in neuro endocrine tumor disease. Ann Surg Oncol 17:2427-2443

65. Singh S, Law C (2012) Chromogranin A: a sensitive biomarker for the detection and post-treatment monitoring of gastroenteropancreatic neuroendocrine tumors. Expert Rev Gastroenterol Hepatol 6:313-334

66. Marotta V, Nuzzo V, Ferrara T, Zuccoli A, Masone M, Nocerino L, Del Prete M, Marciello F, Ramundo V, Lombardi G, Vitale M, Colao A, Faggiano A (2012) Limitations of Chromogranin A in clinical practice. Biomarkers 17:186-191 (LoE $\otimes \bigcirc \bigcirc \bigcirc)$

67. Mosli HH, Dennis A, Kocha W, Asher LJ, Van Uum SH (2012) Effect of short-term proton pump inhibitor treatment and its discontinuation on chromogranin A in healthy subjects. J Clin Endocrinol Metab 97:E1731-E1735 (LoE $\otimes \otimes \bigcirc \bigcirc)$

68. Korse CM, Muller M, Taal BG (2011) Discontinuation of proton pump inhibitors during assessment of chromogranin A levels in patients with neuroendocrine tumours. $\mathrm{Br} \mathrm{J}$ Cancer 105:1173-1175 (LoE $\otimes \bigcirc \bigcirc \bigcirc)$
69. Nikou GC, Marinou K, Thomakos P, Papageorgiou D, Sanzanidis V, Nikolaou P, Kosmidis C, Moulakakis A, Mallas E (2008) Chromogranin A levels in diagnosis, treatment and follow-up of 42 patients with non-functioning pancreatic endocrine tumours. Pancreatology 8:510-519 ( $\mathrm{LoE} \otimes \otimes \bigcirc \bigcirc)$

70. Panzuto F, Severi C, Cannizzaro R, Falconi M, Angeletti S, Pasquali A, Corleto VD, Annibale B, Buonadonna A, Pederzoli P, Delle Fave G (2004) Utility of combined use of plasma levels of chromogranin A and pancreatic polypeptide in the diagnosis of gastrointestinal and pancreatic endocrine tumors. J Endocrinol Invest 27:6-11 (LoE $\otimes \otimes \bigcirc \bigcirc)$

71. Seregni E, Ferrari L, Stivanello M, Dogliotti L (2000) Laboratory tests for neuroendocrine tumours. Q J Nucl Med 44:22-41

72. Korse CM, Taal BG, Vincent A, van Velthuysen ML, Baas P, Buning-Kager JC, Linders TC, Bonfrer JM (2012) Choice of tumour markers in patients with neuroendocrine tumours is dependent on the histological grade. A marker study of chromogranin A, neuron specific enolase, progastrin-releasing peptide and cytokeratin fragments. Eur J Cancer 48:662-671 (LoE $\otimes \otimes \otimes 0)$

73. Shah T, Srirajaskanthan R, Bhogal M, Toubanakis C, Meyer T, Noonan A, Witney-Smith C, Amin T, Bhogal P, Sivathasan N, Warner B, Hochhauser D, Caplin ME (2008) Alpha-fetoprotein and human chorionic gonadotrophin-beta as prognostic markers in neuroendocrine tumour patients. Br J Cancer 99:72-77 (LoE $\otimes \otimes \bigcirc \bigcirc)$

74. Pape UF, Perren A, Niederle B, Gross D, Gress T, Costa F, Arnold R, Denecke T, Plöckinger U, Salazar R, Grossman A, Barcelona Consensus Conference participants (2012) ENETS Consensus Guidelines for the management of patients with neuroendocrine neoplasms from the jejuno-ileum and the appendix including goblet cell carcinomas. Neuroendocrinology 95:135-156

75. Kema IP, de Vries EG, Muskiet FA (1995) Measurement of 5-HIAA in urine. Ann Clin Biochem 32:102-104

76. Kema IP, de Vries EG, Muskiet FA (2000) Clinical chemistry of serotonin and metabolites. J Chromatogr B Biomed Sci Appl 747:33-48

77. O'Toole D, Grossman A, Gross D, Delle Fave G, Barkmanova J, O'Connor J, Pape UF, Plöckinger U (2009) ENETS consensus guidelines for the standards of care in neuroendocrine tumors: biochemical markers. Neuroendocrinology 90:194-202

78. Sjoblom SM (1988) Clinical presentation and prognosis of gastrointestinal carcinoid tumours. Scand J Gastroenterol 23:779-787

79. Tellez MR, Mamikunian G, O'Dorisio TM, Vinik AI, Woltering EA (2013) A single fasting plasma 5-HIAA value correlates with 24-hour urinary 5-HIAA values and other biomarkers in midgut neuroendocrine tumors (NETs). Pancreas 42:405-410 $(\mathrm{LoE} \otimes \otimes \bigcirc \bigcirc)$

80. Allen KR, Degg TJ, Anthoney DA, Fitzroy-Smith D (2007) Monitoring the treatment of carcinoid disease using blood serotonin and plasma 5-hydroxyindoleacetic acid: three case examples. Ann Clin Biochem 44:300-307 (LoE $\otimes \bigcirc \bigcirc \bigcirc)$

81. Rehfeld JF, Gingras MH, Bardram L, Hilsted L, Goetze JP, Poitras P (2011) The Zollinger-Ellison syndrome and mismeasurement of gastrin. Gastroenterology 140:1444-1453

82. Dhillo WS, Jayasena CN, Lewis CJ, Martin NM, Tang KC, Meeran K, Todd JF (2006) Plasma gastrin measurement cannot be used to diagnose a gastrinoma in patients on either proton pump inhibitors or histamine type-2 receptor antagonists. Ann Clin Biochem 43:153-155 (LoE $\otimes \otimes \bigcirc \bigcirc)$

83. Arnold R (2007) Diagnosis and differential diagnosis of hypergastrinemia. Wien Klin Wochenschr 119:564-569

84. Banasch M, Schmitz F (2007) Diagnosis and treatment of gastrinoma in the era of proton pump inhibitors. Wien Klin Wochenschr 119:573-578 
85. Osefo N, Ito T, Jensen RT (2009) Gastric acid hypersecretory states: recent insights and advances. Curr Gastroenterol Rep 11:433-441

86. Rehfeld JF, Bardram L, Hilsted L, Poitras P, Goetze JP (2012) Pitfalls in diagnostic gastrin measurements. Clin Chem 58:831-836

87. Berna MJ, Hoffmann KM, Serrano J, Gibril F, Jensen RT (2006) Serum gastrin in Zollinger-Ellison syndrome. Prospective study of fasting serum gastrin in 309 patients from the National Institutes of Health and comparison with 2,229 cases from the literature. Medicine (Baltimore) 85:295-330 (LoE $\otimes \otimes \otimes \otimes)$

88. Jensen RT, Cadiot G, Brandi ML, de Herder WW, Kaltsas G, Komminoth P, Scoazec JY, Salazar R, Sauvanet A, Kianmanesh R, Barcelona Consensus Conference participants (2012) ENETS Consensus Guidelines for the management of patients with digestive neuroendocrine neoplasms: functional pancreatic endocrine tumor syndromes. Neuroendocrinology 95:98-119

89. Service F (1999) Diagnostic approach to adults with hypoglycaemic disorders. Endocrinol Metab Clin North Am 28:519-532

90. Vezzosi D, Bennet A, Fauvel J, Boulanger C, Tazi O, Louvet JP, Caron P (2003) Insulin levels measured with an insulin-specific assay in patients with fasting hypoglycaemia related to endogenous hyperinsulinism. Eur J Endocrinol 149:413-419 (LoE $\otimes \bigcirc \bigcirc 0)$

91. Wermers RA, Fatourechi V, Kvols LK (1996) Clinical spectrum of hyperglucagonemia associated with malignant neuroendocrine tumors. Mayo Clin Proc 71:1030-1038

92. Krejs GJ (1987) Vipoma syndrome. Am J Med 82:37-48

93. Grier JF (1995) WDHA (watery diarrhea, hypokalemia, achlorhydria) syndrome: clinical features, diagnosis, and treatment. South Med J 88:22-24

94. Sahani DV, Bonaffini PA, Fernandez-Del Castillo C, Blake MA (2013) Gastroenteropancreatic neuroendocrine tumors: role of imaging in diagnosis and management. Radiology 266:38-61

95. Sundin A, Vullierme MP, Kaltsas G, Plöckinger U, Mallorca Consensus Conference participants, European Neuroendocrine Tumor Society (2009) ENETS consensus guidelines for the standards of care in neuroendocrine tumors: radiological examinations. Neuroendocrinology 90:167-183

96. Falconi M, Bartsch DK, Eriksson B, Klöppel G, Lopes JM, O'Connor JM, Salazar R, Taal BG, Vullierme MP, O'Toole D, Barcelona Consensus Conference participants (2012) ENETS consensus guidelines for the management of patients with digestive neuroendocrine neoplasms of the digestive system: well-differentiated pancreatic non-functioning tumors. Neuroendocrinology 95:120-134

97. Malagò R, D’Onofrio M, Zamboni GA, Faccioli N, Falconi M, Boninsegna L, Mucelli RP (2009) Contrast-enhanced sonography of non-functioning pancreatic neuroendocrine tumors. AJR Am J Roentgenol 192:424-430 ( $\mathrm{LoE} \otimes \otimes \bigcirc \bigcirc)$

98. Quaia E, Stacul F, Gaiani S, Ricci P, Passariello R, Curzio D, Pozzi Mucelli R (2004) Comparison of diagnostic performance of unenhanced vs. SonoVue-enhanced ultrasonography in focal liver lesions characterization. The experience of three Italian centers. Radiol Med 108:71-81 (LoE $\otimes \otimes O O)$

99. Mork H, Ignee A, Schuessler G, Ott M, Dietrich CF (2007) Analysis of neuroendocrine tumour metastases in the liver using contrast-enhanced ultrasonography. Scand J Gastroenterol 42:652-662 ( $\mathrm{LoE} \otimes \otimes \bigcirc \bigcirc)$

100. Hoeffel C, Job L, Ladam-Marcus V, Vitry F, Cadiot G, Marcus C (2009) Detection of hepatic metastases from carcinoid tumor: prospective evaluation of contrast-enhanced ultrasonography. Dig Dis Sci 54:2040-2046 (LoE $\otimes \otimes \otimes \bigcirc)$

101. Wu W, Chen MH, Yin SS, Yan K, Fan ZH, Yang W, Dai Y, Huo L, Li JY (2006) The role of contrast enhanced sonography of focal liver lesions before percutaneous biopsy. AJR Am J Roentgenol 187:752-761 ( $\mathrm{LoE} \otimes \otimes \bigcirc \bigcirc)$

102. Chatzipantelis P, Salla C, Konstantinou P, Karoumpalis I, Sakellariou S, Doumani I (2008) Endoscopic ultrasound-guided fine-needle aspiration cytology of pancreatic neuroendocrine tumors: a study of 48 cases. Cancer 114:255-262 (LoE $\otimes \otimes \bigcirc \bigcirc)$

103. Jani N, Khalid A, Kaushik N, Brody D, Bauer K, Schoedel K, Ohori NP, Moser AJ, Lee K, McGrath K (2008) EUS guided FNA diagnosis of pancreatic endocrine tumors: new trends identified. Gastrointest Endosc 67:44-50 (LoE $\otimes \bigcirc \bigcirc \bigcirc)$

104. Fidler JL, Fletcher JG, Reading CC, Andrews JC, Thompson GB, Grant CS, Service FJ (2003) Preoperative detection of pancreatic insulinomas on multiphasic helical CT. AJR Am J Roentgenol 181:775-780 (LoE $\otimes \otimes \bigcirc \bigcirc)$

105. Cwikła JB, Buscombe JR, Caplin ME, Watkinson AF, Walecki J, Gorczyca-Wiśniewska E, Hilson AJ (2004) Diagnostic imaging of carcinoid metastases to the abdomen and pelvis. Med Sci Monit 10(suppl 3):9-16 (LoE $\otimes \otimes \bigcirc \bigcirc)$

106. Kumbasar B, Kamel IR, Tekes A, Eng J, Fishman EK, Wahl RL (2004) Imaging of neuroendocrine tumors: accuracy of helical CT versus SRS. Abdom Imaging 29:696-702 ( $\mathrm{LoE} \otimes \otimes \bigcirc \bigcirc)$

107. Johanssen S, Boivin M, Lochs H, Voderholzer W (2006) The yield of wireless capsule endoscopy in the detection of NET in comparison with CT enteroclysis. Gastrointest Endosc 63:660-665 ( $\mathrm{LoE} \otimes \otimes \otimes O)$

108. Pilleul F, Penigaud M, Milot L, Saurin JC, Chayvialle JA, Valette PJ (2006) Possible small bowel neoplasms: contrastenhanced and water-enhanced multidetector CT enteroclysis. Radiology 241:796-801 ( $\mathrm{LoE} \otimes \otimes \bigcirc \bigcirc)$

109. Kamaoui I, De Luca V, Ficarelli S, Mennesson N, LombardBohas C, Pilleul F (2010) Value of CT enteroclysis in suspected small-bowel carcinoid tumors. Am J Roentgenol 194:629-633 $(\mathrm{LoE} \otimes \mathrm{O} \bigcirc)$

110. Waldmann J, Fendrich V, Habbe N, Bartsch DK, Slater EP, Kann PH, Rothmund M, Langer P (2009) Screening of patients with multiple endocrine neoplasia type 1 (MEN-1): a critical analysis of its value. World J Surg 33:1208-1218 (LoE $\otimes \otimes \bigcirc \bigcirc)$

111. van der Lely AJ, de Herder WW, Krenning EP, Kwekkeboom DJ (2003) Octreoscan radioreceptor imaging. Endocrine 20:307-311

112. Kwekkeboom DJ, Krenning EP, Scheidhauer K, Lewington V, Lebtahi R, Grossman A, Vitek P, Sundin A, Plöckinger U, Mallorca Consensus Conference participants, European Neuroendocrine Tumor Society (2009) ENETS consensus guidelines for the standards of care in neuroendocrine tumors: somatostatin receptor imaging with ${ }^{111}$ In-pentetreotide. Neuroendocrinology 90:184-189

113. Perri M, Erba P, Volterrani D, Lazzeri E, Boni G, Grosso M, Mariani G (2008) Octreo-SPECT/CT imaging for accurate detection and localization of suspected neuroendocrine tumors. Q J Nucl Med Mol Imaging 52:323-333 ( $\mathrm{LoE} \otimes \otimes \otimes \bigcirc)$

114. Gibril F, Reynolds JC, Doppmann JL, Chen CC, Venzon DJ, Termanini B, Weber HC, Stewart CA, Jensen RT (1996) Somatostatin receptor scintigraphy: its sensitivity compared with that of other imaging methods in detecting primary and metastatic gastrinomas: a prospective study. Ann Int Med 125:26-34 (LoE $\otimes \otimes \otimes O)$

115. Shi W, Johnston CF, Buchanan KD, Ferguson WR, Laird JD, Crothers JG, McIlrath EM (1998) Localization of neuroendocrine tumours with [ $\left.{ }^{111} \mathrm{In}\right]-\mathrm{DTPA}$-octreotide scintigraphy (Octreoscan): a comparative study with $\mathrm{CT}$ and MRI imaging. QJM 91:295-301 (LoE $\otimes \otimes O O)$

116. Kaltsas G, Mukherjee JJ, Grossman AB (2001) The value of radiolabeled MIBG and octreotide in the diagnosis and management of neuroendocrine tumours. Ann Oncol 12(Suppl 2):S47-S50 
117. Kaltsas G, Rockall A, Papadogias D, Reznek R, Grossman AB (2004) Recent advances in radiological and radionuclide imaging and therapy of neuroendocrine tumours. Eur $\mathrm{J}$ Endocrinol 151:15-27

118. de Herder WW, Kwekkeboom DJ, Feelders RA, van Aken MO, Lamberts SW, van der Lely AJ, Krenning EP (2006) Somatostatin receptor imaging for neuroendocrine tumors. Pituitary 9:243-248

119. Krenning EP, Kwekkeboom DJ, Bakker WH, Breeman WA, Kooij PP, Oei HY, van Hagen M, Postema PT, de Jong M, Reubi JC et al (1993) Somatostatin receptor scintigraphy with

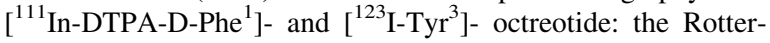
dam experience with more than 1,000 patients. Eur J Nucl Med 20:716-731

120. Reubi JC, Schär JC, Waser B, Wenger S, Heppeler A, Schmitt JS, Mäcke HR (2000) Affinity profiles for human somatostatin receptor subtypes SST1-SST5 of somatostatin radiotracers selected for scintigraphic and radiotherapeutic use. Eur J Nucl Med Mol Imaging 27:273-282

121. Hofmann M, Maecke H, Borner R, Weckesser E, Schoffski P, Oei L, Schumacher J, Henze M, Heppeler A, Meyer J, Knapp H (2001) Biokinetics and imaging with the somatostatin receptor PET radioligand ${ }^{68} \mathrm{Ga}$-DOTATOC: preliminary data. Eur J Nucl Med Mol Imaging 28:1751-1757 ( $\mathrm{LoE} \otimes \bigcirc \bigcirc \bigcirc)$

122. Kowalski J, Henze M, Schumacher J, Maecke HR, Hofmann H, Haberkorn U (2003) Evaluation of positron emission tomography imaging using ${ }^{68} \mathrm{Ga}$-DOTA-Phe ${ }^{1}-\mathrm{Tyr}^{3}$-octreotide in comparison to ${ }^{111}$ In-DTPAOC SPECT. First results in patients with neuroendocrine tumors. Mol Imag Biol 5:42-48 (LoE $\otimes \bigcirc \bigcirc \bigcirc)$

123. Buchmann I, Henze M, Engelbrecht S, Eisenhut S, Runz A, Schäfer M, Schilling T, Haufe S, Herrmann T, Haberkorn U (2007) Comparison of ${ }^{68} \mathrm{Ga}$-DOTATOC PET and ${ }^{111} \mathrm{In}$ DTPAOC (Octreoscan) SPECT in patients with neuroendocrine tumours. Eur J Nucl Med Mol Imaging 34:1617-1626 (LoE $\otimes \otimes \otimes \bigcirc)$

124. Putzer D, Gabriel M, Henninger B, Kendler D, Uprimny C, Dobrozemsky G, Decristoforo C, Bale RJ, Jaschke W, Virgolini IJ (2009) Bone metastases in patients with neuroendocrine tumor: ${ }^{68} \mathrm{Ga}$-DOTA-Tyr ${ }^{3}$-octreotide PET in comparison to CT and bone scintigraphy. J Nucl Med 50:1214-1221 (LoE $\otimes \otimes \otimes O)$

125. Kayani I, Bomanji JB, Groves A, Conway G, Gacinovic S, Win T, Dickson J, Caplin M, Ell PJ (2008) Functional imaging of neuroendocrine tumors with combined PET/CT using $68 \mathrm{Ga}-$ DOTATATE (DOTA-DPhe1, Tyr3-octreotate) and 18F-FDG. Cancer 112:2447-2455 (LoE $\otimes \otimes \bigcirc \bigcirc)$

126. Prasad V, Ambrosini V, Hommann M, Hoersch D, Fanti S, Baum RP (2010) Detection of unknown primary neuroendocrine tumours (CUP-NET) using ${ }^{68}$ Ga-DOTANOC receptor PET/CT. Eur J Nucl Med Mol Imaging 37:67-77 (LoE $\otimes \otimes \bigcirc \bigcirc)$

127. Srirajaskanthan R, Kayani I, Quigley AM, Soh J, Caplin ME, Bomanji J (2010) The role of ${ }^{68} \mathrm{Ga}$-DOTATATE PET in patients with neuroendocrine tumors and negative or equivocal findings on ${ }^{111}$ In-DTPA-octreotide scintigraphy. J Nucl Med 51:875-878 $(\mathrm{LoE} \otimes \otimes \bigcirc \bigcirc)$

128. Poeppel TD, Binse I, Petersenn S, Lahner H, Schott M, Antoch G, Brandau W, Bockisch A, Boy C (2011) ${ }^{68}$ Ga-DOTATOC versus ${ }^{68} \mathrm{Ga}$-DOTATATE PET/CT in functional imaging of neuroendocrine tumors. J Nucl Med 52:1864-1870 (LoE $\otimes \otimes \otimes O)$

129. Kabasakal L, Demirci E, Ocak M, Decristoforo C, Araman A, Ozsoy Y, Uslu I, Kanmaz B (2012) Comparison of ${ }^{68} \mathrm{Ga}-$ DOTATATE and ${ }^{68} \mathrm{Ga}$-DOTANOC PET/CT imaging in the same patient group with neuroendocrine tumours. Eur J Nucl Med Mol Imaging 39:1271-1277 ( $\mathrm{LoE} \otimes \otimes \otimes \bigcirc)$

130. Haug AR, Cindea-Drimus R, Auernhammer CJ, Reincke M, Wängler B, Uebleis C, Schmidt GP, Göke B, Bartenstein P, Hacker M (2012) The role of ${ }^{68} \mathrm{Ga}$-DOTATATE PET/CT in suspected neuroendocrine tumors. J Nucl Med 53:1686-1692 $(\mathrm{LoE} \otimes \otimes \bigcirc \bigcirc)$

131. Gabriel M, Oberauer A, Dobrozemsky G, Decristoforo C, Putzer D, Kendler D, Uprimny C, Kovacs P, Bale R, Virgolini IJ (2009) ${ }^{68} \mathrm{Ga}$-DOTA-Tyr ${ }^{3}$-octreotide PET for assessing response to somatostatin-receptor-mediated radionuclide therapy. J Nucl Med 50:1427-1434 (LoE $\otimes \otimes \otimes O)$

132. Frilling A, Sotiropoulos GC, Radtke A, Malago M, Bockisch A, Kuehl H, Li J, Broelsch CE (2010) The impact of ${ }^{68} \mathrm{Ga}-$ DOTATOC positron emission tomography/computed tomography on the multimodal management of patients with neuroendocrine tumors. Ann Surg 252:850-856 ( $\mathrm{LoE} \otimes \otimes \bigcirc \bigcirc$ )

133. Ruf J, Heuck F, Schiefer J, Denecke T, Elgeti F, Pascher A, Pavel M, Stelter L, Kropf S, Wiedenmann B, Amthauer H (2010) Impact of multiphase ${ }^{68} \mathrm{Ga}$-DOTATOC-PET/CT on therapy management in patients with neuroendocrine tumors. Neuroendocrinology 91:101-109 (LoE $\otimes \otimes \bigcirc \bigcirc)$

134. Kumar R, Sharma P, Garg P, Karunanithi S, Naswa N, Sharma R, Thulkar S, Lata S, Malhotra A (2011) Role of ${ }^{68} \mathrm{Ga}-$ DOTATOC PET-CT in the diagnosis and staging of pancreatic neuroendocrine tumours. Eur Radiol 21:2408-2416 (LoE $\otimes \otimes \bigcirc \bigcirc)$

135. Bombardieri E, Ambrosini V, Aktolun C, Baum RP, BishofDelaloye A, Del Vecchio S, Maffioli L, Mortelmans L, Oyen W, Pepe G, Chiti A, Oncology Committee of the EANM (2010) ${ }^{111}$ In-pentetreotide scintigraphy: procedure guidelines for tumour imaging. Eur J Nucl Med Mol Imaging 37:1441-1448

136. Adams S, Baum R, Rink T, Schumm-Dräger PM, Usadel KH, Hör G (1998) Limited value of fluorine-18 fluorodeoxyglucose positron emission tomography for the imaging of neuroendocrine tumours. Eur J Nucl Med 25:79-83 (LoE $\otimes \otimes \otimes O$ )

137. Pasquali C, Rubello D, Sperti C, Gasparoni P, Liessi G, Chierichetti F, Ferlin G, Pedrazzoli S (1998) Neuroendocrine tumor imaging: can 18F-fluorodeoxyglucose positron emission tomography detect tumors with poor prognosis and aggressive behavior? World J Surg 22:588-592 (LoE $\otimes \bigcirc \bigcirc \bigcirc)$

138. Giammarile F, Billotey C, Lombard-Bohas C, Le Bars D, Bournaud C, Masson S, Walter T, Houzard C, Scoazec JY, Hervieu V, Vuillez JP, Cornu C, Janier M, Borson-Chazot F (2011) 18F-FLT and 18F-FDG positron emission tomography for the imaging of advanced well-differentiated gastro-enteropancreatic endocrine tumours. Nucl Med Commun 32:91-97 $(\mathrm{LoE} \otimes \otimes \otimes O)$

139. Binderup T, Knigge U, Loft A, Mortensen J, Pfeifer A, Federspiel B, Hansen CP, Højgaard L, Kjaer A (2010) Functional imaging of neuroendocrine tumors: a head-to-head comparison of somatostatin receptor scintigraphy, ${ }^{123}$ I-MIBG scintigraphy, and ${ }^{18}$ F-FDG PET. J Nucl Med 51:704-712 (LoE $\left.\otimes \otimes \otimes \bigcirc\right)$

140. Abgral R, Leboulleux S, Déandreis D, Aupérin A, Lumbroso J, Dromain C, Duvillard P, Elias D, de Baere T, Guigay J, Ducreux M, Schlumberger M, Baudin E (2011) Performance of ${ }^{18}$ Fluorodeoxyglucose positron emission tomography and somatostatin receptor scintigraphy for high Ki-67 ( $\geq 10 \%)$ welldifferentiated endocrine carcinoma staging. J Clin Endocrinol Metab 96:665-671 (LoE $\otimes \otimes \otimes O)$

141. Garin E, Le Jeune F, Devillers A, Cuggia M, de Lajarte-Thirouard AS, Bouriel C, Boucher E, Raoul JL (2009) Predictive value of ${ }^{18} \mathrm{~F}$-FDG PET and somatostatin receptor scintigraphy in patients with metastatic endocrine tumors. J Nucl Med 50:858-864 ( $\mathrm{LoE} \otimes \otimes \otimes \bigcirc)$

142. Fuccio C, Musto A, Cambioli S, Castellucci P, Pantaleo MA, Nanni C, Montini GC, Campana D, Tomassetti P, Bellan E, Massaro A, Grassetto G, Rubello D, Fanti S (2011) When should F-18 FDG PET/CT be used instead of ${ }^{68}$ Ga-DOTA-peptides to investigate metastatic neuroendocrine tumors? Clin Nucl Med 36:1109-1111 (LoE $\otimes \bigcirc \bigcirc \bigcirc)$ 
143. Binderup T, Knigge U, Loft A, Federspiel B, Kjaer A (2010) ${ }^{18}$ F-fluorodeoxyglucose positron emission tomography predicts survival of patients with neuroendocrine tumors. Clin Cancer Res 16:978-985 (LoE $\otimes \otimes \otimes O)$

144. Becherer A, Szabó M, Karanikas G, Wunderbaldinger P, Angelberger P, Raderer M, Kurtaran A, Dudczak R, Kletter K (2004) Imaging of advanced neuroendocrine tumors with ${ }^{18} \mathrm{~F}$ FDOPA PET. J Nucl Med 45:1161-1167 (LoE $\otimes \otimes \otimes \bigcirc)$

145. Haug A, Auernhammer CJ, Wangler B, Tiling R, Schmidt G, Göke B, Bartenstein P, Pöpperl G (2009) Intraindividual comparison of ${ }^{68} \mathrm{Ga}$-DOTA-TATE and ${ }^{18} \mathrm{~F}$-DOPA PET in patients with well-differentiated metastatic neuroendocrine tumours. Eur J Nucl Med Mol Imaging 36:765-770 ( $\mathrm{LoE} \otimes \otimes \otimes O)$

146. Koopmans KP, Neels OC, Kema IP, Elsinga PH, Sluiter WJ, Vanghillewe K, Brouwers AH, Jager PL, de Vries EG (2008) Improved staging of patients with carcinoid and islet cell tumors with ${ }^{18} \mathrm{~F}$-dihydroxy-phenyl-alanine and ${ }^{11} \mathrm{C}$-5-hydroxy-tryptophan positron emission tomography. J Clin Oncol 26:1489-1495 $(\mathrm{LoE} \otimes \otimes \bigcirc \bigcirc)$

147. Jager PL, Chirakal R, Marriott CJ, Brouwers AH, Koopmans KP, Gulenchyn KY (2008) 6-L- ${ }^{18}$ F-fluorodihydroxyphenylalanine PET in neuroendocrine tumors: basic aspects and emerging clinical applications. J Nucl Med 49:573-586

148. Kauhanen S, Seppänen M, Ovaska J, Minn H, Bergman J, Korsoff P, Salmela P, Saltevo J, Sane T, Välimäki M, Nuutila P (2009) The clinical value of $[18 \mathrm{~F}]$ fluoro-dihydroxy-phenylalanine positron emission tomography in primary diagnosis, staging, and restaging of neuroendocrine tumors. Endocr Relat Cancer 16:255-265 ( $\mathrm{LoE} \otimes \otimes \bigcirc \bigcirc)$

149. Orlefors H, Sundin A, Garske U, Juhlin C, Oberg K, Skogseid B, Langstrom B, Bergstrom M, Eriksson B (2005) Whole-body ${ }^{11} \mathrm{C}$ 5-hydroxytryptophan positron emission tomography as a universal imaging technique for neuroendocrine tumors: comparison with somatostatin receptor scintigraphy and computed tomography. J Clin Endocrinol Metab 90:3392-3400 (LoE $\otimes \otimes \otimes \bigcirc)$

150. Sundin A, Garske U, Orlefors H (2007) Nuclear imaging of neuroendocrine tumours. Best Pract Res Clin Endocrinol Metab 21:69-85

151. Christ E, Wild D, Forrer F, Brändle M, Sahli R, Clerici T, Gloor B, Martius F, Maecke H, Reubi JC (2009) Glucagon-Like Peptide-1 receptor imaging for localization of insulinomas. J Clin Endocrinol Metab 94:4398-4405 (LoE $\otimes \otimes \bigcirc \bigcirc)$

152. Vannella L, Lahner E, Annibale B (2012) Risk for gastric neoplasias in patients with chronic atrophic gastritis: a critical reappraisal. World J Gastroenterol 18:1279-1285

153. Delle Fave G, Kwekkeboom DJ, Van Cutsem E, Rindi G, KosKudla B, Knigge U, Sasano H, Tomassetti P, Salazar R, Ruszniewski P (2012) ENETS consensus guidelines for the management of patients with gastroduodenal neoplasms. Neuroendocrinology 95:74-87

154. Merola E, Sbrozzi-Vanni A, Panzuto F, D'Ambra G, Di Giulio E, Pilozzi E, Capurso G, Lahner E, Bordi C, Annibale B, Delle Fave G (2012) Type I gastric carcinoids: a prospective study on endoscopic management and recurrence rate. Neuroendocrinology 95:207-213 (LoE $\otimes \otimes \bigcirc \bigcirc)$

155. Ruszniewski P, Amouyal P, Amouyal G, Grange JD, Mignon M, Bouch O, Bernades P (1995) Localization of gastrinomas by endoscopic ultrasonography in patients with Zollinger-Ellison syndrome. Surgery 117:629-635 (LoE $\otimes \otimes \bigcirc \bigcirc)$

156. Yoshikane H, Suzuki T, Yoshioka N, Ogawa Y, Hamajima E, Hasegawa N, Hasegawa C (1995) Duodenal carcinoid tumor: endosonographic imaging and endoscopic resection. Am J Gastroenterol 90:642-644 (LoE $\otimes 000)$

157. Ramage JK, Goretzki PE, Manfredi R, Komminoth P, Ferone D, Hyrdel R, Kaltsas G, Kelestimur F, Kvols L, Scoazec JY, Garcia MI, Caplin ME, Frascati Consensus Conference participants
(2008) Consensus guidelines for the management of patients with digestive neuroendocrine tumors: well differentiated colon and rectum tumor/carcinoma. Neuroendocrinology 87:31-39

158. Scherubl H (2009) Rectal carcinoids are on the rise: early detection by screening endoscopy. Endoscopy 41:162-165

159. Hara AK, Leighton JA, Sharma VK, Heigh RI, Fleischer DE (2005) Imaging of small bowel disease: comparison of capsule endoscopy, standard endoscopy, barium examination, and CT. Radiographics 25:697-711

160. Bellutti M, Fry L, Malfertheiner P, Monkemuller K (2009) Detection of NET of the small bowel by double balloon enteroscopy. Dig Dis Sci 54:1050-1058 (LoE $\otimes \otimes \bigcirc \bigcirc)$

161. Pais SA, Al-Haddad M, Mohamadnejad M, Leblanc JK, Sherman S, McHenry L, DeWitt JM (2010) EUS for pancreatic neuroendocrine tumors: a single-center, 11-year experience. Gastrointest Endosc 71:1185-1193 (LoE $\otimes \otimes \bigcirc \bigcirc)$

162. Atiq M, Bhutani MS, Bektas M, Lee JE, Gong Y, Tamm EP, Shah CP, Ross WA (2012) EUS-FNA for pancreatic neuroendocrine tumors: a tertiary cancer center experience. Dig Dis Sci 57:791-800 (LoE $\otimes \otimes \otimes O)$

163. Puli SR, Bechtold ML, Buxbaum JL, Eloubeidi MA (2013) How good is endoscopic ultrasound-guided fine-needle aspiration in diagnosing the correct etiology for a solid pancreatic mass? A meta-analysis and systematic review. Pancreas 42:20-26 (LoE $\otimes \otimes \otimes O)$

164. Puli SR, Kalva N, Bechtold ML, Pamulaparthy SR, Cashman MD, Estes NC, Pearl RH, Volmar FH, Dillon S, Shekleton MF, Forcione D (2013) Diagnostic accuracy of endoscopic ultrasound in pancreatic neuroendocrine tumors: a systematic review and metaanalysis. World J Gastroenterol 19:3678-3684 (LoE $\otimes \otimes \otimes \bigcirc)$

165. Shumacher B, Lubke HJ, Frieling T, Strohmeyer G, Starke AAR (1996) Prospective study on the detection of insulinomas by endoscopic ultrasonography. Endoscopy 28:273-276 (LoE $\otimes 0 \bigcirc 0)$

166. Gouya H, Vignaux O, Augui J, Dousset B, Palazzo L, Louvel A, Chaussade S, Legmann P (2003) CT, endoscopic sonography, and a combined protocol for preoperative evaluation of pancreatic insulinomas. AJR Am J Roentgenol 181:987-992 (LoE $\otimes \otimes \otimes O)$

167. Bansal R, Tierney W, Carpenter S, Thompson N, Scheiman JM (1999) Cost effectiveness of EUS for preoperative localization of pancreatic endocrine tumors. Gastrointest Endosc 49:19-25 $(\mathrm{LoE} \otimes \otimes \bigcirc \bigcirc)$

168. Hooper K, Mukhtar F, Li S, Eltoum IA (2013) Diagnostic error assessment and associated harm of endoscopic ultrasound-guided fine-needle aspiration of neuroendocrine neoplasms of the pancreas. Cancer Cytopathol 121:653-660 (LoE $\otimes \otimes \bigcirc \bigcirc)$

169. Chang F, Chandra A, Culora G, Mahadeva U, Meenan J, Herbert A (2006) Cytologic diagnosis of pancreatic endocrine tumors by endoscopic ultrasound-guided fine-needle aspiration: a review. Diagn Cytopathol 34:649-658

170. Alsohaibani F, Bigam D, Kneteman N, Shapiro AMJ, Sandha GS (2008) The impact of preoperative endoscopic ultrasound on the surgical management of pancreatic neuroendocrine tumours. Can J Gastroenterol 22:817-820 ( $\mathrm{LoE} \otimes \otimes \otimes O)$

171. Haynes AB, Deshpande V, Ingkakul T, Vagefi PA, Szymonifka J, Thayer SP, Ferrone CR, Wargo JA, Warshaw AL, Fernandez-del Castillo C (2011) Implications of incidentally discovered, nonfunctioning pancreatic endocrine tumors. Short-term and longterm patient outcomes. Arch Surg 146:534-538 (LoE $\otimes \bigcirc \bigcirc 0)$

172. Cheslyn-Curtis S, Sitaram V, Williamson RC (1993) Management of non-functioning neuro-endocrine tumours of the pancreas. Br J Surg 80:625-627

173. Caplin M, Sundin A, Nillson O, Baum RP, Klose KJ, Kelestimur F, Plöckinger U, Papotti M, Salazar R, Pascher A (2012) ENETS 
consensus guidelines for the management of patients with digestive neuroendocrine neoplasms: colorectal neuroendocrine neoplasms. Neuroendocrinology 95:88-97

174. Modlin IM, Kidd M, Latich I, Zikusoka MN, Shapiro MD (2005) Current status of gastrointestinal carcinoids. Gastroenterology 128:1717-1751

175. Van der Lely AJ, de Herder WW (2005) Carcinoid syndrome: diagnosis and medical management. Arq Bras Endocrinol Metab 49:850-860

176. Vinik AI, McLeod MK, Fig LM, Shapiro B, Lloyd RV, Cho K (1989) Clinical features, diagnosis, and localization of carcinoid tumors and their management. Gastroenterol Clin North Am 18:865-896

177. Kulke MH, Mayer RJ (1999) Carcinoid tumors. N Engl J Med 340:859-868

178. Janson ET, Holmberg L, Stridsberg M, Eriksson B, Theodorsson E, Wilander E, Öberg K (1997) Carcinoid tumors: analysis of prognostic factors and survival in 301 patients from a referral center. Ann Oncol 8:685-690 (LoE $\otimes \otimes \otimes O)$

179. Soga J, Yakuwa Y, Osaka M (1999) Carcinoid syndrome: a statistical evaluation of 748 reported cases. J Exp Clin Cancer Res 18:133-141 (LoE $\otimes \otimes \bigcirc \bigcirc)$

180. Tomassetti P, Migliori M, Lalli S, Campana D, Tomassetti V, Corinaldesi R (2001) Epidemiology, clinical features and diagnosis of gastroenteropancreatic endocrine tumours. Ann Oncol 12(Suppl 2):S95-S99

181. Kaltsas G, Besser GM, Grossman AB (2004) The diagnosis and medical management of advanced neuroendocrine tumors. Endocr Rev 25:458-511

182. Creutzfeldt W (1996) Carcinoid tumours: development of our knowledge. World J Surg 20:126-131

183. Davì MV, Bodei L, Francia G, Bartolomei M, Oliani C, Scilanga L, Reghellin D, Falconi M, Paganelli G, Lo Cascio V, Ferdeghini M (2006) Carcinoid crisis induced by receptor radionuclide therapy with 90Y-DOTATOC in a case of liver metastases from bronchial neuroendocrine tumor (atypical carcinoid). J Endocrinol Invest 29:563-567 (LoE $\otimes \bigcirc \bigcirc \bigcirc)$

184. Vinik AI, Gonzales MRC (2011) New and emerging syndromes due to neuroendocrine tumors. Endocrinol Metab Clin North Am 40:19-63

185. McCormick D (2002) Carcinoid tumors and syndrome. Gastroenterol Nurs 25:105-111

186. Gustafsson BI, Hauso O, Drosdo I, Kidd M, Modlin IM (2008) Carcinoid heart disease. Int J Cardiol 129:318-324

187. Izikson L, English JC 3rd, Zirwas MJ (2006) The flushing patient: differential diagnosis, workup, and treatment. J Am Acad Dermatol 55:193-208

188. Feldman J, Lee E (1985) Serotonin content of foods: effect on urinary excretion of 5-hydroxyindoleacetic acid. Am J Clin Nutr 42:639-643

189. Richter G, Stockmann F, Conlon JM, Creutzfeldt W (1986) Serotonin release into blood after food and pentagastrin. Studies in healthy subjects and in patients with metastatic carcinoid tumors. Gastroenterology 91:612-618 ( $\mathrm{LoE} \otimes \mathrm{O} \mathrm{O})$

190. Mashige F, Matsushima Y, Kanazawa H, Sakuma I, Takai N, Bessho F, Ohkubo A (1996) Acidic catecholamine metabolites and 5-hydroxyindoleacetic acid in urine: the influence of diet. Ann Clin Biochem 33:43-49

191. Feldman JM (1987) Carcinoid tumors and syndrome. Semin Oncol 14:237-246

192. Feldman JM, O'Dorisio TM (1986) Role of neuropeptides and serotonin in the diagnosis of carcinoid tumors. Am J Med 81:41-48

193. Eriksson B, Oberg K, Stridsberg M (2000) Tumor markers in neuroendocrine tumors. Digestion 62(Suppl 1):33-38

194. Öberg K (2011) Circulating biomarkers in gastroenteropancreatic neuroendocrine tumours. Endocr Relat Cancer 18(Suppl 1):S17-S25
195. Tomassetti P, Migliori M, Simoni P, Casadei R, De Iasio R, Corinaldesi R, Gullo L (2001) Diagnostic value of plasma chromogranin A in neuroendocrine tumours. Eur J Gastroenterol Hepatol 13:55-58

196. Rockall AG, Reznek RH (2007) Imaging of neuroendocrine tumours (CT/MR/US). Best Pract Res Clin Endocrinol Metab 21:43-68

197. Dromain C, de Baere T, Lumbroso J, Caillet H, Laplanche A, Boige V, Ducreux M, Duvillard P, Elias D, Schlumberger M, Sigal R, Baudin E (2005) Detection of liver metastases from endocrine tumors: a prospective comparison of somatostatin receptor scintigraphy, computed tomography, and magnetic resonance imaging. J Clin Oncol 23:70-78 ( $\mathrm{LoE} \otimes \otimes \otimes O)$

198. Dromain C, de Baere T, Baudin E, Galline J, Ducreux M, Boige V, Duvillard P, Laplanche A, Caillet H, Lasser P, Schlumberger M, Sigal R (2003) MR imaging of hepatic metastases caused by neuroendocrine tumors: comparing four techniques. AJR Am J Roentgenol 180:121-128 (LoE $\otimes \otimes \bigcirc \bigcirc)$

199. Boudreaux JP, Klimstra DS, Hassan MM, Woltering EA, Jensen RT, Goldsmith SJ, Nutting C, Bushnell DL, Caplin ME, Yao JC, North American Neuroendocrine Tumor Society (NANETS) (2010) The NANETS consensus guideline for the diagnosis and management of neuroendocrine tumors: well-differentiated neuroendocrine tumors of the Jejunum, Ileum, Appendix, and Cecum. Pancreas 39:753-766

200. Modlin IM, Latich I, Zikusoka M, Kidd M, Eick G, Chan AK (2006) Gastrointestinal carcinoids: the evolution of diagnostic strategies. J Clin Gastroenterol 40:572-582

201. Bhattacharyya S, Toumpanakis C, Caplin ME, Davar J (2008) Analysis of 150 patients with carcinoid syndrome seen in a single year at one institution in the first decade of the twentyfirst century. Am J Cardiol 101:378-381 (LoE $\otimes \otimes \otimes \bigcirc)$

202. Roy P, Venzon DJ, Shojamanesh H, Abou-Saif A, Peghini P, Doppman JL, Gibril F, Jensen RT (2000) Zollinger-Ellison syndrome: clinical presentation in 261 patients. Medicine (Baltimore) 79:379-411 ( $\mathrm{LoE} \otimes \otimes \bigcirc \bigcirc)$

203. Roy P, Venzon DJ, Feigenbaum KM, Koviack PD, Bashir S, Ojeaburu JV, Gibril F, Jensen RT (2001) Gastric secretion in Zollinger-Ellison syndrome. Correlation with clinical expression, tumor extent and role in diagnosis-a prospective NIH study of 235 patients and a review of 984 cases in the literature. Medicine (Baltimore) 80:189-222 ( $\mathrm{LoE} \otimes \otimes \bigcirc \bigcirc)$

204. Jensen RT, Niederle B, Mitry E, Ramage JK, Steinmuller T, Lewington V, Scarpa A, Sundin A, Perren A, Gross D, O'Connor JM, Pauwels S, Kloppel G, Frascati Consensus Conference; European Neuroendocrine Tumor Society (2006) Gastrinoma (duodenal and pancreatic). Neuroendocrinology 84:173-182

205. Ellison EC, Johnson JA (2009) The Zollinger-Ellison syndrome: a comprehensive review of historical, scientific, and clinical considerations. Curr Probl Surg 46:13-106

206. Corleto VD, Annibale B, Gibril F, Angeletti S, Serrano J, Venzon DJ, Delle Fave G, Jensen RT (2001) Does the widespread use of proton pump inhibitors mask, complicate and/or delay the diagnosis of Zollinger-Ellison syndrome? Aliment Pharmacol Ther 15:1555-1561

207. Gibril F, Schumann M, Pace A, Jensen RT (2004) Multiple endocrine neoplasia type 1 and Zollinger-Ellison syndrome. A prospective study of 107 cases and comparison with 1,009 patients from the literature. Medicine (Baltimore) 83:43-83 $(\mathrm{LoE} \otimes \otimes \otimes O)$

208. Kulke MH, Anthony LB, Bushnell DL, de Herder WW, Goldsmith SJ, Klimstra DS, Marx SJ, Pasieka JL, Pommier RF, Yao JC, Jensen RT, North American Neuroendocrine Tumor Society (NANETS) (2010) NANETS treatment guidelines: well-differentiated neuroendocrine tumors of the stomach and pancreas. Pancreas 39:735-752 
209. Ramundo V, Milone F, Severino R, Savastano S, Di Somma C, Vuolo L, De Luca L, Lombardi G, Colao A, Faggiano A (2011) Clinical and prognostic implications of the genetic diagnosis of hereditary NET syndromes in asymptomatic patients. Horm Metab Res 43:794-800

210. Gibril F, Jensen RT (2005) Advances in evaluation and management of gastrinoma in patients with Zollinger-Ellison syndrome. Curr Gastroenterol Rep 7:114-121

211. Kloppel G, Anlauf M (2007) Gastrinoma-morphological aspects. Wien Klin Wochenschr 119:579-584

212. Stabile BE, Morrow DJ, Passaro E Jr (1984) The gastrinoma triangle: operative implications. Am J Surg 147:25-31 (LoE $\otimes 000)$

213. Vinik AI, Woltering EA, Warner RR, Caplin M, O'Dorisio TM, Wiseman GA, Coppola D, Go VL (2010) NANETS consensus guidelines for the diagnosis of neuroendocrine tumor. Pancreas 39:713-734

214. Jensen RT (2001) Zollinger-Ellison syndrome. In: Doherty GM, Skogseid B (eds) Surgical endocrinology: clinical syndromes. Lippincott Williams \& Wilkins, Philadelphia, pp 291-344

215. Lau JY, Sung J, Hill C, Henderson C, Howden CW, Metz DC (2011) Systematic review of the epidemiology of complicated peptic ulcer disease: incidence, recurrence, risk factors and mortality. Digestion 84:102-113

216. Jensen RT (2006) Consequences of long-term proton pump blockade: highlighting insights from studies of patients with gastrinomas. Basic Clin Pharmacol Toxicol 98:4-19

217. Agréus L, Storskrubb T, Aro P, Ronkainen J, Talley NJ, Sipponen $\mathrm{P}$ (2009) Clinical use of proton-pump inhibitors but not H2blockers or antacid/alginates raises the serum levels of amidated gastrin-17, pepsinogen I and pepsinogen II in a random adult population. Scand J Gastroenterol 44:564-570 (LoE $\otimes \otimes \bigcirc \bigcirc)$

218. Kim BW, Lee BI, Kim HK, Cho YS, Chae HS, Lee HK, Kim HJ, Han SW (2009) Influence of long-term gastric acid suppression therapy on the expression of serum gastrin, chromogranin A, and ghrelin. Korean J Gastroenterol 53:84-89 (LoE $\otimes \otimes \bigcirc \bigcirc)$

219. Campana D, Piscitelli L, Mazzotta E, Bonora M, Serra C, Salomone L, Corinaldesi R, Tomassetti P (2005) Zollinger-Ellison syndrome. Diagnosis and therapy. Minerva Med 96:187-206

220. Poitras P, Gingras MH, Rehfeld JF (2012) The Zollinger-Ellison syndrome: dangers and consequences of interrupting antisecretory treatment. Clin Gastroenterol Hepatol 10:199-202 (LoE $\otimes 000)$

221. Poitras P, Gingras MH, Rehfeld JF (2013) Secretin stimulation test for gastrin release in Zollinger-Ellison syndrome: to do or not to do? Pancreas 42:903-904

222. Desir B, Poltras P (2001) Oral pantoprazole for acid suppression in the treatment of patients with Zollinger-Ellison syndrome. Can J Gastroenterol 15:795-798 (LoE $\otimes \bigcirc \bigcirc)$

223. Berna MJ, Hoffmann KM, Long SH, Serrano J, Gibril F, Jensen RT (2006) Serum gastrin in Zollinger-Ellison syndrome. II. Prospective study of gastrin provocative testing in 293 patients from the National Institutes of Health and comparison with 537 cases from the literature. Evaluation of diagnostic criteria, proposal of new criteria, and correlations with clinical and tumoral features. Medicine (Baltimore) 85:331-364 (LoE $\otimes \otimes \otimes \otimes)$

224. Fraker DL, Norton JA, Alexander HR, Venzon DJ, Jensen RT (1994) Surgery in Zollinger-Ellison syndrome alters the natural history of gastrinoma. Ann Surg 220:320-330 (LoE $\otimes \otimes \bigcirc \bigcirc)$

225. Norton JA, Fraker DL, Alexander HR, Gibril F, Liewehr DJ, Venzon DJ, Jensen RT (2006) Surgery increases survival in patients with gastrinoma. Ann Surg 244:410-419 (LoE $\otimes \otimes \bigcirc \bigcirc)$

226. Morrow EH, Norton JA (2009) Surgical management of Zollinger-Ellison syndrome; state of the art. Surg Clin North Am 89:1091-1103
227. Senniappan S, Shanti B, James C, Hussain K (2012) Hyperinsulinaemic hypoglycaemia: genetic mechanisms, diagnosis and management. J Inherit Metab Dis 35:589-601

228. McAulay V, Deary IJ, Frier BM (2001) Symptoms of hypoglycaemia in people with diabetes. Diabet Med 18:690-705

229. Cox D, Gonder-Frederick L, McCall A, Kovatchev B, Clarke W (2002) The effects of glucose fluctuation on cognitive function and QOL: the functional costs of hypoglycaemia and hyperglycaemia among adults with type 1 or type 2 diabetes. Int J Clin Pract 56 (Suppl Jul 129):20-26

230. Okabayashi T, Shima Y, Sumiyoshi T, Kozuki A, Ito S, Ogawa Y, Kobayashi M, Hanazaki K (2013) Diagnosis and management of insulinoma. World J Gastroenterol 19:829-837

231. Cryer PE, Axelrod L, Grossman AB, Heller SR, Montori VM, Seaquist ER, Service FJ, Endocrine Society (2009) Evaluation and management of adult hypoglycemic disorders: an Endocrine Society Clinical Practice Guideline. J Clin Endocrinol Metab 94:709-728

232. Davda R, Seddon BM (2007) Mechanisms and management of non-islet cell tumour hypoglycaemia in gastrointestinal stromal tumour: case report and a review of published studies. Clin Oncol (R Coll Radiol) 19:265-268 (LoE $\otimes \bigcirc \bigcirc \bigcirc)$

233. Waickus CM, de Bustros A, Shakil A (1999) Recognizing factitious hypoglycemia in the family practice setting. J Am Board Fam Pract 12:133-136 ( $\mathrm{LoE} \otimes 0 \bigcirc \bigcirc)$

234. Placzkowski KA, Vella A, Thompson GB, Grant CS, Reading CC, Charboneau JW, Andrews JC, Lloyd RV, Service FJ (2009) Secular trends in the presentation and management of functioning insulinoma at the Mayo Clinic, 1987-2007. J Clin Endocrinol Metab 94:1069-1073 (LoE $\otimes \otimes \bigcirc \bigcirc)$

235. Toaiari M, Davì MV, Dalle Carbonare L, Boninsegna L, Castellani C, Falconi M, Francia G (2013) Presentation, diagnostic features and glucose handling in a monocentric series of insulinoma. J Endocrinol Invest 36:753-758 (LoE $\otimes \bigcirc \bigcirc \bigcirc)$

236. Phan GQ, Yeo CJ, Hruban RH, Lillemoe KD, Pitt HA, Cameron JL (1998) Surgical experience with pancreatic and peripancreatic neuroendocrine tumors: review of 125 patients. J Gastrointest Surg 2:473-482 ( $\mathrm{LoE} \otimes \otimes \bigcirc \bigcirc)$

237. Mathur A, Gorden P, Libutti SK (2009) Insulinoma. Surg Clin North Am 89:1105-1121

238. Dizon AM, Kowalyk S, Hoogwerf BJ (1999) Neuroglycopenic and other symptoms in patients with insulinomas. Am J Med 106:307-310 (LoE $\otimes \otimes 0 \bigcirc)$

239. Starke A, Saddig C, Kirch B, Tschahargane C, Goretzki P (2006) Islet hyperplasia in adults: challenge to preoperatively diagnose non-insulinoma pancreatogenic hypoglycemia syndrome. World J Surg 30:670-679 (LoE $\otimes \otimes O O$ )

240. van Bon AC, Benhadi N, Endert E, Fliers E, Wiersinga WM (2009) Evaluation of endocrine tests. D: the prolonged fasting test for insulinoma. Neth J Med 67:274-278 (LoE $\otimes 0 \bigcirc 0)$

241. Baudin E, Caron P, Lombard-Bohas C, Tabarin A, Mitry E, Reznick Y, Taieb D, Pattou F, Goudet P, Vezzosi D, Scoazec JY, Cadiot G, Borson-Chazot F, Do Cao C, on behalf of the Société française d'endocrinologie and the Groupe d'étude des tumeurs endocrines (2013) Malignant insulinoma: recommendations for characterisation and treatment. Ann Endocrinol 74:523-533

242. McLean A (2004) Endoscopic ultrasound in the detection of pancreatic islet cell tumours. Cancer Imaging 4:84-91

243. Liu Y, Song Q, Jin HT, Lin XZ, Chen KM (2009) The value of multidetector-row CT in the preoperative detection of pancreatic insulinomas. Radiol Med 114:1232-1238 ( $\mathrm{LoE} \otimes \otimes \bigcirc \bigcirc)$

244. Anaye A, Mathieu A, Closset J, Bali MA, Metens T, Matos C (2009) Successful preoperative localization of a small pancreatic insulinoma by diffusion-weighted MRI. JOP 10:528-531 (LoE Q0००) 
245. Minn H, Kauhanen S, Seppänen M, Nuutila $P(2009){ }^{18} \mathrm{~F}$ FDOPA: a multiple-target molecule. J Nucl Med 50:1915-1918

246. Wild D, Christ E, Caplin ME, Kurzawinski TR, Forrer F, Brändle M, Seufert J, Weber WA, Bomanji J, Perren A, Ell PJ, Reubi JC (2011) Glucagon-like peptide-1 versus somatostatin receptor targeting reveals 2 distinct forms of malignant insulinomas. J Nucl Med 52:1073-1078 (LoE $\otimes \otimes \bigcirc \bigcirc)$

247. Wiesli P, Uthoff H, Perren A, Pfammatter T, Zwimpfer C, Seiler H, Kindhauser R, Spinas GA, Schmid C (2011) Are biochemical markers of neuroendocrine tumors coreleased with insulin following local calcium stimulation in patients with insulinomas? Pancreas 40:995-999 (LoE $\otimes \bigcirc \bigcirc 0)$

248. Guettier JM, Kam A, Chang R, Skarulis MC, Cochran C, Alexander HR, Libutti SK, Pingpank JF, Gorden P (2009) Localization of insulinomas to regions of the pancreas by intraarterial calcium stimulation: the $\mathrm{NIH}$ experience. J Clin Endocrinol Metab 94:1074-1080 (LoE $\otimes \otimes \bigcirc \bigcirc)$

249. Proye C, Malvaux P, Pattou F, Filoche B, Godchaux JM, Maunoury V, Palazzo L, Huglo D, Lefebvre J, Paris JC (1998) Noninvasive imaging of insulinomas and gastrinomas with endoscopic ultrasonography and somatostatin receptor scintigraphy. Surgery 124:1134-1143 discussion 1143-1144 (LoE $\otimes \otimes \otimes O$ )

250. Bellizzi AM (2013) Assigning site of origin in metastatic neuroendocrine neoplasms: a clinically significant application of diagnostic immunohistochemistry. Adv Anath Pathol 20:285-314

251. Kirshbom PM, Kherani AR, Onaitis MW, Feldman JM, Tyler DS (1998) Carcinoids of unknown origin: comparative analysis with foregut, midgut, and hindgut carcinoids. Surgery 124:1063-1070 (LoE $\otimes \otimes \bigcirc \bigcirc)$

252. Pavel M, Baudin E, Couvelard A, Krenning A, Öberg K, Steinmüller T, Anlauf M, Wiedenmann B, Salazar R, all other Barcelona Consensus Conference participants (2012) ENETS consensus guidelines for the management of patients with liver and other distant metastases from neuroendocrine neoplasms of foregut, midgut, hindgut, and unknown primary. Neuroendocrinology 95:157-176

253. Catena L, Bichisao E, Milione M, Valente M, Platania M, Pusceddu S, Ducceschi M, Zilembo N, Formisano B, Bajetta E (2011) Neuroendocrine tumors of unknown primary site: gold dust or misdiagnosed neoplasms? Tumori 97:564-567
254. NCCN clinical practice guidelines in oncology. Neuroendocrine tumors. Version 2.2014. http://www.nccn.org/professionals/phy sician_gls/pdf/neuroendocrine.pdf. Accessed 21 Jan 2014

255. Srivastava A, Hornick JL (2009) Immunohistochemical staining for CDX-2, PDX-1, NESP-55, and TTF-1 can help distinguish gastrointestinal carcinoid tumors from pancreatic endocrine and pulmonary carcinoid tumors. Am J Surg Pathol 33:626-632 $(\mathrm{LoE} \otimes \otimes \bigcirc \bigcirc)$

256. Joseph S, Wang YZ, Boudreaux JP, Anthony LB, Campeau R, Raines D, O'Dorisio T, Go VL, Vinik AI, Cundiff J, Woltering EA (2011) Neuroendocrine tumors: current recommendations for diagnosis and surgical management. Endocrinol Metab Clin N Am 40:205-231

257. Wang SC, Parekh JR, Zuraek MB, Venook AP, Bergsland EK, Warren RS, Nakakura EK (2010) Identification of unknown primary tumors in patients with neuroendocrine liver metastases. Arch Surg 145:276-280

258. Gabriel M, Decristoforo C, Kendler D, Dobrozemsky G, Heute D, Uprimny C, Kovacs P, Von Guggenberg E, Bale R, Virgolini IJ (2007) ${ }^{68}$ Ga-DOTA-Tyr ${ }^{3}$-octreotide PET in neuroendocrine tumors: comparison with somatostatin receptor scintigraphy and CT. J Nucl Med 48:508-518 (LoE $\otimes \otimes \otimes \bigcirc)$

259. Wang SC, Fidelman N, Nakakura EK (2013) Management of well-differentiated gastrointestinal neuroendocrine tumors to the liver. Semin Oncol 40:69-74

260. Giesel FL, Kratochwil C, Mehndiratta A, Wulfert S, Moltz JH, Zechmann CM, Kauczor HU, Haberkorn U, Ley S (2012) Comparison of neuroendocrine tumor detection and characterization using DOTATOC-PET in correlation with contrast enhanced CT and delayed contrast enhanced MRI. Eur J Radiol 81:2820-2825 ( $\mathrm{LoE} \otimes \otimes \bigcirc \bigcirc)$

261. Lindholm DP, Oberg K (2011) Biomarkers and molecular imaging in gastroenteropancreatic neuroendocrine tumors. Horm Metab Res 43:832-837

262. Ichikawa T, Peterson MS, Federle MP, Baron RL, Haradome H, Kawamori Y, Nawano S, Araki T (2000) Islet cell tumor of the pancreas: biphasic CT versus MR imaging in tumor detection. Radiology 216:163-171 (LoE $\otimes \otimes \bigcirc \bigcirc)$ 